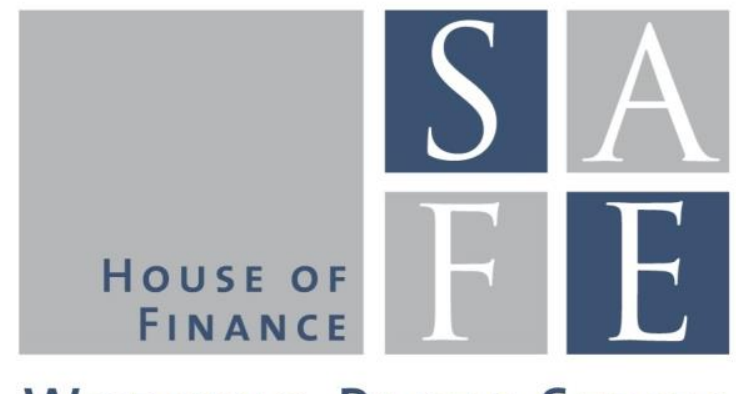

WORKING PAPER SERIES

Andreas Hackethal | Sven-Thorsten Jakusch | Steffen Meyer

\title{
Taring all Investors with the same Brush? Evidence for Heterogeneity in Individual Preferences from a Maximum Likelihood Approach
}

SAFE Working Paper No. 147

SAFE I Sustainable Architecture for Finance in Europe A cooperation of the Center for Financial Studies and Goethe University Frankfurt 


\section{Non-Technical Summary}

Notable efforts have been made on the question of how individual investors in financial markets should handle their financial assets according to theory and how their trading actually differs from these models. The spectrum of implications drawn from theories on trading volume is vast and comprises extreme positions such as the famous No-Trade Theorem, according to which, in efficient markets and given a pool of homogeneous investors with rational expectations, investors cannot profit from trading as stocks offered for sale will not be bought by any counterparty. This contradicts the observation that individual investors engage in excessive trading and the empirical fact that bids are frequently matched with corresponding asks. Indeed, individual investors were found to be markedly heterogeneous in their personal and sociodemographic characteristics and, accordingly, in the formation of their subjective expectations which appears to be correlated with trading patterns such as the Disposition Effect and other trading strategies. However, heterogeneity in investors' expectations on market returns seems to add only partly to the overall question of why people trade in such huge amounts. Empirical evidence suggests that individual investors may not only differ with respect to their expectations but also in the structure of their risk preferences.

In order to shed some light on the questions of which preferences (in terms of microeconomic utility models) prevail in stock markets and by how much those preferences drive trading decisions of individual investors, we adopted, modified and applied a customized maximum likelihood approach on a randomly selected dataset of 656 private investors of a large German discount brokerage firm.

In concord with numerous studies on this topic, we find evidence that the majority of the investors in our dataset follow a trading pattern broadly reconcilable with Prospect Theory; but in contrast to those studies, we are not able to connect the utility-type classification to exogenous variables such as gender or age, thus concluding that the classification of a particular investor is independent. This implies that observable characteristics, used e.g. by financial advisors and serving as proxies for risk preferences, may not be the right instruments for this purpose.

Furthermore, we find some evidence that preferences seem to drive trading decisions by a moderate proportion although we fail to establish a link to most of the personal traits of the individual investors in our dataset. 


\title{
TARING ALL INVESTORS WITH THE SAME BRUSH? EVIDENCE FOR HETEROGENEITY IN INDIVIDUAL PREFERENCES FROM A MAXIMUM LIKELIHOOD APPROACH
}

\author{
ANDREAS HACKETHAL \\ SVEN THORSTEN JAKUSCH \\ STEFFEN MEYER
}

\begin{abstract}
Microeconomic modeling of investors behavior in financial markets and its results crucially depends on assumptions about the mathematical shape of the underlying preference functions as well as their parameterizations. With the purpose to shed some light on the question, which preferences towards risky financial outcomes prevail in stock markets, we adopted and applied a maximum likelihood approach from the field of experimental economics on a randomly selected dataset of 656 private investors of a large German discount brokerage firm. According to our analysis we find evidence that the majority of these clients follow trading pattern in accordance with Prospect Theory (Kahneman and Tversky (1979)). We also find that observable sociodemographic and personal characteristics such as gender or age don't seem to correlate with specific preference types. With respect to the overall impact of preferences on trading behavior, we find a moderate impact of preferences on trading decisions of individual investors. A classification of investors according to various utility types reveals that the strength of the impact of preferences on an investors' trading behavior is not connected to most personal characteristics, but seems to be related to round-trip length.
\end{abstract}

\footnotetext{
Date: 19th. May, 2015.

Key words and phrases. Utility Theory, Maximum Likelihood, Individual Investors.

House of Finance, Goethe University Frankfurt, Grueneburgplatz 1, D-60323 Frankfurt am Main, Germany. Andreas Hackethal is Professor for Personal Finance at Goethe University Frankfurt / Germany. Steffen Meyer is Professor for Finance at the University of Hannover and Member of Retail Banking Competence Center and eFinance Lab at Goethe University Frankfurt. Sven Jakusch is a doctoral student at House of Finance, Goethe University Frankfurt and Senior Quantitative Consultant at Ernst \& Young GmbH. We are grateful for comments by Glenn Harrison, John Hey and Chris Orme. Furthermore, we also like to thank Joachim Weber for programming and research support related to our $M y S Q L$ database. We gratefully acknowledge research support from the Research Center SAFE, funded by the state of Hessen initiative for research LOEWE. The corresponding authors can be reached by svenjakusch@yahoo.de. Please note that parts of this paper were written when Sven Jakusch was working at Ernst \& Young Wirtschaftspruefungsgesellschaft $\mathrm{GmbH}$, however, any views, statements or opinions expressed in this paper are solely those of the authors and not related to Ernst \& Young.
} 


\section{INTRODUCTION}

Notable efforts have been put on the question how individual investors in financial markets should handle their financial assets according to theory and how their trading actually differs from these models. The spectrum of implications drawn from theories on trading volume is vast and comprises extreme positions such as the famous No-Trade Theorem (Aumann (1976), Milgrom and Stokey (1982) and Tirole (1982)), according to which, in efficient markets and given a pool of homogeneous investors with rational expectations, investors cannot profit from trading as stocks offered for sale will not be bought by any counterparty. This contradicts the observation that individual investors engage in excessive trading (e.g. Odean (1999) and Barber and Odean (2000)) and the empirical fact that bids are frequently matched with corresponding asks. Karpoff (1987b) offers a solution by introducing heterogeneity on the level of investors, leading to differences in opinion about stock prices at which these investors are willing to commission purchase or sales orders, thus creating considerable trading volume (Wang (1994)). Indeed, besides high variations in expectations (Glaser and Weber (2007)), individual investors were found to be markedly heterogeneous in their personal and sociodemographic characteristics, which appears to be correlated with trading pattern such as the Disposition Effect, the susceptibility to offload assets that gained in value while hesitating to sell assets whose value recently depreciated (Shefrin and Statman (1985), Odean (1998), Grinblatt and Keloharju (2001b), Dhar and Zhu (2006) and Kaustia (2010)). At the same time, individual investors show a significant variability in their demand for positively skewed assets (Mitton and Vorkink (2007), Kumar and Goetzmann (2008), Kumar (2009b)), display a high dispersion in the composition of their portfolios, usually tantamount to poor diversification (Kumar and Goetzmann (2008)) and reveal a significantly increased trading volume in bear markets as well as around price peaks (Cohen et al. (2002), Dhar and Kumar (2002), Hvidkjaer (2006)).

Heterogeneity in investors' expectations as proposed by Karpoff (1987b) seems to add only partly to the overall picture why people trade in such huge amounts (DeBondt (1998)). ${ }^{1}$ Empirical evidence suggests that individual investors may not only differ with respect to their expectations (exemplarily Andreassen (1987), Patel et al. (1991), DeBondt (1993), DeBondt (1998)) but also in the structure of their risk preferences (e.g. Hey and Orme (1994), Harrison and Rutstrom (2009)) and risk aversion (e.g. Laury and Holt (2005) for experimental evidence and AitSahalia and Lo (2000), Jackwerth (2000), Kliger and Levy (2002), Bliss and Panigirtzoglou (2004), Brunnermeier and Nagel (2008), Guiso and Paiella (2008) as well as Chiappori and Paiella (2011) for evidence from financial markets). Furthermore, from a theoretical perspective, attempts to reconciliate observed high trading frequency and extensive trading volume with predictions from models on dynamic optimization using expected utility frequently failed (e.g. Bonaparte and Cooper (2010)). In contrast, replacing expected utility in those dynamic models by alternative preferences such as Rank-dependent Utility (Quiggin (1982)), Prospect Theory, conceptualized by Kahneman and Tversky (1979) and Cumulative Prospect Theory as a refinement of the former (posed in Tversky and Kahneman (1992)), theoretically unfolds considerable trading activity (see Barberis and Xiong (2009), Barberis (2011) and Ingersoll and Jin (2013)).

With the purpose to shed some light on the questions, which preferences (in terms of microeconomic utility models) prevail in stock markets and by how much

\footnotetext{
${ }^{1}$ Hirshleifer (2001) and Barber and Odean (2013) provide an overview of the ample evidence for the observed high trading volume of individual investors from experiments and empirical data. 
those preferences drive trading decisions of individual investors, we adopted, modified and applied a customized maximum likelihood approach on a randomly selected dataset of 656 private investors of a large German discount brokerage firm. In concord with numerous studies on this topic, we also find evidence that the majority of these investors follow a trading pattern broadly reconcilable with Prospect Theory (Kahneman and Tversky (1979)) but in contrast to those studies, we are not able to connect the utility-type classification to exogenous variables such as gender or age, thus concluding that the classification of a particular investor is independent from his or her personal and sociodemographic characteristics. Furthermore, we find some evidence that preferences seem to drive trading decisions by a moderate proportion, but we also fail to establish a link to most of the personal traits of the individual investors in our dataset.

With respect to the structure of this paper, we provide a brief overview over the relevant literature in the first chapter before we present the econometric methodology in Chapter two. Chapter three comprises the results of a classification of 656 individual investors from a large German discount brokerage firm into various utility types such as Expected Utility (von Neumann and Morgenstern (1947)) or Prospect Theory (Kahneman and Tversky (1979), Tversky and Kahneman (1992)) and relates this classification to the investors' observable personal and sociodemographic characteristics. Chapter four addresses the question, by how much the trading behavior of these investors is governed by their preferences and how the size of the impact of preferences is related to observable personal traits before we derive a conclusion in Chapter five.

\section{INVESTORS' PREFERENCES AND TRADING BEHAVIOR: EVIDENCE FROM THE LITERATURE}

Financial economists predominantly agree that individual investors' trading behavior differs from institutions, who are seen as informed and rational investors (Kaniel et al. (2008)). In contrast, individuals are often characterized as Noise Traders (Kyle (1985), Black (1986), DeLong et al. (1990), Campbell and Kyle (1993), Campbell et al. (1993) and Llorente et al. (2002)), as individual investors were found to trade on economically irrelevant factors (Kyle (1985) and Black (1986)) such as past price pattern (Grinblatt and Keloharju (2001b), Garvey and Murphy (2004) and Kaustia (2010)). Although noise trading has the potential to influence volatility (Andrade et al. (2008)), it requires correlation in trade directions to affect market prices in a systematic manner (Barber et al. (2009a) and Lin and $\mathrm{Hu}$ (2010), but also Black (1986)) if efficient market hypothesis holds. Research on individual investors indicated that, besides noise, individual investors' trades contain systematic components (Kumar and Lee (2006), Dorn et al. (2008), Kaniel et al. (2008), Hvidkjaer (2008) and Barber et al. (2009b)) such as similar preference structures within a group of investors, which in turn leads to the required correlated trading behavior.

Heterogeneity in individual preferences has been used to model trading volume (e.g. Berrada et al. (2007)) aiming to investigate their role as potential causes of various observed trading pattern such as individuals' reluctance to realize losses in contrast to gains, irrespective of portfolio adjustments and other plausible reasons (e.g. mean reversion etc.) that might trigger a similar trade pattern (Shefrin and Statman (1985), Odean (1998), Grinblatt and Keloharju (2001b), Dhar and 
Zhu (2006) and Kaustia (2010)). Other studies find that individual investors systematically miss the merits of diversification (Kumar and Goetzmann (2008)), are attracted by stocks that can be characterized by low expected returns and highly positive skewness (Mitton and Vorkink (2007), Kumar and Goetzmann (2008), Kumar (2009b)), tend to more familiar investments (Barber and Odean (2008), Keloharju et al. (2012)), trade more after an increase in stock market prices (Cohen et al. (2002), Dhar and Kumar (2002), Hvidkjaer (2006)) and are succumb to various cognitive traps that negatively affect their performance (e.g. DeBondt (1998), Barber and Odean (2000) and Barber et al. (2009)). Empirical evidence suggests that these trading patterns, if emerging concurrently, have the potential to affect cross-sectional dependence in returns (see e.g. Grinblatt and Han (2005b) and Han and Kumar (2010) for the impact of trading pattern and Kumar (2007) for evidence on portfolio choice), variations in market volatility and prices (French (1980), Shiller (1981), Roll (1986), French and Roll (1986), Karpoff (1987a), Andreassen (1988), Gallant et al. (1992), Schwert (2002), Kumar and Lee (2006), Brandt et al. (2010) and Foucault et al. (2011)) and even higher moments of the return distribution (Kraus and Litzenberger (1976), Mitton and Vorkink (2007) and Barberis and Huang (2008)).

Early models on financial decision making, in which preferences are treated as such a systematic and unobservable component, rely on expected utility (von Neumann and Morgenstern (1947)), usually combined with the assumption of a homogeneous pool of investors. In particular, a classical (and still widely held) consensus is the notion that investors exhibit decreasing absolute $(D A R A)$ and constant relative risk aversion $(C R R A)$ as first set up by Arrow $(1971)^{2}$. This view seems to be supported by empirical and experimental studies (Gordon et al. (1972), Friend and Blume (1975), Blume and Friend (1975), Schlarbaum et al. (1975), Kroll et al. (1988), Landskroner (1988), Levy (1994), Brunnermeier and Nagel (2008), Guiso and Paiella (2008) and Chiappori and Paiella (2011), see also Morin and Suarez (1983) for $D R R A$ ) as well as from the field of evolutionary finance, conjecturing that financial markets, if seen as coherent entities, should be characterized by a pool of homogeneous investors with logarithmic utility as a result of certain survival processes (Latane (1959), Blume and Easley (1992) and Sinn (2003)). Accordingly, research on utility functions in finance and asset pricing dominantly focuses on the risk aversion coefficient of a prespecified utility function (e.g. Ait-Sahalia and Lo (2000), Jackwerth (2000), Kliger and Levy (2002) and Bliss and Panigirtzoglou (2004) among others) to recover risk aversion from observed asset prices (see Cuoco and Zapatero (2000) for a discussion of this approach), although the picture of a representative investor, characterized by a unique utility function, seems questionable (e.g. Wang (1994), Blackburn and Ukhov (2006), Bruhin et al. (2007) and Harrison and Rutstrom (2009)).

\footnotetext{
${ }^{2}$ Arrow (1971), p. 96 mentioned, that $D A R A$ emerges as natural fact and seems supported by everyday observation. His favoring of increasing relative risk aversion $(I R R A)$ and the conclusion that relative risk aversion hovers around unity though is based on the required boundedness of the utility function and thus on purely theoretical ground. Its noteworthy that logarithmic utility, frequently assumed in financial studies (and championed by its proponents Latane (1959), Hakansson (1971) and Markowitz (1976)), is unbounded and serves as approximation of $U(W)$ but implies CRRA. As far as we know, one of the earliest attempts to characterize the behavior of $U(W)$ with respect to changes in wealth can be found in Bernoulli (1954), argumentatively supporting a logarithmic form of $U(W)$. He noted that "[...]any increase in wealth [...] will always result in an increase in utility which is inversely proportionate to the quantity of goods already possessed." (omissions by authors), meaning $\partial U(W) / \partial W=W^{-1}$, which corresponds to $U(W)=\log (W)$.
} 
Another point that adds to this criticism is the fact that literature came up quite early with notable exceptions of the general notion according to which investors are generally risk averse (Friedman and Savage (1948), Markowitz (1952), Kahneman and Tversky (1979) and Tversky and Kahneman (1992)) and act in concord with axiomatic consistency (see Preston and Baratta (1948), Allais (1953), Edwards (1953) and Edwards (1954) for some early references). ${ }^{3}$ Subsequent studies that address various shortcomings of expected utility theory in the attempt to reconciliate empirical evidence with theoretical predictions prompted the development of generalized expected utility theories (e.g. Edwards (1962), Karmarkar (1978), Karmarkar (1979), Quiggin (1982), Yaari (1987) and Wakker (1994)) which involves modifications of the linearity feature of the expectations operator via transforming probability weights. Another direction of research modified the utility functional itself and led to the creation of Utility-of-Income models (Friedman and Savage (1948), Markowitz (1952), Yaari (1965), Kahneman and Tversky (1979), Hershey and Schoemaker (1980)) with the purpose to explain simultaneous demand for gambling and insurance. ${ }^{4}$ The fact that a modification of the utility function or the expectation operator alone cannot account for many empirical features has led Kahneman and Tversky (1979) and Tversky and Kahneman (1992) to propose Prospect Theory as a descriptive non-expected utility theory that combines both strands of research in an unified model. At the same time this debate has been enriched by conclusions drawn from empirical evidence (Tversky and Kahneman (1991), Tversky and Kahneman (1992), Rabin (2000) and Rabin and Thaler (2001) among many others) indicating that individuals are more averse towards losses than they enjoy gains of equal magnitude (see Wakker (2010) for a survey).

Alternative preferences and generalized expected utility models received some support from experimental studies (e.g. Lattimore et al. (1992), Hey and Orme (1994) and Abdellaoui (2000)) with results mostly consistent with an inverse $S$ shaped probability weighting function (Wu and Gonzalez (1996), Wu and Gonzalez (1999), Abdellaoui (2000), Bleichrodt and Pinto (2000), Abdellaoui et al. (2005)) and, moreover consistent with a concave value function in the domain of gains, being backed in recent studies that deal with the best fitting shape (see e.g. Blondel (2002), Stott (2006) and Wakker (2008), for contradicting evidence Levy and Levy (2002), but also Wakker (2003)). The properties of diminishing sensitivity towards variations were confirmed in Wakker and Deneffe (1996), Fox and Tversky (1998)

\footnotetext{
${ }^{3}$ Furthermore, classical utility functions such as $C R R A$ have been questioned lately on a different level of argumentation, particularly due to their inability to provide satisfying explanations for several puzzles regarding market risk premium and stock market participation (see Kocherlakota (1996) for a discussion of theoretically justified risk aversion coefficients). Mehra and Prescott (1985) argued that, if the equilibrium price in terms of returns on the stock market is calculated using the most simplistic model as proposed by Lucas (1978), calibrated with historical US-Data, the historical average return in the US stock market appears to be too high to be compatible with common assumptions about risk aversion in finance (see for a brief overview Gollier (2001)). Goetzman and Ibbotson (2005) and Mehra (2008) provide compressed reviews on the equity premium puzzle and more explanations. For instance, Mankiw and Zeldes (1991) addressed the question about the size of $C R R A$ using a dynamic consumption approach and found the $R(W)$ to be near 26. Even higher values can be found in Blake (1996), using data drawn from the Financial Research Survey on households and their portfolio allocation decisions, assuming that households portfolio decisions are subject a power function. His findings point to high coefficients of relative risk aversion between 8 and up to 47 with further evidence for $D R R A$. See also Rabin (2000) for a critical review on risk aversion parameterizations.

${ }^{4}$ Although there's ample experimental evidence that individuals don't treat probabilities linearly, contributions by Hakansson (1970) showed that the notion of risk aversion can be consistent with Friedman-Savage utility even in the absence of decision weights, thus leaving the expectation operator unchanged.
} 
and Fennema and van Assen (1999). In finance however, the state of fact is less clear although alternative utility models such as Prospect Theory that have been frequently proposed as explanation for various trading pattern, particularly as evidence for Prospect Theory from experimental economics seems to be compelling (Currim and Sarin (1989), Camerer and Ho (1994), Fennema and Wakker (1997), Hey and Orme (1994), Loomes et al. (2002), Wu et al. (2005) among others) despite the fact that Prospect Theory is far away from being seen as a definitive theory (Birnbaum et al. (1999), Starmer (2000)). Exemplarily, theoretical and empirical literature suspects a relation between Prospect Theory and various phenomena such as portfolio choice behavior (Berkelaar et al. (2004), Gomes (2005), Polkovnichenko (2005), Jin and Zhou (2008), Bernard and Ghossoub (2010), He and Zhou (2011)) or particular trading pattern, among which the perhaps most intuitive, but recently highly disputed link between Prospect Theory and trading patterns has been seen in the so called Disposition Effect, initially coined by Shefrin and Statman (1985) and approved in countless empirical findings and numberless settings (Ferris et al. (1988), Odean (1998)). ${ }^{5}$ The presence of Prospect Theory in financial markets has not only implications for asset pricing (see Benartzi and Thaler (1995), Barberis and Huang (2001), Barberis et al. (2001), see Shefrin (2008) for an overview) but also sets the stage for explaining the presence of equity premium (Benartzi and Thaler (1995)), excess stock return volatility (Barberis et al. (2001)), overinsurance (Cutler and Zeckhauser (2004)), stock market momentum (Grinblatt and Han (2005b), Grinblatt and Han (2005a)) as well as its implications on market liquidity (Pasquariello (2008)), return forecasts (Barberis and Huang (2001)), the underperformance of IPO's (Green and Hwang (2011)), the observed low mean returns of of lottery-like stocks (Polkovnichenko (2005), Kumar and Goetzmann (2008), notably Barberis and Huang (2008), Kumar (2009b)) and herding behavior in stock markets (Lin and $\mathrm{Hu}(2010)$ ).

Traditional studies matching the best fitting preference representation to observed aggregate behavior frequently draw upon the concept of a representative investor, ignoring that investors may vary in their preference functions and differ in their individual degree of risk aversion. Outside of the representative investor framework, heterogeneity in preferences is usually modeled as distribution in risk aversion parameters given a particular class of utility function (e.g. Kliger and Levy (2002), von Gaudecker et al. (2009) and Kliger and Levy (2009), for Prospect Theory see Dimmock and Kouwenberg (2010) and Hwang and Satchell (2011)), although first attempts have been made to widen the spectrum to allow various kinds of different utility functions to coexist in the same market as suggested by Bruhin

\footnotetext{
${ }^{5}$ The suspicion that the Disposition Effect is engendered by differences in the values attached to potential gains and losses was initially listed in Shefrin and Statman (1985) and has lead subsequent studies to cite Prospect Theory as the main, if not only driver of the Disposition Effect (Weber and Camerer (1998), Odean (1998), Garvey and Murphy (2004), Jordan and Diltz (2004), Lehenkari and Perttunen (2004), Frazzini (2006), Dhar and Zhu (2006), Kaustia (2010) and Vlcek and Hens (2011)). If individual preferences follow predictions of Prospect Theory, phenomena like the Disposition Effect also should be observable in other environments. In fact, evidence for the Disposition Effect has been found among individual investors in the stock market (e.g. Schlarbaum et al. (1978a), Odean (1998), Odean (1999)), in financial advice of stock brokers (Shapira and Venezia (2001)), in the behavior of future trades (Heisler (1994), Frino et al. (2004), Coval and Shumway (2005) as well as Locke and Mann (2005)), IPO trading volume (Kaustia (2004a)), in real estate markets (Genesove and Mayer (2001)), insurance contracts (e.g. Schoemaker and Kunreuther (1979), Camerer and Kunreuther (1989)) and observed risk behavior in laboratory environments for stocks (Weber and Camerer (1998), Oehler et al. (2003), Lee et al. (2008)) and monetary endowments (see Chui (2001), also Barberis (2013) for a comprehensive survey of the literature).
} 
et al. (2007), Harrison and Rutstrom (2009), Easley and Yang (2011) and Wahal and Yavuz (2013a) to capture evidence for heterogeneity in preferences (Hey and Orme (1994), Barsky et al. (2002), Blackburn and Ukhov (2006), Choi et al. (2007) and Chiappori et al. (2009)) and to understand the various different ways individual investors trade financial assets (Odean (1998)). Empirical studies on this subject seem to support this latest strand of literature as they found a pronounced diversity in trading behavior and strategies on individual level (Grinblatt and Keloharju (2001b), Shapira and Venezia (2001), Chui (2001), Garvey and Murphy (2004), Feng and Seasholes (2005), Dhar and Zhu (2006), Goetzmann and Massa (2008), Kumar (2009a) and Wahal and Yavuz (2013b)). To calibrate such theoretical models that incorporate utility function heterogeneity successfully, the fraction of each utility type needs to be determined and estimated efficiently based on a relevant dataset, for which the model was designed for. In the next section, we introduce such an estimation method and dataset for which we exemplarily unravel underlying utility functions and try to answer some of the questions mentioned above.

\section{How to IDENTIFY INDIVIDUAL INVESTORS' PREFERENCES: \\ A DESCRIPTION OF THE METHODOLOGY}

Empirical and theoretical studies presented in the previous section provide a multifaceted picture when it comes to the question, which utility functions prevail in financial markets. These articles are based on various methods and datasets, thus are difficult to compare directly and provide results that are virtually impossible to conciliate. Furthermore, most studies frequently simplify matters substantially by assuming the existence of a representative investor or a homogeneous pool of traders although, due to its defect to allow for heterogeneity, this assumption seems empirically questionable. For example, articles located in the area of empirical asset pricing particularly favor expected utility (e.g. Latane (1959), Hakansson (1971), Friend and Blume (1975), Blume and Friend (1975), Schlarbaum et al. (1975), Markowitz (1976), Morin and Suarez (1983), Landskroner (1988), Blume and Easley (1992), Ait-Sahalia and Lo (2000), Jackwerth (2000), Kliger and Levy (2002), Bliss and Panigirtzoglou (2004), Brunnermeier and Nagel (2008), Guiso and Paiella (2008) and Chiappori and Paiella (2011)) probably due to its convenient technical properties and inherent consistency of its results. Evidence based on trading data in contrast predominantly advocates alternative utility models such as Prospect Theory or Regret Aversion Models, backed by conclusions frequently derived from argumentation based on intuition rather than from statistically valid investigation (Weber and Camerer (1998), Odean (1998), Garvey and Murphy (2004), Jordan and Diltz (2004), Lehenkari and Perttunen (2004), Frazzini (2006), Dhar and Zhu (2006) among others).

In the quest to understand the behavior of their participants, to distinguish systematic factors from random effects and finally to circumvent dubious assumptions concerning the homogeneity among individuals, experimental economists developed various discrete choice models and customized maximum likelihood methods, thus provided the econometric toolbox needed to answer the question of the best fitting utility function (e.g. Hey and Orme (1994), particularly Orme (1995)). It occurs to be a natural conclusion to combine both strands of literature for our purpose and to account for the specific particularities of datasets containing trading records similar to those used in Odean (1998), for example generated by the way investors obtain estimates to approximate uncertain financial outcomes (Andreassen and Kraus (1990), Greenwood (2014)) and by tracking accrued returns through time. In this section, we sketch an adapted customized maximum likelihood approach 
similar to those proposed in Hey and Orme (1994), Harrison and Rutstrom (2008) and de Palma et al. (2008) where we explicate the adjustments made to deal with deficiencies of the likelihood function, that might have an impact on utility model selection and which have to be made before applying this customized maximum likelihood to financial data.

In financial markets, investment decisions are usually characterized by their sequential nature and the implicit option to revise previous decisions as time proceeds. These features permit to treat decisions as a sequence of single decisions and to model the underlying investment process as a dynamic optimization problem. For classical preference models such as expected utility, this approach works fine, but reaches its limits if one tries to find time consistent solutions for alternative utility functions (Nielssen and Jaffray (2004), Barberis (2011) and Ebert and Strack (2012), also see Eckstein and Wolpin (1989), Rust (1994) and Adda and Cooper (2003) for surveys). Despite this tendency to to apply dynamic programming to identify optimal trading strategies, empirical evidence suggests that observed trading behavior of individual investors seems more comparable with discrete (and myopic) decision processes (Rust (1992), Thaler et al. (1997) and Gneezy and Potters (1997)) although notable exceptions exist (Normandin and St-Amour (2008)).

Given the myopic nature of the investors decision process, this implies that an investors' decision to trade a stock is based on differences in utilities from the stock as a representation of a risky asset of a particular day $t$, denoted as $V_{k}\left(W_{t}, R_{S, t} \mid \boldsymbol{\theta}_{k}\right)$ and the utility from a riskfree asset, here denoted by $V_{k}\left(W_{t}, R_{f, t} \mid \boldsymbol{\theta}_{k}\right)$, where the difference in utilities is denoted as $\Delta_{t}\left(U_{k} \mid \boldsymbol{\theta}_{\boldsymbol{k}}\right)$, which is in line with recent literature such as Kaustia (2004b), Kaustia (2010) and Vlcek and Hens (2011). Herein, the gross return of a riskfree investment is typically approximated by a money market account and abbreviated as $R_{f, t}$, given a parameter set $\boldsymbol{\theta}_{k}$ to represent the utility-specific parameters of utility model-type $k$ and a wealth level $W_{t}$ as evaluated at day $t$. In contrast, the utility resulting from the risky asset $V_{k}\left(W_{t}, R_{S, t} \mid \boldsymbol{\theta}_{k}\right)$ comprises a set of market parameters $R_{S, t}$ stemming from a risky asset, namely a common stock, with $S$ denoting the state of nature. ${ }^{6}$ As changes in preferences or market parameters embedded in the respective utility function contribute only partly to purchase or selling decisions, models of discrete choice usually contain an investor specific additively separable stochastic component $\epsilon_{i}$ to introduce a certain unsharpness in the decision process (Train (1986), Rust (1994) and Train (2009)). It is important to note that this component accounts for the fact that only a fraction of attributes for these decisions are observable and thus avoids the necessity to explicitly model other (potentially unobservable) variables or data imperfections (Cramer (1986), Rust (1994)), which allows a further decomposition $V_{k}\left(W_{t}, R_{S, t} \mid \boldsymbol{\theta}_{k}\right)=U_{k}\left(W_{t}, R_{S, t} \mid \boldsymbol{\theta}_{k}\right)+\epsilon_{i}$ where $U_{k}\left(W_{t}, R_{S, t} \mid \boldsymbol{\theta}_{k}\right)$ denotes the functional form of utility model of type $k$.

To restrict the set of utility functions that specify $\Delta_{t}\left(U_{k} \mid \boldsymbol{\theta}_{\boldsymbol{k}}\right)$, we focus primarily on those preferences mentioned by the studies presented above, in particular on expected utility (EUT) as commonly found in texts on asset pricing (e.g. Duffie (2001), Gollier (2001), Back (2012) and Munk (2013)) and used in empirical

\footnotetext{
${ }^{6}$ It should be noted that, although dynamic discrete choice models such as the multinomial probit model are difficult to estimate (Rust (1994)), methods such as maximum simulated likelihood (Train (1986), Train (2009)), certain approximations (Horowitz et al. (1982)) and alternative estimation methods (Magnac and Thesmar (2002)) have been proposed to circumvent the evaluation of the multinomial probit function. 
Table 1. Description of Set of Preference Parameters $\boldsymbol{\theta}_{\boldsymbol{k}}$

The table provides a description of parameter set $\boldsymbol{\theta}_{\boldsymbol{k}}$. Expected utility models are denoted as $E U T$, Rank-dependent Utility is denoted as $R D U$. For Simple Prospect Theory (Tversky and Kahneman (1992)) we use the denotation $S P T$, whereas Cumulative Prospect Theory (Tversky and Kahneman (1992)) is denoted as CPT. Furthermore, we use the denotation $C R R A$ for utility functionals with constant relative risk aversion and $E X P O$ to denote exponential power utility functions (Saha (1993)). For SPT and CPT, we use the denotation POWR to indicate models with kinked power-functionals, where in addition $D H G 0$ denotes value functionals as defined in DeGiorgi and Hens (2006).

\begin{tabular}{|c|c|c|c|c|}
\hline \multicolumn{2}{|c|}{$U_{k}\left(W_{t}, R_{S, t} \mid \boldsymbol{\theta}_{\boldsymbol{k}}\right)$} & \multirow{2}{*}{$\begin{array}{l}\text { Set } \boldsymbol{\theta}_{\boldsymbol{k}} \\
\alpha\end{array}$} & \multirow{2}{*}{$\begin{array}{l}\text { Interpretation } \\
\text { Risk Aversion }\end{array}$} & Key Reference \\
\hline H & CRRA & & & Gollier (2001) \\
\hline s & EXPO & $\alpha$ & Risk Aversion & Saha (1993) \\
\hline & & $\rho$ & Scaling Parameter & Saha et al. (1994) \\
\hline \multirow{5}{*}{$\stackrel{p}{a}$} & \multirow{3}{*}{ CRRA } & $\alpha$ & Risk Aversion & Quiggin (1982), Quiggin (1993) \\
\hline & & $\gamma$ & Weighting Parameter & Quiggin (1982), Tversky and Kahneman (1992) \\
\hline & & $\alpha$ & Risk Aversion & Saha (1993) \\
\hline & \multirow{2}{*}{ EXPO } & $\rho$ & Scaling Parameter & Saha et al. (1994) \\
\hline & & $\gamma$ & Weighting Parameter & Quiggin (1982) \\
\hline \multirow{8}{*}{$\begin{array}{l}H_{n}^{-} \\
\hat{n}_{n}\end{array}$} & \multirow{4}{*}{ CRRA } & $\alpha$ & Risk Sensitivity & Gomes (2005) \\
\hline & & $\lambda$ & Loss Aversion & Kahneman and Tversky (1991) \\
\hline & & $\gamma$ & Weighting Parameter & Quiggin (1982), Tversky and Kahneman (1992) \\
\hline & & $\alpha$ & Risk Sensitivity & Kahneman and Tversky (1979) \\
\hline & POWR & $\lambda$ & Loss Aversion & Kahneman and Tversky (1991) \\
\hline & & & Weighting Parameter & Quiggin (1982), Tversky and Kahneman (1992) \\
\hline & DGHO & $\alpha^{ \pm}, \lambda^{ \pm}$ & Scaling Parameter & DeGiorgi and Hens (2006) \\
\hline & & $\gamma$ & Weighting Parameter & Quiggin (1982), Tversky and Kahneman (1992) \\
\hline & & $\alpha$ & Risk Sensitivity & Gomes (2005) \\
\hline & CRRA & $\lambda$ & Loss Aversion & Kahneman and Tversky (1991) \\
\hline \multirow{6}{*}{ 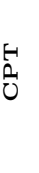 } & & $\gamma$ & Weighting Parameter & Quiggin (1982), Tversky and Kahneman (1992) \\
\hline & & $\alpha$ & Risk Sensitivity & Tversky and Kahneman (1992) \\
\hline & POWR & $\lambda$ & Loss Aversion & Kahneman and Tversky (1991) \\
\hline & & & Weighting Parameter & Quiggin (1982), Tversky and Kahneman (1992) \\
\hline & DGHO & $\alpha^{ \pm}, \lambda^{ \pm}$ & Scaling Parameters & DeGiorgi and Hens (2006) \\
\hline & & $\gamma$ & Weighting Parameter & Quiggin (1982), Tversky and Kahneman (1992) \\
\hline
\end{tabular}

studies (Landskroner (1988), Morin and Suarez (1983), Blume and Easley (1992), Levy (1994), Ait-Sahalia and Lo (2000), Jackwerth (2000), Kliger and Levy (2002), Bliss and Panigirtzoglou (2004), Brunnermeier and Nagel (2008), Guiso and Paiella (2008) as well as Chiappori and Paiella (2011)). We also modeled $\Delta_{t}\left(U_{k} \mid \boldsymbol{\theta}_{\boldsymbol{k}}\right)$ using various versions of generalization of $E U T$ as proposed by Quiggin (1982), Quiggin (1993) and Wakker (1994) with combinations of selected features. To acknowledge the recent stream of literature on behavioral finance, we also captured models of alternative utility such as those by (Kahneman and Tversky (1979) and Tversky and Kahneman (1992)). We provide an overview of parameter set $\boldsymbol{\theta}_{\boldsymbol{k}}$ in Table (1) and enlisted the various utility functions used in our analysis to populate $\Delta_{t}\left(U_{k} \mid \boldsymbol{\theta}_{\boldsymbol{k}}\right)$ in Table (2), for further details we refer to the Appendix.

To specify the set of financial payoffs, we assume that a money market account approximates the riskless asset, which yields a known riskless gross return of $R_{f, t}$. As it is common practice in experimental studies to model risky outcomes as lotteries, the stochastic price of the risky asset, essentially any stock traded by the investor over the respective period, is assumed to be characterized by a binomial process (Cox et al. (1979), Rendleman and Bartter (1979), Hull and White (1988)) in which two disjunct states $S$ of the world can be identified, yielding a gross return of $R_{S, t}$. Arguments for the outcomes of the lotteries used in $\Delta_{t}\left(U_{k} \mid \boldsymbol{\theta}_{\boldsymbol{k}}\right)$ are estimated from this binomial process, where in the upside state $U$, associated with some unknown physical probability $p_{t}>0$ and where $t$ indicates a particular day, the stock price follows a rise and yields an upside return $R_{U, t}>1$, whereas in the downside state $D$ with corresponding probability $1-p_{t}$, the stock declines, generating a downside return $0 \leq R_{D, t}<1$. The binomial model was originally 


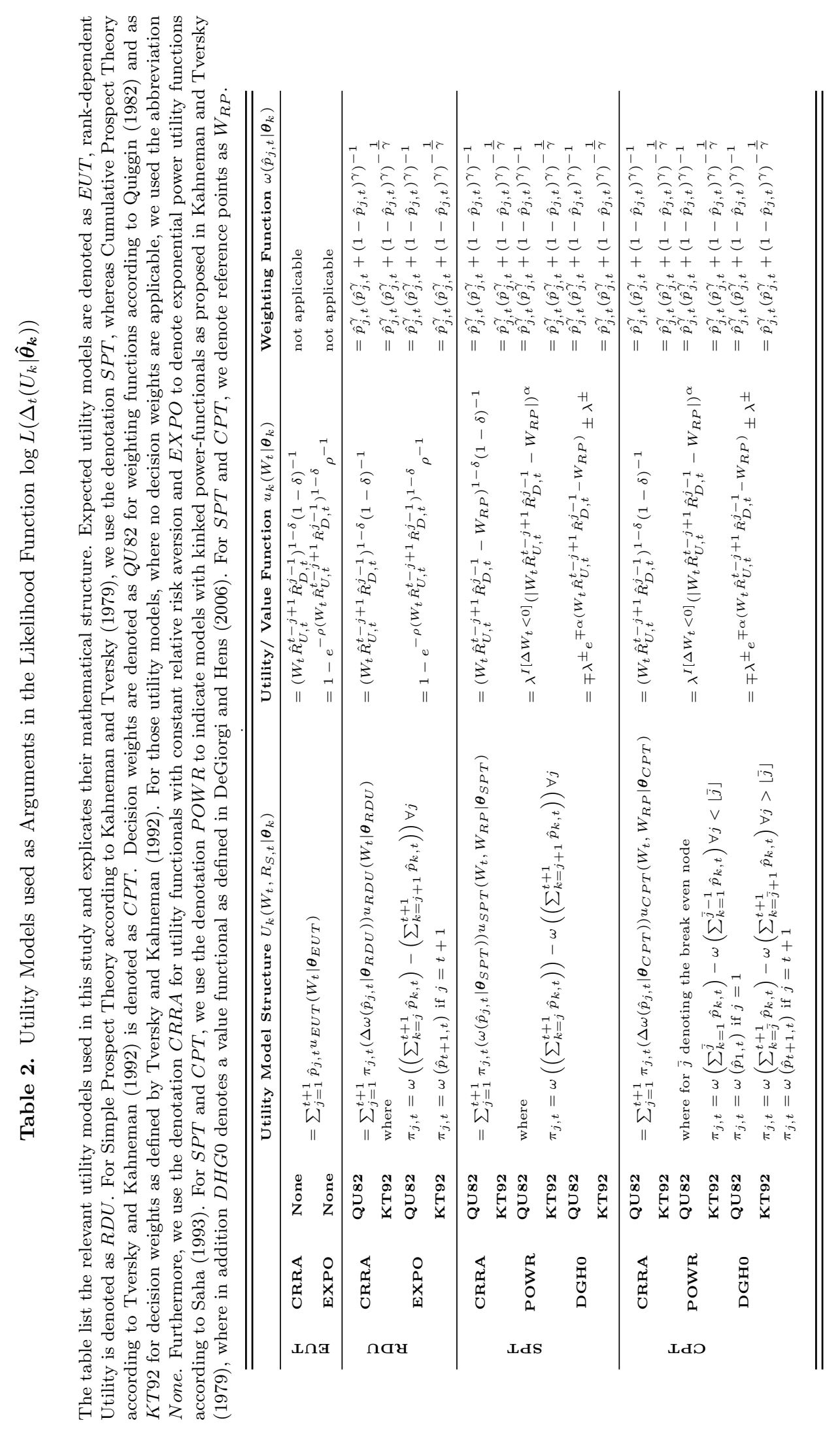


constructed under the assumption of equally likely up- and downward-movements in stock prices, which seems hardly to be justified for empirical time series of stocks. Empirical studies on return characteristics provide ample evidence that distributions of logarithmed returns are far from being symmetric or approximately normally distributed as persistent excess skewness has been detected (e.g. Kon (1984), Singleton and Wingender (1986), Aggarwal and Rao (1990), Turner and Weigel (1992), Harvey and Siddique (2000) and Smith (2007)) which seems to relate positively with investors preferences for high but rare realizations of returns (Mitton and Vorkink (2007), Kumar and Goetzmann (2008), Kumar (2009b)). In the binomial process, this non-normality of log returns can be incorporated via a skewness parameter, denoted as $\Gamma_{t}$, serving as argument in the specification of $p_{t}$. To derive financial outcomes that enter $\Delta_{t}\left(U_{k} \mid \boldsymbol{\theta}_{\boldsymbol{k}}\right)$ as arguments, we assume that the stock prices' evolve according to a binomial process for which we need to estimate the market parameters based upon the return for each security contained in the portfolio of each individual investor. Given the presentation of time series of stock prices of the online brokerage firm, we use a rolling window estimation technique for the time series of each stock given the brokers default setting of the lookback horizon $l$, to obtain estimates of the stocks respective mean $\hat{\mu}_{t}$ and its volatility $\hat{\sigma}_{t}$. From these time series we furthermore infer upside probabilities $\hat{p}_{t}$ and upside and downside returns, denoted as $\hat{R}_{U, t}$ and $\hat{R}_{D, t}$, respectively, which are matched with the skewness of the respective stock, $\hat{\Gamma}_{t} \cdot{ }^{7}$ We provide further details on the estimation of the required market parameters in the Appendix.

Given the stochastic properties of an investor-specific error term $\epsilon_{i}$, from which the respective conditional choice probabilities can be obtained, the required likelihood function of an investor $i$, henceforth denoted as $L\left(\Delta_{t, i}\left(U_{k} \mid \boldsymbol{\theta}_{\boldsymbol{k}, \boldsymbol{i}}\right)\right)$, can be derived. ${ }^{8}$ For the remainder of this paper, we drop the index $i$ for simplicity whenever possible (except for the error term itself) but need to keep in mind, that all calculations are performed on investor level. To specify the stochastic properties of the error term needed to construct $L\left(\Delta_{t}\left(U_{k} \mid \boldsymbol{\theta}_{\boldsymbol{k}}\right)\right)$, we follow Hey and Orme (1994) and Carbone and Hey (2000) and assume $\epsilon_{i}$ to be normally distributed $\epsilon_{i} \sim N\left(0, \sigma_{i}^{2}\right)$ with density according to $\phi\left(\epsilon_{i}\right)=\left(2 \pi \sigma_{i}^{2}\right)^{-\frac{1}{2}} e^{-\frac{1}{2}\left(\epsilon_{i} / \sigma_{i}\right)^{2}}$ as those other components and factors, that may drive the investment decisions of individual investors, are assumed to be unsystematic with respect to utility $U_{k}\left(W_{t}, R_{S, t} \mid \boldsymbol{\theta}_{k}\right) .{ }^{9}$ To customize the discrete choice model and to derive the respective choice probabilities given $\Delta_{t}\left(U_{k} \mid \boldsymbol{\theta}_{\boldsymbol{k}}\right)$, we introduce a buy-or-hold index $I_{k, t}:=I\left[\Delta_{t}\left(U_{k} \mid \boldsymbol{\theta}_{\boldsymbol{k}}\right)+\epsilon_{i} \geq 0\right]$, assumed to be one if the condition in the brackets is met and zero otherwise, thus

\footnotetext{
${ }^{7}$ Note that another way to obtain $\hat{p}_{t}$ is to follow Weber and Camerer (1998), in which individual investors infer $\hat{p}_{t}$ by averaging observed up- and downticks, given the investor observes a change in prices, since the true probability $p$ of the underlying binomial process is unknown.

${ }^{8}$ As a minor technicality, based on the predictability of $R_{f, t}$ and the fact that the utility of the riskfree money market account carries no uncertainty (at least in the short run), we assume that the investor specific error is zero for payoffs generated by the riskfree asset. This avoids the necessity to evaluate all elements of the covariance matrix of errors (Train (2009)).

${ }^{9}$ It should not go unmentioned that other distributional assumptions can be made such as inHarless and Camerer (1994), Hey and Orme (1994), Loomes and Sugden (1995), see Booij et al. (2010) for lognormal distributed error terms see Harrison and Rutstrom (2008) and Train (2009) for logistically distributed errors. We refer to Ballinger and Wilcox (1997) for a discussion of Cauchy and Laplace distributed errors. Note that different specifications of $\epsilon_{i}$ may affect the selection of the best fitting utility model (e.g. Wilcox (2008) for a discussion of the selection implications if $\epsilon_{i}$ is assumed to follow an extreme value distribution as sketched in Train (1986)).
} 
the probability to buy or hold the risky asset is defined as

$$
\begin{aligned}
p\left(\Delta_{t}\left(U_{k} \mid \boldsymbol{\theta}_{\boldsymbol{k}}\right) \geq 0\right) & =\int_{-\infty}^{\infty} I\left[\Delta_{t}\left(U_{k} \mid \boldsymbol{\theta}_{\boldsymbol{k}}\right)+\epsilon_{i}>0\right] \phi\left(\epsilon_{i}\right) d \epsilon_{i} \\
& =\int_{-\infty}^{\frac{\Delta_{t}\left(U_{k} \mid \boldsymbol{\theta}_{\boldsymbol{k}}\right)}{\sigma_{i}}} \phi\left(\epsilon_{i}\right) d \epsilon_{i}=\Phi\left(\Delta_{t}\left(U_{k} \mid \boldsymbol{\theta}_{\boldsymbol{k}}\right) / \sigma_{i}\right) .
\end{aligned}
$$

Thus, based on the normal distribution of $\epsilon_{i}$, we denote the conditional choice probability to hold the stock as $\Phi\left(\Delta_{t}\left(U_{k} \mid \boldsymbol{\theta}_{\boldsymbol{k}}\right) / \sigma_{i}\right)$ and the probability to invest in the riskless asset as $1-\Phi\left(\Delta_{t}\left(U_{k} \mid \boldsymbol{\theta}_{\boldsymbol{k}}\right) / \sigma_{i}\right)=\Phi\left(-\Delta_{t}\left(U_{k} \mid \boldsymbol{\theta}_{\boldsymbol{k}}\right) / \sigma_{i}\right)$, where $\Phi$ denotes the cumulative normal density function. For the ease of handling these conditional choice probabilities, we aggregate both probabilities in a single variable, henceforth represented by $p_{I_{k, t}}$. Note that the choice probabilities satisfy the conditions if stocks generate an infinite stream of utility (e.g. $\Delta_{t}\left(U_{k} \mid \boldsymbol{\theta}_{\boldsymbol{k}}\right) \rightarrow \infty$ ), the choice probability to hold the stock converges to unity, implying that the investor almost surely favors holding the stock and approaches zero if $\Delta_{t}\left(U_{k} \mid \boldsymbol{\theta}_{\boldsymbol{k}}\right) \rightarrow-\infty$ otherwise (Rust (1994)). Consequently, the binary choice feature of the discrete choice setting combined with the normal distribution of the error term allows us to construct a customized likelihood function $\log L\left(\Delta_{t}\left(U_{k} \mid \boldsymbol{\theta}_{\boldsymbol{k}}\right)\right)$ similar to Hey and Orme (1994), Harrison and Rutstrom (2008) and de Palma et al. (2008), representing a non-linear in arguments probit model (Marschak (1960), Amemiya (1975), McFadden (1980), Amemiya (1981), Amemiya (1985), Train (1986), Ben-Akiva and Lerman (1985), Train (2009)). The overall logarithmized likelihood function of an investor $i$ of utility type $k$ can accordingly be expressed as

$$
\log L\left(\Delta_{t}\left(U_{k} \mid \boldsymbol{\theta}_{\boldsymbol{k}}\right)\right)=\sum_{t \in T} \sum_{I \in I_{k, t}} I_{k, t} \log p_{I_{k, t}}\left(\Delta_{t}\left(U_{k} \mid \boldsymbol{\theta}_{\boldsymbol{k}}\right)\right),
$$

in which $p_{I_{k, t}}\left(\Delta_{t}\left(U_{k} \mid \boldsymbol{\theta}_{\boldsymbol{k}}\right)\right)$ denotes the respective conditional probabilities as defined above. $^{10}$

To identify the best fitting underlying utility function of type $k$, we hark back to insights from likelihood theory according to which the selection of the utility model that explains observed data best should be based on the maximized likelihood value of each model $k$ (Kullback (1968), Akaike (1973), Schwarz (1978), Amemiya (1980), Pawitan (2001), Burnham and Anderson (2002) and Burnham and Anderson (2004)). ${ }^{11}$ The application of the "pure" value of the maximized likelihood function $\log L\left(\Delta_{t}\left(U_{k} \mid \boldsymbol{\theta}_{\boldsymbol{k}}\right)\right)$ as a model selection criterion is usually not recommended for utility model selection as the maximized likelihood function could be subject to overfitting, tendentially favoring multiparameter utility models (Carbone and Hey (1994), Hey and Orme (1994), Carbone and Hey (1995) and Stott (2006)). Instead, literature on model selection suggests sorting utility models according to the Akaike Information Criterion $(A I C)$ that controls explicitly for varying number of parameters instead of using the maximized $\log L\left(\Delta_{t}\left(U_{k} \mid \boldsymbol{\theta}_{\boldsymbol{k}}\right)\right)$ (Akaike (1973), Akaike (1974), Bozdogan (2000), Pawitan (2001) and Burnham and Anderson (2004)). The $A I C$ is commonly expressed as

$$
A I C=-\frac{2 \log L\left(\Delta_{t}\left(U_{k} \mid \hat{\boldsymbol{\theta}}_{\boldsymbol{k}}\right)\right)}{n t}+\frac{2 K_{k}}{n t}
$$

\footnotetext{
${ }^{10}$ Note that, given the binary choice assumption, the log-likelihood function can explicitly written in a binomial form as used in Harrison and Rutstrom (2008).

${ }^{11}$ Early studies such as Fisher (1922), Fisher (1956) and Kullback (1968) concluded that the maximized likelihood function $\log L\left(\Delta_{t}\left(U_{k} \mid \hat{\boldsymbol{\theta}}_{\boldsymbol{k}}\right)\right)$ not only allows to estimate the elements of $\hat{\boldsymbol{\theta}}_{k}$ but also reflects the information content of each model $k$ and thus offers the opportunity to identify the best-fitting utility model among all $k$ utility models.
} 
according to Akaike (1974) in the representation of Amemiya (1980), where dividing by $n t$, the number of observations in terms of trading days $t$ and traded stocks $n$, corrects for the different number of observations and where $K_{k}$ denotes the rank of $\boldsymbol{\theta}_{\boldsymbol{k}}$, representing the number of parameters to be estimated in utility model $k$. To take the varying sample size (particularly as our dataset contains portfolios with short trading history and very few stocks) and the general finiteness of our dataset into account, we apply the corrected Akaike Information Criterion $(A I C C)$, defined by

$$
A I C C=-\frac{2 \log L\left(\Delta_{t}\left(U_{k} \mid \hat{\boldsymbol{\theta}}_{\boldsymbol{k}}\right)\right)}{n t}+\frac{2 K_{k}}{n t}+\frac{2 K_{k}\left(K_{k}+1\right)}{n t\left(n t-K_{k}-1\right)},
$$

as first proposed by Sugiura (1978) for OLS regressions and suggested by Hurvich and Tsai (1989), McQuarrie and Tsai (1998) and Brockwell and Davis (2009) for time series model selection (for a discussion of the original version of the Akaike Information Criterion $A I C$ and $A I C C$ as model selection criterion we refer to Burnham and Anderson (2002) and Burnham and Anderson (2004)), which replaces the penalty term of $A I C$ by its exact term for bias adjustment, resulting in a greater penalty for models with additional parameters in comparison to the original $A I C$.

For the empirical analysis, we wrote a program using the statistical software Stata in the maximum likelihood environment of version 10.1 (Gould et al. (2006)), which offers a convenient way to implement and define customized likelihood functions (Harrison (2008)). As the ml model command combined by the maximize option implicitly draws upon the underlying optimize functions embedded in Mata, it evokes and enables the selection of several numerical search algorithm. Based on various tests of our program, which were based on simulated trading data with known utility models and parameter settings and which we used to analyze the sensitivity of our results with respect to various numerical search algorithm, we decided to define these algorithm explicitly instead of relying on the default setting to avoid the numerical search algorithm to get stuck or to generate unreliable results. Running the program in these tests revealed that the surface of $\log \left(L\left(\Delta_{t}\left(U_{k} \mid \boldsymbol{\theta}_{\boldsymbol{k}}\right)\right)\right)$ seems to determine breakdowns in the search algorithm. For example, similar to previous studies on the efficiency of utility model selection such as Carbone and Hey (1994), we identified convex segments in the likelihood function, causing the termination or hang-ups of the numerical search algorithm. These shortcomings might have an impact on utility model selection as it cannot be ruled out that $\hat{\boldsymbol{\theta}}_{\boldsymbol{k}}$ and thus the level of $\log \left(L\left(\Delta_{t}\left(U_{k} \mid \boldsymbol{\theta}_{\boldsymbol{k}}\right)\right)\right)$ as a central ingredient for model selection, is the result of a stopped numerical search due to local maxima or other deficiencies of $L\left(\Delta_{t}\left(U_{k} \mid \boldsymbol{\theta}_{\boldsymbol{k}}\right)\right)$ (McCullough and Vinod (2003)).

To deal with problems in the numerical search algorithm and the termination in the iteration process due to flat or convex regions of the likelihood function $\log \left(L\left(\Delta_{t}\left(U_{k} \mid \boldsymbol{\theta}_{\boldsymbol{k}}\right)\right)\right.$ ), we follow the relevant literature (Judge et al. (1985), Ruud (2000), Gould et al. (2006)) and change the numerical algorithm in a systematic manner: we use a mixed iteration procedure where we run a Newton-Ralphson procedure for the first five steps and switch to the Davidon-Fletcher-Powell algorithm (Fletcher (1980)) for the next five iterations to push the estimates outside of the critical section of the likelihood function and then return to the former technique if no solution is obtained or the numerical algorithm fails to converge within five steps. To avoid getting trapped in a local maximum, we decided to repeatedly use various starting values for the numerical algorithm (Liu and Mahmassani (2000)) and check, whether the same ranking of utility models is obtained. In detail, we 
randomly altered the starting values of vector $\boldsymbol{\theta}_{\boldsymbol{k}}$ within the numerical search algorithm and rerun the evaluation of $\log \left(L\left(\Delta_{t}\left(U_{k} \mid \boldsymbol{\theta}_{\boldsymbol{k}}\right)\right)\right)$ for each of the individual investors under investigation. Among the different maximized likelihoods, we subsequently selected the highest of the obtained values for $\log \left(L\left(\Delta_{t}\left(U_{k} \mid \boldsymbol{\theta}_{\boldsymbol{k}}\right)\right)\right) .{ }^{12}$

In order to capture errors in investors' decision making (e.g. preference reversals as mentioned in Hey (1995), Hey and Carbone (1995), Loomes and Sugden (1995), Carbone (1997), Carbone and Hey (2000) and Loomes et al. (2002)), and to account for the presence of other trading factors that are independent from preferences (e.g. Grinblatt and Keloharju (2000), Grinblatt and Keloharju (2001b) or Kaustia (2010)) and to deal with possible deficiencies in $\log \left(L\left(\Delta_{t}\left(U_{k} \mid \boldsymbol{\theta}_{\boldsymbol{k}}\right)\right)\right)$, we implement an element of additional flexibility and estimate a nuisance parameter $\sigma_{i}^{2}$ along with parameterset $\boldsymbol{\theta}_{\boldsymbol{k}}$ as in Harrison and Rutstrom (2008) and Harrison (2008). Additionally, as suggested by Dhrymes (1971) and Cramer (1986), another purpose of $\hat{\sigma}_{i}^{2}$ is to absorb the impact of shortcomings in the likelihood function $L\left(\Delta_{t}\left(U_{k} \mid \boldsymbol{\theta}_{\boldsymbol{k}}\right)\right) .{ }^{13}$ In the following Chapter, we present a dataset of trade histories and demographic characteristics on investor level from a large German discount brokerage firm and discuss the results of the application of the presented likelihood approach.

\section{The Distribution of Preferences among Individual Investors: Results from Discount Brokerage Data}

To answer the questions in this paper, it is appropriate to conduct investigations and perform analyses on individual level as it has been advised and repeatedly applied in experimental economics (Hensher and Johnson (1981), Train (1986), Harrison and Rutstrom (2008) and Train (2009)). A well established way to investigate individual investor's behavior is to use trading data from discount brokers (Odean (1998), Barber and Odean (1999), Odean (1999), Barber and Odean (2000), Barber and Odean (2001b), Kumar and Goetzmann (2008) and Kumar (2009a) among others). The structure of our dataset resembles those used by Odean (1999) and Barber and Odean (2000) and contains details of portfolio compositions at any point in time as well as information on executed trades during the observation period, where single transactions can be uniquely attributed to each individual enlisted (see Weber et al. (2014) for details). ${ }^{14}$ This history of trades, usually dubbed trade file, represents actively stated decisions of a random selection of 5.000 individual investors. We consider this as an advantage as portfolio positions may not fully reflect risk preferences due to stale positions in portfolios (Calvet et al. (2009) and Bilias et al. (2010)) which may affect revealed risk preferences and thus could have an impact on the classification of the underlying utility functions. We admit, that this comes at the costs of a certain loss of information (see e.g. Carbone and Hey (1994)) as portfolio weights are not considered - consequently, we refrain from presenting the results of vector $\hat{\boldsymbol{\theta}}_{\boldsymbol{k}}$ as similar trade pattern can be generated by

\footnotetext{
${ }^{12}$ Note that by generating random starting values, we intend to rule out systematic biases in $\log \left(L\left(\Delta_{t}\left(U_{k} \mid \boldsymbol{\theta}_{\boldsymbol{k}}\right)\right)\right)$ due to local maxima in the likelihood function as those local maxima were detected and found to be critical for utility model selection (Carbone and Hey (1994)).

${ }^{13}$ For the estimation of the standard deviation of the error term, we transform $\sigma_{i}$ into an exponential function to ensure that the ascertained estimator is strictly positive (Rabe-Hersketh and Everitt (2004)) and recovered the estimator for $\sigma_{i}$ and the associated standard errors using the nlcom command in Stata.

${ }^{14}$ We emphasize that our analysis complements the study of Weber et al. (2014), who used the same dataset for their analysis of individual investors trading behavior and the dependencies of various investment biases identified therein.
} 
different values of $\boldsymbol{\theta}_{\boldsymbol{k}}$ if the distribution of the error term $\sigma_{i}$ is very small (the investor makes nearly no mistakes and decides according to the difference in utilities).

Similar to empirical studies on portfolio choice and trading behavior of individual investors such as Barber and Odean (2000), Barber and Odean (2001b), Graham and Kumar (2004), Mitton and Vorkink (2007), Kumar and Goetzmann (2008) and Barber et al. (2011), we focus exclusively on trading records of stocks. ${ }^{15}$ Our decision to discard trades in mutual funds, bonds as well as options and other financial products with asymmetric payoffs is based on the fact that the time series of returns and the observed trading of these discarded financial products may be characterized by features and trading motives that differ from preferences and thus may bias our findings. Exemplarily, empirical studies indicate that performance data used to determine market parameters for each instrument may be driven by autocorrelation as for mutual funds (Grinblatt and Titmann (1989), Grinblatt and Titmann (1993), Brown and Goetzmann (1995), Carhart (1997), Daniel et al. (1997), Chan et al. (2000), Wermers (2000), Coval and Moskowitz (2001) and Kosowski et al. (2006)), generating trades that may imitate preference-based trading pattern (Murstein (2003)). Furthermore, the time series of other excluded financial products such as bonds may be governed by inherent mean reversion (pull-to-par effect), lacking market liquidity as in the case of (corporate) fixed income instruments (causing stale-price-problems and delayed execution of trade orders) or strategic pricing motives by market makers as in the case of structured products (Baule and Tallau (2011)). These features appear not only inconsistent with the characteristics of the underlying binomial model that we apply in case of returns, but may also result in strategies that interfere with the presumptions of Karpoff (1987b) and imitate those trading pattern that are possibly driven by preferences (Barberis and Xiong (2009)) such as the Disposition Effect (Odean (1998), Hung and Yu (2006) and Kaustia (2010)). Moreover, studies by Ivcovich and Weisbrenner (2009), Chang et al. (2012) and Entrop et al. (2013) provide evidence that trading in stocks actually differs from trading in investment funds and retail structured products in terms of turnover, trade timing and trade duration, which are essential ingredients for the likelihood approach applied.

To provide an empirically tractable model of discrete choice, results obtained from a large number of empirical and theoretical studies need to be considered when it comes to individual investors' trading behavior. Empirical research provides some indication that individual investors treat different streams of income such as dividends as well as cash flows resulting from corporate actions and other stocks (Shefrin and Statman (1984), Baker and Wurgler (2004)) in different mental accounts (Thaler (1985)). Furthermore, the tendency to evaluate risky lotteries separately, known as narrow framing (Barberis and Huang (2001), Barberis et al. (2001), Barberis et al. (2001), Berkelaar et al. (2004), Gomes (2005), Barberis and Huang (2009)) is in line with Shefrin and Statman (1985), complementing recent studies on individual investors that examine the trading decisions for each stock separately (see for instance Odean (1998), Odean (1999), Barber and Odean (2000), Barberis and Huang (2001), Grinblatt and Keloharju (2001a), Grinblatt

\footnotetext{
${ }^{15}$ Our restriction to trading in equities may naturally exclude the possibility to gain insights to asset allocation decisions and the inherent preferences for skewness as described in Barberis and Huang (2001) and Barberis and Huang (2008). Investing in securities with asymmetric payoffs may represent a trade off in terms of utility from reduced portfolio variance due to diversification with benefits from increased portfolio skewness (Mitton and Vorkink (2007), Barberis and Huang (2008)). We consider an exclusion as not harmful to our analysis as Weber et al. (2014) reports that investments in asymmetric products are quite uncommon in our dataset.
} 
and Keloharju (2001b), Barber and Odean (2002), Dhar and Kumar (2002), Hong and Kumar (2002), Zhu (2002), Grinblatt and Han (2005b), Lim (2006), Frazzini (2006), Barber and Odean (2008)). Narrow framing, in turn, allows us to define a finite and exhaustive set of alternatives satisfying the requirements for a discrete choice set (Amemiya (1980), Train (1986), Train (2009)). To derive this discrete choice set from the time series recorded in the trade file, Train (2009) notes that mutually exclusive options need to be defined.

The central task is therefore to translate complex trade pattern from brokerage data into a sequence of binary choices to specify the index $I_{k, t}$ in equation (3.2) as trading data usually contains discrete quantities (Schlarbaum et al. (1978a), Shefrin and Statman (1985), Odean (1998), Shapira and Venezia (2001)). For this purpose, we adopt common accounting principles such as First-in-First-outPrinciple (FIFO) or Last-in-First-out-Principle (LIFO) that allows us to decompose complex transactions into simple and self-contained trade components, known as round-trips as proposed by Schlarbaum et al. (1978b) and Schlarbaum et al. (1978a) and popularized by Shapira and Venezia (2001). ${ }^{16}$ These round-trips can be used to indicate, whether an investor is invested in a stock, which meets the requirements of an exhaustive choice set and avoids inconsistencies in the likelihood function in the case of compounded order flows. ${ }^{17}$ Due to tax treatments in Germany, we opted for an application of FIFO throughout the dataset, assuming that mental accounting of individual investors follows the current tax framework.

Confronted with the computational burden of evaluating all utility models and their associated likelihood functions numerically for each investor, we randomly selected a sub-sample of 656 investors, covering 3,724 distinct securities, for which we constructed likelihood functions for each of the 18 utility models presented in Table (2). Given the trade history of the subsample, this theoretically sums up to $309,359,880$ single likelihood functions with an average of 37,872 observations per investor. Due to the overlapping-window procedure in our estimation of the stocks' characteristics $\mu_{t}, \sigma_{t}$ and $\Gamma_{t}$, this number of likelihood functions is reduced by those observations falling within the lookback period, which we assumed to be 60 days. Consequently we removed 606 securities (equivalent to 2,130,138 single likelihood functions) from our analysis as their time series spans less than 60 days. In the process of transferring these market parameters into risk and return features of the respective stocks that can serve as arguments of the utility functions, we additionally filtered for implausible binomial parameters (e.g. those which imply violations of non-arbitrage conditions or represented extreme outliers) such that the total

\footnotetext{
${ }^{16}$ Round-trip length and the application of accounting principles to stock trading as set out first in Lacey (1945) are commonly used to determine purchase prices or reference points to assess the profitability and to determine tax implications of trading strategies (e.g. Schlarbaum et al. (1978a), Silber (1984), Shefrin and Statman (1985), Odean (1998), Barber and Odean (2000), Shapira and Venezia (2001), Grinblatt and Keloharju (2004), Locke and Mann (2005), Brown et al. (2006) and Kaustia (2010)). In our study, accounting principles determine round-trips that result in unambiguous trading sequences, which were used as central arguments to determine the alternating sign of the arguments of the likelihood function via $I_{k, t}$.

${ }^{17}$ To exemplify the latter point, assume a sequence of a bid order over 70 stocks at time 1 , followed by another bid over 120 stocks at time 2, an ask over 50 stocks at time 3 and a sale of the remaining 140 stocks at time 4 , which could be decomposed into three round-trips. For each observation between time 1 and 2 and time 3 and 4 , the overall likelihood function contains three single likelihood functions $\log p_{I_{k, t}}\left(\Delta_{t}\left(U_{k} \mid \boldsymbol{\theta}_{\boldsymbol{k}}\right)\right)$ with opposite signs for $\Delta_{t}\left(U_{k} \mid \boldsymbol{\theta}_{\boldsymbol{k}}\right)$, resulting in ambiguous effects on $\log L\left(\Delta_{t}\left(U_{k} \mid \boldsymbol{\theta}_{\boldsymbol{k}}\right)\right)$. In the above illustration, the application of FIFO could solve this inconsistency although we acknowledge that a different compounding of an order flows may require a different accounting principle to address the problem adequately.
} 
number of $\log p_{I_{k, t}}\left(\Delta_{t}\left(U_{k} \mid \boldsymbol{\theta}_{\boldsymbol{k}}\right)\right)$ was further cut down to $307,077,930$ single likelihood functions. ${ }^{18}$ After removing critical components in our market parameter time series, the remaining observations span 38,903 round trips in our sample, conducted during 1999 and 2012 in equity instruments, with an average of approximately 107 and a median of 65 round trips per investor. Given this set of likelihood functions, we tried to evaluate 46, 200 preference and nuisance parameters numerically, from which we actually estimated 27,959 parameters successfully, summing up to a total number of 6,415 out of 11,808 utility models. ${ }^{19}$

Table 3. Frequency of Appearance for each Utility Model

The table captures the proportion of evaluated utility models to the total number of utility models evaluated (6.415 models in our dataset), denoted as \% calc., as well as the proportion of utility models, where the numerical seach algorith was terminated, to the total number of utility models, where the search algorith was terminated (5.393 models in our dataset), denoted as \% $\neg$ calc. Expected utility models are denoted as EUT, Rank-dependent Utility is denoted as $R D U$. Simple Prospect Theory (Kahneman and Tversky (1979)) uses the denotation SPT, whereas Cumulative Prospect Theory (Tversky and Kahneman (1992)) is denoted as CPT. Decision weights in accord to Quiggin (1982) are denoted as QU82 and as KT92 for decision weights as in Tversky and Kahneman (1992). If no decision weights are applicable, we used the abbreviation None. Furthermore, we use the denotation $C R R A$ for CRRA utility functionals and EXPO to denote utility functions as in Saha (1993). For $S P T$ and $C P T$, we use the denotation $P O W R$ for models with kinked power-functionals as in Kahneman and Tversky (1979) and used DHG0 to denote value functionals as defined in DeGiorgi and Hens (2006).

\begin{tabular}{|c|c|c|c|c|c|c|c|c|c|}
\hline & & \multicolumn{2}{|c|}{ EUT } & \multicolumn{2}{|c|}{ RDU } & \multicolumn{2}{|c|}{ SPT } & \multicolumn{2}{|c|}{ CPT } \\
\hline & & $\%$ calc. & $\% \neg$ calc. & $\%$ calc. & $\% \neg$ calc. & $\%$ calc. & $\% \neg$ calc. & $\%$ calc. & $\% \neg$ calc. \\
\hline \multirow{3}{*}{ 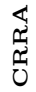 } & None & $6.14 \%$ & $4.86 \%$ & $0.00 \%$ & $0.00 \%$ & $0.00 \%$ & $0.00 \%$ & $0.00 \%$ & $0.00 \%$ \\
\hline & QU82 & $0.00 \%$ & $0.00 \%$ & $3.99 \%$ & $7.42 \%$ & $7.72 \%$ & $2.99 \%$ & $1.82 \%$ & $9.99 \%$ \\
\hline & КT92 & $0.00 \%$ & $0.00 \%$ & $5.30 \%$ & $5.86 \%$ & $6.86 \%$ & $4.01 \%$ & $5.02 \%$ & $6.19 \%$ \\
\hline \multirow{3}{*}{$\begin{array}{l}0 \\
\stackrel{1}{x} \\
\times \\
\text { I }\end{array}$} & None & $6.56 \%$ & $4.36 \%$ & $0.00 \%$ & $0.00 \%$ & $0.00 \%$ & $0.00 \%$ & $0.00 \%$ & $0.00 \%$ \\
\hline & QU82 & $0.00 \%$ & $0.00 \%$ & $5.33 \%$ & $5.82 \%$ & $0.00 \%$ & $0.00 \%$ & $0.00 \%$ & $0.00 \%$ \\
\hline & КT92 & $0.00 \%$ & $0.00 \%$ & $5.33 \%$ & $5.82 \%$ & $0.00 \%$ & $0.00 \%$ & $0.00 \%$ & $0.00 \%$ \\
\hline \multirow{3}{*}{ 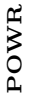 } & None & $0.00 \%$ & $0.00 \%$ & $0.00 \%$ & $0.00 \%$ & $0.00 \%$ & $0.00 \%$ & $0.00 \%$ & $0.00 \%$ \\
\hline & QU82 & $0.00 \%$ & $0.00 \%$ & $0.00 \%$ & $0.00 \%$ & $5.02 \%$ & $6.19 \%$ & $0.73 \%$ & $11.29 \%$ \\
\hline & КТ92 & $0.00 \%$ & $0.00 \%$ & $0.00 \%$ & $0.00 \%$ & $4.22 \%$ & $7.14 \%$ & $3.96 \%$ & $7.45 \%$ \\
\hline \multirow{3}{*}{ 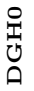 } & None & $0.00 \%$ & $0.00 \%$ & $0.00 \%$ & $0.00 \%$ & $0.00 \%$ & $0.00 \%$ & $0.00 \%$ & $0.00 \%$ \\
\hline & QU82 & $0.00 \%$ & $0.00 \%$ & $0.00 \%$ & $0.00 \%$ & $8.40 \%$ & $2.17 \%$ & $6.52 \%$ & $4.41 \%$ \\
\hline & КТ92 & $0.00 \%$ & $0.00 \%$ & $0.00 \%$ & $0.00 \%$ & $8.71 \%$ & $1.80 \%$ & $8.36 \%$ & $2.23 \%$ \\
\hline
\end{tabular}

Results from model selection procedures strongly rely on the accuracy of the assessment of the respective models, therefore it is mandatory to examine whether all

\footnotetext{
${ }^{18}$ We sorted the realized returns and removed the upper and lower $1 \%$. Removing outliers prevents us from diluting the ranking of utility functions as extreme returns may drive estimated market parameters, which affects the level of the likelihood function. Accompanying simulations have shown that the effects of extreme returns in the time series on the selection of utility functions is twofold: on one hand, large changes in market parameters due to extreme returns loosen the correlation between past returns and other parameters $\mu_{t}, \sigma_{t}$ and $t$, that enter the utility functions as arguments, thus dampen potential multicollinearity problems stemming from the stocks risk and return parameters. On the other hand, if the amplitude of these changes is too high, the purchase or sale of the affected stock may be optimal under different utility models, say model $k$ and competing utility model $m$, causing ambiguity in model selection based on observed roundtrips as the obtained values of the maximized $\log L\left(\Delta_{t}\left(U_{k} \mid \boldsymbol{\theta}_{\boldsymbol{k}}\right)\right)$ are closer to $\log L\left(\Delta_{t}\left(U_{m} \mid \boldsymbol{\theta}_{\boldsymbol{m}}\right)\right)$. These likelihoods may not be significantly different anymore, yielding high $p$-values of either a Vuong- or Likelihood-Ratio test if both likelihoods are tested against each other. Our pretests have shown that by removing outliers the latter effect dominates such that our selection procedure of utility models is enhanced.

${ }^{19}$ We had to drop 3 investors as, due to their trade history, no utility model can be evaluated.
} 
models under consideration face equal conditions to reflect their information content. We noted that running our program required constant monitoring and made manual interventions necessary whenever, due to deficiencies in $\log L\left(\Delta_{t}\left(U_{k} \mid \boldsymbol{\theta}_{\boldsymbol{k}}\right)\right)$ and of the underlying dataset, the numerical search algorithm got bogged down and the execution stopped, indicating that the requirements of computational equality between different utility models might not be met throughout the dataset. As a consequence, the impossibility to evaluate and to obtain estimates regarding $\boldsymbol{\theta}_{\boldsymbol{k}}$ predetermines the baseline probability of appearance of each utility model, which in turn forms the starting point for our analysis. If each model can be assessed properly and thus is equally likely to occur, the baseline probability of an individual investor to be of utility type $k$ is approximately $5.556 \%$. Table (3) shows that not all models were evaluated equally successful such that the chances of observing a particular utility model vary and deviate from the baseline probability. Accordingly, although these problems occured for all types of utility models under consideration, we found that predominantly non-expected utility models such as Cumulative Prospect Theory were affected. ${ }^{20}$ Yet, we found that approximately $62.5 \%$ of all utility models, corresponding to an average of 11.2 (median of 12 with a maximum number of 17) utility models per investor, were evaluated successfully.

A further inspection of the percentage of utility models, where our program misses to provide values for $\log L\left(\Delta_{t}\left(U_{k} \mid \hat{\boldsymbol{\theta}}_{\boldsymbol{k}}\right)\right)$, revealed that for 5.393 utility models the numerical search algorithm suffers from several specific types of failure. While performing the evaluation of all utility models for all investors in our dataset, Stata reported that the iteration was terminated due to specialties in the surface of $\log L\left(\Delta_{t}\left(U_{k} \mid \hat{\boldsymbol{\theta}}_{\boldsymbol{k}}\right)\right)$. In particular, the termination of the numerical search was frequently caused by local convexities and saddle points containing pronounced flat sections. ${ }^{21}$ It turned out that terminations of the search algorithm predominantly occurred in those iterations where the Newton-Ralphson method was applied. This particular numerical search algorithm runs into problems if the Hessian matrix is degenerate as the step size is determined by $\boldsymbol{- H}\left(\Delta_{t}\left(U_{k} \mid \boldsymbol{\theta}_{\boldsymbol{k}}\right)\right)^{-1}$. Closer investigation of key elements of the numerical search algorithm revealed that for plausible values of $\boldsymbol{\theta}_{\boldsymbol{k}}$, the determinant of the Hessian matrix $\operatorname{det} \boldsymbol{H}\left(\Delta_{t}\left(U_{k} \mid \hat{\boldsymbol{\theta}}_{\boldsymbol{k}}\right)\right)$ is indeed fairly close to zero and contains both positive and negative Eigenvalues. These results might be caused by flat sections (such as plateaus and saddle points) in the surface of the likelihood function, indicating that, besides a possible impact of $\Delta_{t}\left(U_{k} \mid \boldsymbol{\theta}_{\boldsymbol{k}}\right)$ on $\log L\left(\Delta_{t}\left(U_{k} \mid \hat{\boldsymbol{\theta}}_{\boldsymbol{k}}\right)\right)$, a certain degree of multicollinearity in $\log L\left(\Delta_{t}\left(U_{k} \mid \hat{\boldsymbol{\theta}}_{\boldsymbol{k}}\right)\right)$ (Griffiths et al. (1987)) or potential underidentification problems (Judge et al. (1985), Keele and Park (2006) and Greene (2008), for utility models see Carbone and Hey (1994)) might be present. ${ }^{22}$ In other cases where Stata reports successful convergence, thus provides values for the likelihood function and assigns values to $\boldsymbol{\theta}_{k}$,

\footnotetext{
${ }^{20}$ However, we noted that under a value functional specified as in DeGiorgi and Hens (2006), problems in the evaluation of $\log L\left(\Delta_{t}\left(U_{k} \mid \boldsymbol{\theta}_{\boldsymbol{k}}\right)\right)$ were less frequent. We suspect that the mathematical shape of a negative exponential power functional seems to foster the evaluation of the likelihood function.

${ }^{21}$ In these cases, the numerical search algorithm fails to converge within the 30 iteration steps by which we capped the maximum number of iterations as recommended by Cramer (1986), thus yielding missing values for $\log L\left(\Delta_{t}\left(U_{k} \mid \hat{\boldsymbol{\theta}}_{\boldsymbol{k}}\right)\right)$.

${ }^{22}$ Under moderate multicollinearity, the step size of a search algorithm is reduced if entering flat segments of $\log L\left(\Delta_{t}\left(U_{k} \mid \hat{\boldsymbol{\theta}}_{\boldsymbol{k}}\right)\right)$ as a flattening of the likelihood function might indicate that the maximum is close (Train (2009)). If $\log L\left(\Delta_{t}\left(U_{k} \mid \hat{\boldsymbol{\theta}}_{\boldsymbol{k}}\right)\right)$ is characterized by a flat surface over a large range of plausible $\boldsymbol{\theta}_{\boldsymbol{k}}$ due to a sufficient degree of multicollinearity, the application of such an algorithm results in an increased number of iteration steps or a termination of the search procedure given a cap on the maximum number of iteration steps such that the respective utility model is not evaluated adequately.
} 
associated standard errors were set to missing. In these cases we found that, despite repeated execution of the evaluation of $\log L\left(\Delta_{t}\left(U_{k} \mid \boldsymbol{\theta}_{\boldsymbol{k}}\right)\right)$ by using random starting values for the search algorithm to reduce the impact of local maxima, our program reported that the likelihood function is not concave in the last iteration step, setting standard errors to missing such that values for the maximized $\log L\left(\Delta_{t}\left(U_{k} \mid \hat{\boldsymbol{\theta}}_{\boldsymbol{k}}\right)\right)$ cannot be considered to be reliable (Gould et al. (2006)).

Problems in the surface of $\log L\left(\Delta_{t}\left(U_{k} \mid \boldsymbol{\theta}_{\boldsymbol{k}}\right)\right)$ due to convexities and insufficient steepness of the likelihood function can compromise our model selection procedure. Literature on numerical methods offers several solutions, according to which these problems can be solved by applying a numerical search algorithm that does not directly rely on the Hessian matrix but uses an approximation of it (such as those proposed by Berndt et al. (1974)) or by adding a positive term to the elements of the Hessian until it becomes invertible such that $\boldsymbol{-} \boldsymbol{H}\left(\Delta_{t}\left(U_{k} \mid \boldsymbol{\theta}_{\boldsymbol{k}}\right)\right)^{-1}$ exists (Marquardt (1963)). Similar to Griffiths et al. (1987), previous test of our program using simulations have shown that many of the likelihood functions of those utility models, where the Newton-Ralphson algorithm failed, can now be forced to converge to a solution, although a large sum of utility models still cannot be evaluated accurately. This is in line with Train (2009) as the Berndt-Hall-Hall-Hausman algorithm is an approximation of the Newton-Ralphson algorithm (Berndt et al. (1974)). Consequently, for non-quadratic $\log L\left(\Delta_{t}\left(U_{k} \mid \hat{\boldsymbol{\theta}}_{\boldsymbol{k}}\right)\right)$, where the Newton-Ralphson algorithm fails to proceed, the application of the Berndt-Hall-Hall-Hausman algorithm should not perform significantly better. In addition, literature from the field of experimental economics usually does not recommend the Berndt-Hall-Hall-Hausman method for estimation of utility functions (Harrison and Rutstrom (2008) and Harrison $(2008))^{23}$

Hitherto, our discussion focused on the aspect that not every utility model under consideration was evaluated properly accordingly, but we didn't provide further details on the information content of $\log L\left(\Delta_{t}\left(U_{k} \mid \hat{\boldsymbol{\theta}}_{\boldsymbol{k}}\right)\right)$. In particular, it is not clear whether $\log L\left(\Delta_{t}\left(U_{k} \mid \hat{\boldsymbol{\theta}}_{\boldsymbol{k}}\right)\right)$ is a result of pure coincidence as trading decisions based on noise and irrelevant information could imitate trading pattern of a particular utility model. Literature on noise trading such as Black (1986), DeLong et al. (1990), Campbell and Kyle (1993), Campbell et al. (1993) and Llorente et al. (2002) indicates that individual investors indeed base their decisions on factors that neither provide economical value nor represent relevant information (e.g. such as past prices, see Grinblatt and Keloharju (2001b), Garvey and Murphy (2004) and Kaustia (2010)). If an investors trading pattern is characterized by undirected fluctuations in portfolio positions as a consequence of randomly commissioning bid and ask orders (thus being independent from preference considerations), these underlying factors may be described by an error term $\epsilon^{\text {Noise }} \sim N\left(\mu_{\text {Noise }}, \sigma_{\text {Noise }}\right)$. This noise is assumed to be unsystematic and therefore approximately normally distributed and hence orthogonal to preferences - in the style of (Kyle (1985)) we refer to such an investor as Random Trader henceforth. ${ }^{24}$ We hypothesize that if

\footnotetext{
${ }^{23}$ Moreover, analyzing the iteration procedure and the surface of the likelihood function from our pretests revealed that a quadratic approximation of the maximized likelihood $\log L\left(\Delta_{t}\left(U_{k} \mid \hat{\boldsymbol{\theta}}_{\boldsymbol{k}}\right)\right)$, especially for non-expected utility models, performs poorly as a considerable number of iteration steps is required (Train (2009)). Note that a perfect quadratic approximation theoretically requires only one iteration to reach the maximum.

${ }^{24}$ Admittedly, the decision to hold the respective stock could correlate with other trading factors - consequently we cannot exclude directional trading by mere coincidence (e.g. Barber et al. (2006)). However, in this paper, we implicitly assume that the effect of these factors on the likelihood is negligible such that an utility model $k$ doesn't contribute to the likelihood of a Random
} 
an investor trades randomly, the associated likelihood $\log L\left(\Delta_{t}\left(U_{k} \mid \hat{\boldsymbol{\theta}}_{\boldsymbol{k}}\right)\right)$ should be close and statistically not distinct to the baseline $\log$-likelihood $\log L\left(\Delta_{t}\left(\epsilon^{\text {Noise }}\right)\right)$. Note that irrespective of the utility model under investigation, all models, for which we estimate $\hat{\boldsymbol{\theta}}_{\boldsymbol{k}}$, should not contribute further information on the observed trading data of a Random Trader - consequently, the utility classification of a Random Trader should be random if ranked according to AICC. To address this suspicion, we proceeded in three steps: First, we sorted all utility models, for which we obtained solutions for $\log L\left(\Delta_{t}\left(U_{k} \mid \hat{\boldsymbol{\theta}}_{\boldsymbol{k}}\right)\right)$ according to the corrected Akaike Information Criterion (AICC). In a second step, for each investor in our dataset, to whom we assign a list of ranked utility models, we constructed a Random Trader counterpart by performing accompanying simulations where we used 120 repetitions given the observations of the investor under investigation to construct (artificial) trading histories of such a Random Trader counterpart. For each of these 120 draws, we generated trade signals by replacing the difference in utilities $\Delta_{t}\left(U_{k} \mid \boldsymbol{\theta}_{\boldsymbol{k}}\right)$ by the stochastic element $\epsilon^{\text {Noise }}$. Accordingly, the Random Trader has a positive exposure in the stock if argument $\epsilon^{\text {Noise }}$ yields a cumulative density $\Phi\left(\epsilon^{\text {Noise }}\right)$ above $50 \%$ and prefers to hold the riskless investment otherwise. ${ }^{25}$ In the final step, we perform a test of the likelihoods of each utility model of each individual investor with respect to the likelihood functions of their Random Trader counterpart. If our hypothesis, that these individual investors trade on noise in terms of $\epsilon^{\text {Noise }}$ rather than preferences, is correct, the Likelihood-ratio tests we applied shouldn't indicate significant differences between the obtained values of $\log L\left(\Delta_{t}\left(U_{k} \mid \hat{\boldsymbol{\theta}}_{\boldsymbol{k}}\right)\right)$ and the baseline $\log L\left(\Delta_{t}\left(\epsilon^{\text {Noise }}\right)\right) .^{26}$

To perform the necessary tests for the difference between $\log L\left(\Delta_{t}\left(U_{k} \mid \hat{\boldsymbol{\theta}}_{\boldsymbol{k}}\right)\right)$ and $\log L\left(\Delta_{t}\left(\epsilon^{\text {Noise }}\right)\right)$, we performed 768,800 Likelihood-ratio tests and aggregated the resulting $p$-values using Fisher's Combination Method (Fisher (1925), Fisher (1948), Van Zweet and Oosterhoff (1967)) to obtain the basis for the significance levels of Table (4). ${ }^{27}$ From Table (4) it can be seen that the observed maximized likelihood values for all ranked utility models are significantly distinct from the respective

Trader such that its likelihood $\log L\left(\Delta_{t}\left(U_{k} \mid \hat{\boldsymbol{\theta}}_{\boldsymbol{k}}\right)\right)$ should be largely independent from the utility model under consideration. Any effect on $\log L\left(\Delta_{t}\left(U_{k} \mid \hat{\boldsymbol{\theta}}_{\boldsymbol{k}}\right)\right)$ could results from an imitation of the respective trading behavior under utility model $k$ and is suspected to be spurious. Consequently, we opted to use a normally distributed error term as described to imitate the trading behavior of an individual investor trading randomly.

${ }^{25}$ Values of $\mu_{N o i s e}$ and $\sigma_{N o i s e}$ were determined using grid search such that resulting round trip durations were comparable to the trade duration of the respective investor. For example, the trading sequences of a Random Trader matches (on average) to trading sequences of an investor with an average trade duration of 41 days if we set $\mu_{\text {Noise }}=1.0002$ and $\sigma_{\text {Noise }}=0.50$. Note that (in this setting and in distinction to real investors) the Random Trader is invested during $97 \%$ of the time in the same stock. Results are sensitive to changes in $\sigma_{N o i s e}$ but rather robust with respect to modifications of $\mu_{\text {Noise }}$.

${ }^{26}$ Concomitant with the fact that it is difficult to approximate the surface of $\log L\left(\Delta_{t}\left(U_{k} \mid \hat{\boldsymbol{\theta}}_{\boldsymbol{k}}\right)\right)$ using a second-order Taylor expansion around $\boldsymbol{\theta}_{\boldsymbol{k}}$, our Likelihood-ratio tests may be biased as their applicability presupposes a sufficient quadratic approximation of the likelihood function (Pawitan (2001)). In our pretest, we found that particularly for SPT and CPT, a large number of iteration steps is necessary before a stable solution for $\boldsymbol{\theta}_{\boldsymbol{k}}$ is obtained, pointing to a surface of $\log L\left(\Delta_{t}\left(U_{k} \mid \hat{\boldsymbol{\theta}}_{\boldsymbol{k}}\right)\right)$ for which a second-order Taylor expansion performs poorly. We suspect that for $S P T$ and $C P T$, the underlying value functionals and decision weights, probably impose convex sections in the likelihood function, driving our results with respect to $\log L\left(\Delta_{t}\left(U_{k} \mid \hat{\boldsymbol{\theta}}_{\boldsymbol{k}}\right)\right)$.

${ }^{27}$ In detail, aggregated $p$-values are calculated according to $-2 \sum_{i=1}^{K} \ln \left(p_{i}\right) \sim \chi_{2 K}^{2}$, based on the assumption that $p_{i}$ follows a uniform distribution $U(0,1)$ (note that $i$ indicates a summation index here and does not refer to an individual). Herein, $K$ denotes the number of utility models of type $k$ that obtain first rank and $p_{i}$ denotes $p$-values from respective Likelihood-ratio tests of the respective utility model tested against the baseline $\log$-likelihood $\log L\left(\Delta_{t}\left(\epsilon^{\text {Noise }}\right)\right)$. 
baseline likelihood function of the Random Trader for the majority of our investors such that we reject the hypothesis, that both likelihood values are equal. ${ }^{28}$ However, contrary to our hypothesis, according to which the assignment of first-rank utility models to a Random Trader should be random, we found that SPT tends to obtain the first rank, whereby this phenomenon happens more frequently following an increase in the variance of $\epsilon^{\text {Noise }}$, generating shorter round-trips, although we noted that for all simulated round-trips, $S P T$ is statistically not distinct from the respective second-rank utility models on a $10 \%$-level. However, it should be noted that there are several drawbacks with respect to Fishers Combination Method as it relies on the assumption of independent observations (Westberg (1985)) and treats small and large $p$-values differently (Rice (1990)). We found that, whenever $p$ values indicate significance, although these values were positively related (similar Brown (1975)), corresponding $\chi_{2 K}^{2}$-values were at least four-digit numbers such that we expect little change even if positive correlation among $p$-values had been taken into account. Yet, we aknowledge that Fischer's Combination Method tends to reject the Null hypothesis too frequently (Rice (1990)), such that, regarding the low significance of $S P T$ as first-rank utility model in our comparison of firstrank to second-rank utility models, this inherent drawback of Fisher's Combination Method supports the rejection of our hypothesis. ${ }^{29}$ In the light of these findings, an inspection of $\log L\left(\Delta_{t}\left(U_{k} \mid \hat{\boldsymbol{\theta}}_{\boldsymbol{k}}\right)\right)$ for the first-ranked utility models of our dataset furthermore revealed that variations of $\boldsymbol{\theta}_{\boldsymbol{k}}$ result in significant changes of the likelihood values (reflected in the results of the Likelihood-ratio tests), providing further indications that the contribution of the winning utility model to explain trading behavior might be not trivial.

Apart from deviations in the baseline likelihood as shown in Table (3), sorting utility models according to (3.4) could affect model selection even if variations in the number of parameters between different utility models are explicitly considered (Sugiura (1978), also Pawitan (2001), Burnham and Anderson (2002) and Burnham and Anderson (2004)). Likelihood functions can be susceptible to overfitting problems in the rankings such that multiparameter utility models such as SPT may be preferred (Pawitan (2001)) if parameter corrections as in (3.4) are insufficient, explaining the high share of Prospect Theory models in our sample, although results from Table (3) could point to a dominance of EUT in comparison to some versions of SPT. To identify possible overfitting issues, recall that we added a DeGiorgi and Hens (2006) (DGH0) functional to the different functional specifications of Simple Prospect Theory $(S P T)$ and Cumulative Prospect Theory $(C P T)$. According to DeGiorgi and Hens (2006), the $D G H 0$ value functional is defined as piecewise negative exponential value function and contains four different risk sensitivity parameters and one decision weight parameter (dependent of the version to be estimated), adding up to six parameters including the nuisance parameter for the error term $\sigma_{i}{ }^{30}$ If the likelihood function $\log L\left(\Delta_{t}\left(U_{k} \mid \hat{\boldsymbol{\theta}}_{\boldsymbol{k}}\right)\right)$ is prone to overfitting, then models

\footnotetext{
${ }^{28}$ Note that this is in line with our finding of high steepness of $\log L\left(\Delta_{t}\left(U_{k} \mid \hat{\boldsymbol{\theta}}_{\boldsymbol{k}}\right)\right)$ among the majority of individual investors in our dataset, as according to likelihood theory (e.g. Cramer (1986), Pawitan (2001) and Train (2009)), the steepness of the likelihood surface indicates the relative fit of the respective utility model and thus its information content to the observations in our dataset.

${ }^{29}$ However, we also noted that, if Likelihood-ratio tests were performed for first-rank utility models only, the results were even more pronounced: The maximized likelihood of all first-rank utility models are without exception statistically distinct to the likelihood of their respective Random Trader counterparts.

${ }^{30}$ In addition to our procedure of randomly assigning values to the starting point of the parameter vector for the numerical search algorithm, similar to DeGiorgi and Hens (2006), we also run an estimation using a parameter vector for the numerical search algorithm, where we determined 
containing a $D G H 0$ functional should end up in higher ranks compared to $S P T$ and $C P T$ models with a power or $C R R A$-value function. To determine whether our results suffer from overfitting, we checked the average rank each utility model obtained in our dataset as we report in Table (4). Inspection of our results reveals that a $D G H 0$ formulation of the value function obtained on average higher ranks within our subsample, but only in comparison to EUT and $R D U$, which are at most two or three parameter models respectively. In contrast to SPT and CPT as proposed by Kahneman and Tversky (1979), Prospect Theory models with a $D G H 0$ functional obtained significantly lower ranks, particularly if compared to $S P T$ given a $C R R A$-value function (Wilcoxon signed-rank test $p$-value 0.022 ) and and $C P T$ under a power value function (Wilcoxon signed-rank test $p$-value 0.018) such that overfitting doesn't seem to drive our results. ${ }^{31}$

In the quest to identify the best fitting utility model, recall that ranking competing models according to (3.4) is a widely accepted approach in experimental economics (e.g. Carbone and Hey (1994), Hey and Orme (1994), Carbone and Hey (1995) and Stott (2006)), but further information regarding the discrimination between two competing models can only be found in a few studies (e.g. Carbone and Hey (1995), Starmer (2000), Loomes et al. (2002), Conte et al. (2011)) and focuses predominantly on $\hat{\boldsymbol{\theta}}_{\boldsymbol{t}}$. Testing utility models of different rank against each other might be of some importance as we found that first and second rank utility models differ only by a small amount in their maximized likelihoods $L\left(\Delta_{t}\left(U_{k} \mid \hat{\boldsymbol{\theta}}_{\boldsymbol{k}}\right)\right) .^{32}$ To provide a measure of reliability and to discriminate first and second rank utility models we supplement the results by appropriate significance tests between the first and second rank utility models for a proper distinction. In particular, whenever nested models are tested against each other, the usual Likelihood-ratio test was used (Rao (1973), Kent (1982)), in other cases, where we need to derive $p$-values for contrasting non-nested models such as $C R R A$ and $C P T$, we apply a non-nested Likelihood-ratio test according to Vuong (1989). ${ }^{33}$ We provide an overview of the

its starting values such that they correspond to parameter estimates of Tversky and Kahneman (1992). We found that this procedure generated inferior results and on average lower values for $\log L\left(\Delta_{t}\left(U_{k} \mid \hat{\boldsymbol{\theta}}_{\boldsymbol{k}}\right)\right)$ in comparison to the method of random starting values for $\boldsymbol{\theta}_{\boldsymbol{k}}$.

${ }^{31}$ Furthermore, where DGH0-models obtained the first rank, we tested for the similarity of the likelihood to the likelihood of those utility models that obtained second rank according to a test for non-nested models (Vuong (1989)). We found that for almost all cases, the likelihoods of the DGH0-model were not significantly distinct from the second rank utility model, supporting our conclusion that overfitting doesn't appear to be much of a concern for utility model selection in our sample. Note that, similar to the findings in Hey and Orme (1994), we also find that utility models containing a Quiggin (1982) decision weight appear to obtain higher rankings compared to models with Tversky and Kahneman (1992) decision weights.

${ }^{32}$ We checked the ranking of utility models and rerun the ranking according to the Schwartz Information Criterion (also known as Bayes Information Criterion (Schwarz (1978))) as well as the original AIC but found the same ranking of our results irrespective of the criterion used.

${ }^{3}$ Technically, the Vuong test specifies that, under the null hypothesis, the expectation of the logarithm of the likelihood ratio is symmetrically distributed around zero. In cases where this ratio is not close to a normal distribution, alternative non-nested model tests have been proposed (e.g., Clarke (2003) and Clarke (2007)). According to Shapiro-Wilk and Skewness tests (D'Agostino et al. (1990)), only a few likelihood functions in our dataset satisfy this normality assumption. However, an application of Clarke's test revealed only small differences in comparison to Vuong's test, leaving our results unaltered. 
Table 4. Median Ranking and log-Likelihoods $\log L\left(\Delta_{t}\left(U_{k} \mid \hat{\boldsymbol{\theta}}_{\boldsymbol{k}}\right)\right)$ by Utility Model

The table captures the obtained median rankings for each utility model (denoted as Rank) as well as associated, averaged values for $\log L\left(\Delta_{t}\left(U_{k} \mid \hat{\boldsymbol{\theta}}_{\boldsymbol{k}}\right)\right)$ per observation (denoted as $l o g$ L.). $P$-values from Likelihood-ratio tests of each utility model per investor with respect to the baseline $\log$-likelihood $\log L\left(\Delta_{t}\left(\epsilon^{\text {Noise }}\right)\right)$ from simulated Random Traders were calculated for each draw and then aggregated using Fisher's Combination Method (Fisher (1925), Fisher (1948), Van Zweet and Oosterhoff (1967)). Expected utility models are denoted as EUT, Rankdependent Utility is denoted as $R D U$. For Simple Prospect Theory according to Kahneman and Tversky (1979), we use the denotation SPT, whereas Cumulative Prospect Theory according to Tversky and Kahneman (1992) is denoted as CPT. Decision weights are denoted as QU82 for weighting functions according to Quiggin (1982) and as KT92 for decision weights as defined by Tversky and Kahneman (1992). For those utility models, where no decision weights are applicable, we used the abbreviation None. Furthermore, we use the denotation $C R R A$ for utility functionals with constant relative risk aversion and $E X P O$ to denote exponential power utility functions according to Saha (1993). For SPT and CPT, we use the denotation POWR to indicate models with kinked power-functionals as proposed in Kahneman and Tversky (1979), where in addition DHG0 denotes a value functional as defined in DeGiorgi and Hens (2006). We use $* * *, * *$ and $*$ for significance at the $1 \%, 5 \%$ and $10 \%$ levels respectively. Test statistics of Fisher's Combination Method are not reported.

\begin{tabular}{|c|c|c|c|c|c|c|c|c|c|}
\hline & & \multicolumn{2}{|c|}{ EUT } & \multicolumn{2}{|c|}{ RDU } & \multicolumn{2}{|c|}{ SPT } & \multicolumn{2}{|c|}{ CPT } \\
\hline & & Rank & $\log \mathrm{L}$. & Rank & $\log \mathrm{L}$ & Rank & $\log \mathrm{L}$ & Rank & $\log \mathrm{L}$ \\
\hline 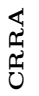 & $\begin{array}{l}\text { None } \\
\text { QU82 } \\
\text { KT92 }\end{array}$ & $\begin{array}{c}11.0 \\
0.0 \\
0.0\end{array}$ & $\begin{array}{c}-0.675^{* *} \\
0.0 \\
0.0\end{array}$ & $\begin{array}{c}0.0 \\
9.0 \\
10.0\end{array}$ & $\begin{array}{c}0.0 \\
-0.590^{* * *} \\
-0.645^{* * *}\end{array}$ & $\begin{array}{l}0.0 \\
2.0 \\
3.0\end{array}$ & $\begin{array}{c}0.0 \\
-0.386^{* * *} \\
-0.398^{* * *}\end{array}$ & $\begin{array}{l}0.0 \\
5.0 \\
6.0\end{array}$ & $\begin{array}{c}0.0 \\
-0.532^{* * *} \\
-0.504^{* * *}\end{array}$ \\
\hline $\begin{array}{l}0 \\
0 \\
x \\
\text { II }\end{array}$ & $\begin{array}{l}\text { None } \\
\text { QU82 } \\
\text { KT92 }\end{array}$ & $\begin{array}{l}10.0 \\
0.0 \\
0.0\end{array}$ & $\begin{array}{c}-0.653^{* * *} \\
0.0 \\
0.0\end{array}$ & $\begin{array}{l}0.0 \\
8.0 \\
8.0\end{array}$ & $\begin{array}{c}0.0 \\
-0.583^{* * *} \\
-0.590^{* * *}\end{array}$ & $\begin{array}{l}0.0 \\
0.0 \\
0.0\end{array}$ & $\begin{array}{l}0.0 \\
0.0 \\
0.0\end{array}$ & $\begin{array}{l}0.0 \\
0.0 \\
0.0\end{array}$ & $\begin{array}{l}0.0 \\
0.0 \\
0.0\end{array}$ \\
\hline $\begin{array}{l}x_{1}^{2} \\
\sum_{0}^{2} \\
0\end{array}$ & $\begin{array}{l}\text { None } \\
\text { QU82 } \\
\text { KT92 }\end{array}$ & $\begin{array}{l}0.0 \\
0.0 \\
0.0\end{array}$ & $\begin{array}{l}0.0 \\
0.0 \\
0.0\end{array}$ & $\begin{array}{l}0.0 \\
0.0 \\
0.0\end{array}$ & $\begin{array}{l}0.0 \\
0.0 \\
0.0\end{array}$ & $\begin{array}{l}0.0 \\
2.0 \\
2.0\end{array}$ & $\begin{array}{c}0.0 \\
-0.351^{* * *} \\
-0.326^{* * *}\end{array}$ & $\begin{array}{l}0.0 \\
7.0 \\
7.0\end{array}$ & $\begin{array}{c}0.0 \\
-0.540^{* * *} \\
-0.511^{* * *}\end{array}$ \\
\hline 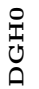 & $\begin{array}{l}\text { None } \\
\text { QU82 } \\
\text { KT92 }\end{array}$ & $\begin{array}{l}0.0 \\
0.0 \\
0.0\end{array}$ & $\begin{array}{l}0.0 \\
0.0 \\
0.0\end{array}$ & $\begin{array}{l}0.0 \\
0.0 \\
0.0\end{array}$ & $\begin{array}{l}0.0 \\
0.0 \\
0.0\end{array}$ & $\begin{array}{l}0.0 \\
3.0 \\
5.0\end{array}$ & $\begin{array}{c}0.0 \\
-0.427^{* * *} \\
-0.491^{* * *}\end{array}$ & $\begin{array}{l}0.0 \\
7.0 \\
7.0\end{array}$ & $\begin{array}{c}0.0 \\
-0.537^{* * *} \\
-0.538^{* * *}\end{array}$ \\
\hline
\end{tabular}




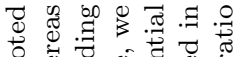
可记

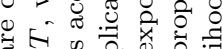

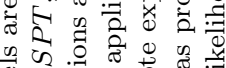
$\frac{10}{8}$ का 记

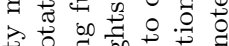

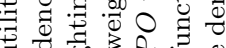
일

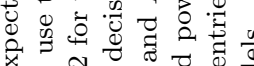

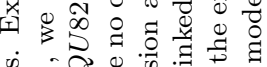

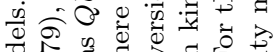

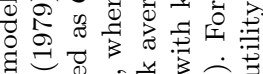

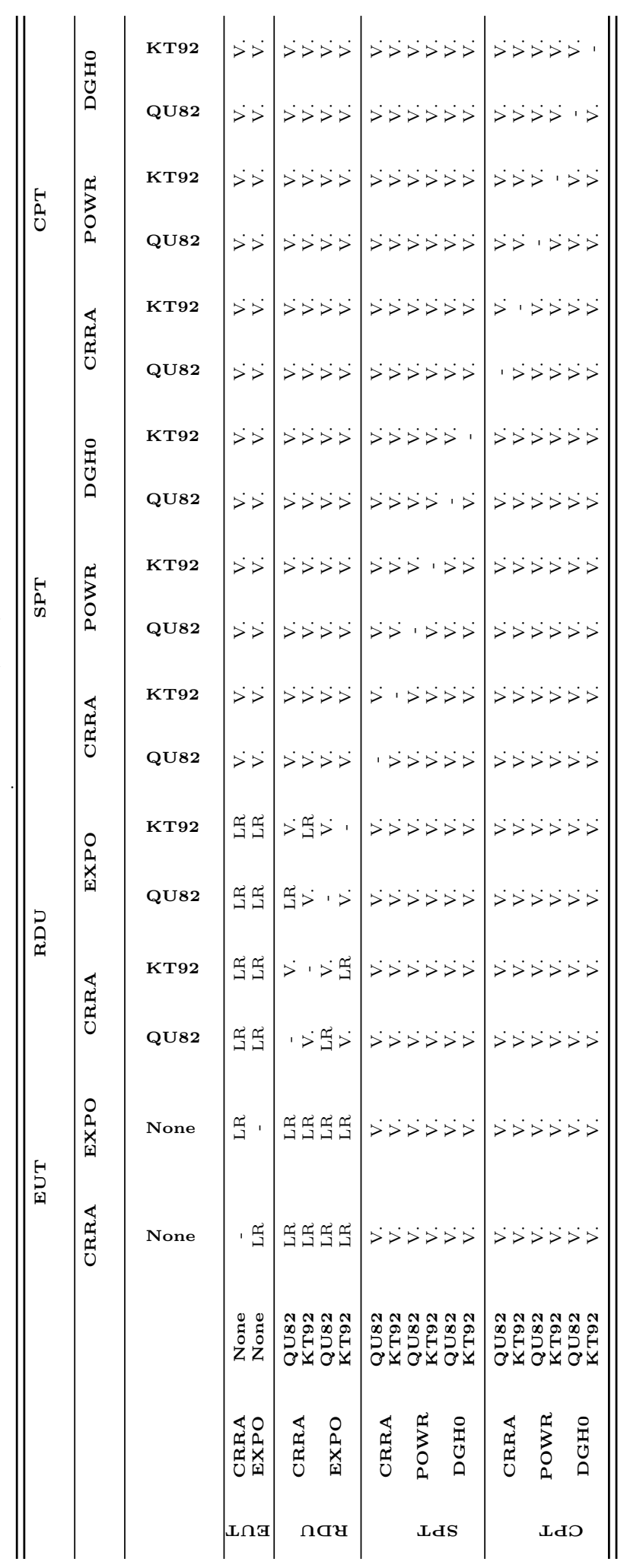


Table 6. First-rank Utility Models to Second-rank Utility Models: Summary Statistics sorted by Significance

This table displays the proportion of first-rank utility models, that are statistically distinct to second-rank models on a 10\%-/5\%-/1\%-significance level, to the total number of firstrank utility models that are statistically distinct to second-rank models on a $10 \%-/ 5 \%$ - $/ 1 \%$ significance level. Results for Expected utility models are omitted as no model was found to be significantly distinct from second-rank models on a 10\%-level. Rank-dependent Utility is denoted as $R D U$. For Simple Prospect Theory according to Kahneman and Tversky (1979), we use the denotation $S P T$, whereas Cumulative Prospect Theory according to Tversky and Kahneman (1992) is denoted as CPT. Decision weights are denoted as QU82 for weighting functions according to Quiggin (1982) and as KT92 for decision weights as defined by Tversky and Kahneman (1992). For those utility models, where no decision weights are applicable, we used the abbreviation None. Furthermore, we use the denotation $C R R A$ for utility functionals with constant relative risk aversion and EXPO to denote exponential power utility functions according to Saha (1993). For $S P T$ and $C P T$, we use the denotation $P O W R$ to indicate models with kinked power-functionals as proposed in Kahneman and Tversky (1979), where in addition $D H G 0$ denotes a value functional as defined in DeGiorgi and Hens (2006).

\begin{tabular}{|c|c|c|c|c|c|c|c|c|c|c|}
\hline & \multirow[b]{2}{*}{$p$-values } & \multicolumn{3}{|c|}{ RDU } & \multicolumn{3}{|c|}{ SPT } & \multicolumn{3}{|c|}{ CPT } \\
\hline & & $<10 \%$ & $<5 \%$ & $<1 \%$ & $<10 \%$ & $<5 \%$ & $<1 \%$ & $<10 \%$ & $<5 \%$ & $<1 \%$ \\
\hline \multirow{3}{*}{ 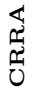 } & None & $0.00 \%$ & $0.00 \%$ & $0.00 \%$ & $0.00 \%$ & $0.00 \%$ & $0.00 \%$ & $0.00 \%$ & $0.00 \%$ & $0.00 \%$ \\
\hline & QU82 & $0.00 \%$ & $0.00 \%$ & $0.00 \%$ & $22.18 \%$ & $21.93 \%$ & $21.52 \%$ & $0.96 \%$ & $0.80 \%$ & $0.65 \%$ \\
\hline & КТ92 & $1.15 \%$ & $1.01 \%$ & $1.09 \%$ & $17.59 \%$ & $17.91 \%$ & $17.83 \%$ & $1.34 \%$ & $1.21 \%$ & $1.09 \%$ \\
\hline \multirow{3}{*}{$\begin{array}{l}0 \\
\stackrel{x}{x} \\
\text { I }\end{array}$} & None & $0.00 \%$ & $0.00 \%$ & $0.00 \%$ & $0.00 \%$ & $0.00 \%$ & $0.00 \%$ & $0.00 \%$ & $0.00 \%$ & $0.00 \%$ \\
\hline & QU82 & $0.00 \%$ & $0.00 \%$ & $0.00 \%$ & $0.00 \%$ & $0.00 \%$ & $0.00 \%$ & $0.00 \%$ & $0.00 \%$ & $0.00 \%$ \\
\hline & KT92 & $0.00 \%$ & $0.00 \%$ & $0.00 \%$ & $0.00 \%$ & $0.00 \%$ & $0.00 \%$ & $0.00 \%$ & $0.00 \%$ & $0.00 \%$ \\
\hline \multirow{3}{*}{$\begin{array}{l}\sum_{1}^{2} \\
\sum_{0}^{2} \\
n_{1}\end{array}$} & None & $0.00 \%$ & $0.00 \%$ & $0.00 \%$ & $0.00 \%$ & $0.00 \%$ & $0.00 \%$ & $0.00 \%$ & $0.00 \%$ & $0.00 \%$ \\
\hline & QU82 & $0.00 \%$ & $0.00 \%$ & $0.00 \%$ & $15.30 \%$ & $14.69 \%$ & $14.35 \%$ & $0.19 \%$ & $0.00 \%$ & $0.00 \%$ \\
\hline & КТ92 & $0.00 \%$ & $0.00 \%$ & $0.00 \%$ & $18.36 \%$ & $18.71 \%$ & $19.13 \%$ & $1.34 \%$ & $1.41 \%$ & $1.09 \%$ \\
\hline \multirow{3}{*}{ 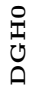 } & None & $0.00 \%$ & $0.00 \%$ & $0.00 \%$ & $0.00 \%$ & $0.00 \%$ & $0.00 \%$ & $0.00 \%$ & $0.00 \%$ & $0.00 \%$ \\
\hline & QU82 & $0.00 \%$ & $0.00 \%$ & $0.00 \%$ & $16.83 \%$ & $17.30 \%$ & $17.83 \%$ & $0.76 \%$ & $0.80 \%$ & $0.87 \%$ \\
\hline & KT92 & $0.00 \%$ & $0.00 \%$ & $0.00 \%$ & $1.91 \%$ & $2.01 \%$ & $2.17 \%$ & $2.10 \%$ & $2.21 \%$ & $2.39 \%$ \\
\hline
\end{tabular}

tests used given the structure of utility models in Table (5). ${ }^{34}$

Following Table (6), our dataset still displays a pronounced tendency to classify $S P T$ as winning utility model. ${ }^{35}$ The question arises immediately, whether our analysis is subject to some mechanical bias towards $S P T$ apart from problems in the evaluation of some types of utility functions as depicted in Table (3). By using the buy-or-hold index $I_{k, t}:=I\left[\Delta_{t}\left(U_{k} \mid \boldsymbol{\theta}_{\boldsymbol{k}}\right)+\epsilon_{i} \geq 0\right]$ within the likelihood function $L\left(\Delta_{t}\left(U_{k} \mid \boldsymbol{\theta}_{\boldsymbol{k}}\right)\right)$, the length of a trading sequence, or round-trip, is one of the critical components that might drive our results from utility model selection. If round-trip

\footnotetext{
${ }^{34}$ Further inspections of the estimates for $\boldsymbol{\theta}_{\boldsymbol{k}}$ have revealed a markedly imprecision. If nested models are modeled and tested alongside with nesting models, this imprecision favors nesting utility models such as expo-power utility (Saha (1993)) to nested ones such as e.g. CRRA, yielding estimates for $\boldsymbol{\theta}_{\boldsymbol{k}}$ that are not statistically distinct to those constraining values, under which the nested utility model coincides with a nesting one. We found that $\hat{\boldsymbol{\theta}}_{\boldsymbol{k}}$ highly depends upon the characteristics of the investors' trading history, such that, due to the imprecision of $\boldsymbol{\theta}_{\boldsymbol{k}}$, we obtain a ranking of utility models where nesting models prevail in the upper ranks, although differences are not significant as it can be seen in Table (6).

${ }^{35}$ Note that after filtering for significant first-ranked utility models on a $10 \%$ level, our dataset comprises 523 investors (130 investors dropped out as their first-rank utility model was not statistically distinct from the second-rank utility model on a 10\%-level). On a 5\%-level, only 497 investors remained in our dataset, whereas filtering at a $1 \%$ significance-level left us with 460 investors in our dataset. In addition, it is noteworthy that our results from Table (6) correspond to our findings from Table (4), as we detect a tendency towards higher likelihoods for SPT utility models.
} 
duration is crucial for the classification of an individual investor in terms of utility models, then one way to (mechanically) generate different round-trip lengths is to change the underlying accounting rule from a First-in-First-out-Principle (FIFO) to specify the index $I_{k, t}$ in equation (3.2) to a Last-in-First-out-Principle (LIFO). For instance, if the appliciation of LIFO generates round trips with shorter durations (assuming the realized returns remain the same for complex trades, which might not necessarily be the case) and if shorter round-trips are indicative for $S P T$, the application of $L I F O$ could bias our results towards $S P T$. Exemplarily, a link between round-trip length and $S P T$ could be established based on the insights from our pretests of our program based on simulations of Random Traders. Recall that we found that, contrary to our hypothesis, according to which first-rank utility models are expected to be randomly assigned (given different levels of $\sigma_{\text {Noise }}$ ), SPT also tends to obtain the first rank, whereby this phenomenon is positively related to an increase in the variance of $\epsilon^{\text {Noise }}$, which translates into shorter round-trips.

A natural way to investigate whether a change from FIFO to $L I F O$ affects our results is to completely rerun our analysis after changing the accounting rule and to compare the outcomes, which comes at a high computational burden. Alternatively, we could approximate the effect of a change of the accounting rule and determine the percentage of complex trades as these are the round-trips, that might be affected by a change of the accounting rule. ${ }^{36}$ Although detecting the proportion of complex round-trips is a preferable strategy, the outcomes of a switch to LIFO are less clear as not only round-trip durations, but also a trade timing component, namely realized returns, are affected. Consequently, the timing of a particular trade and the accrued return makes the outcomes of a utility model selection process less predictable as the selection of a specific utility model not only depends on roundtrip length, but also on other parameters such as the realized return. Thus, given realized returns are not affected by a different accounting rule, if round-trip length is comparable across utility types and statistically not distinct for various different utility models, then we would expect only moderate effects from a shortening of round-trip durations on utility model selection if all trades are affected equally and simultaneously. Note that, even if shorter round-trips correspond to trading decisions following $S P T$, recall that we defined $I_{k, t}$ under FIFO, which, according to our argumentation, should not facilitate the selection of $S P T$. On the other hand, the evidence of a few $C R R A$ traders in our subsample might be an artifact of the FIFO principle if long round-trip durations are tantamount to trading under an expected utility regime. According to Table (6), no first-rank expected utility model is statistically distinct to its second-rank successor, which might be another indication that EUT-type investors could be an artifact of the application of FIFO. We inspected the ranking of utility models for the 653 trading histories of our simulated Random Traders and detected a similar tendency to select $S P T$ as

\footnotetext{
${ }^{36}$ Furthermore, theoretical research on portfolio choice under Prospect Theory indicates that myopic optimization under $C P T$ and $S P T$ yields extreme portfolio positions and results in simple round-trips (full sales of existing positions) if budget constraints are imposed. According to Jin and Zhou (2008), Bernard and Ghossoub (2010), He and Zhou (2011), portfolio choice of SPT-type and CPT-type investors are predominantly characterized by corner solutions in the optimization process, yielding a pronounced stability of round-trip durations, irrespective of the application of FIFO or LIFO. Thus, the presence of simple round-trips as detected in other studies on individual investors such as in Calvet et al. (2007) could also indicate the presence of Prospect Theory in our dataset and consequently strengthen our findings, according to which the majority of the individual investors in our dataset follow trading pattern consistent with SPT.
} 
winning utility model. ${ }^{37}$ Note that these results are in line with Carbone and Hey (1994), who investigated the reliability of customized maximum likelihood methods to reveal the underlying utility function used to generate a simulated dataset of decisions. In particular, these authors used extensive simulations to test the reliability of maximum likelihood estimation techniques and found that the identification of the correct utility model is severely compromised if an additional error term $\epsilon^{\text {Noise }}$ is modeled along with the decision process.

Table 7. Average Trade Duration and Hazard Rates by Utility Model

The table presents the average round-trip duration as well as hazard rates from a proportional hazard model (Cox (1972)) for first-rank utility models. Expected utility models are denoted as EUT, Rank-dependent Utility is denoted as $R D U$. For Simple Prospect Theory according to Kahneman and Tversky (1979), we use the denotation $S P T$, whereas Cumulative Prospect Theory according to Tversky and Kahneman (1992) is denoted as CPT. Decision weights are denoted as QU82 for weighting functions according to Quiggin (1982) and as KT92 for decision weights as defined by Tversky and Kahneman (1992). For those utility models, where no decision weights are applicable, we used the abbreviation None. Furthermore, we use the denotation $C R R A$ for utility functionals with constant relative risk aversion and EXPO to denote exponential power utility functions according to Saha (1993). For $S P T$ and $C P T$, we use the denotation $P O W R$ to indicate models with kinked power-functionals as proposed in Kahneman and Tversky (1979), where in addition $D H G 0$ denotes a value functional as defined in DeGiorgi and Hens (2006). We denote round-trip durations in days by Dur. and used the abbreviation Hazard for the hazard rates of a proportional hazard model (Cox (1972)). Logrank tests rejected the hypothesis that the hazard rates equal one such that indicators for significance levels and standard errors are omitted.

\begin{tabular}{|c|c|c|c|c|c|c|c|c|c|}
\hline & & \multicolumn{2}{|c|}{ EUT } & \multicolumn{2}{|c|}{ RDU } & \multicolumn{2}{|c|}{ SPT } & \multicolumn{2}{|c|}{ CPT } \\
\hline & & Dur. & Hazard & Dur. & Hazard & Dur. & Hazard & Dur. & Hazard \\
\hline \multirow{3}{*}{ 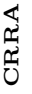 } & None & 73.55 & 1.44 & 0.00 & 0.00 & 0.00 & 0.00 & 0.00 & 0.00 \\
\hline & QU82 & 0.00 & 0.00 & 0.00 & 0.00 & 693.46 & 1.08 & 222.96 & 1.04 \\
\hline & КТ92 & 0.00 & 0.00 & 164.18 & 1.60 & 507.97 & 1.01 & 181.76 & 1.17 \\
\hline \multirow{3}{*}{$\begin{array}{l}0 \\
\alpha \\
x \\
\text { a }\end{array}$} & None & 88.90 & 0.75 & 0.00 & 0.00 & 0.00 & 0.00 & 0.00 & 0.00 \\
\hline & QU82 & 0.00 & 0.00 & 83.72 & 0.69 & 0.00 & 0.00 & 0.00 & 0.00 \\
\hline & KT92 & 0.00 & 0.00 & 59.86 & 0.97 & 0.00 & 0.00 & 0.00 & 0.00 \\
\hline \multirow{3}{*}{$\begin{array}{l}\underbrace{2}_{1} \\
0 \\
0 \\
0\end{array}$} & None & 0.00 & 0.00 & 0.00 & 0.00 & 0.00 & 0.00 & 0.00 & 0.00 \\
\hline & QU82 & 0.00 & 0.00 & 0.00 & 0.00 & 793.82 & 0.82 & 27.36 & 1.45 \\
\hline & КТ92 & 0.00 & 0.00 & 0.00 & 0.00 & 777.84 & 1.04 & 141.04 & 0.88 \\
\hline \multirow{3}{*}{ 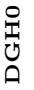 } & None & 0.00 & 0.00 & 0.00 & 0.00 & 0.00 & 0.00 & 0.00 & 0.00 \\
\hline & QU82 & 0.00 & 0.00 & 0.00 & 0.00 & 392.40 & 0.99 & 121.84 & 1.05 \\
\hline & КТ92 & 0.00 & 0.00 & 0.00 & 0.00 & 136.51 & 0.89 & 177.08 & 0.70 \\
\hline
\end{tabular}

If round-trip length, but not the timing of a round-trip (as it is the case for a Random Trader), is crucial to the choice of the utility model, then accounting rules that shorten round-trip durations could accidently favor the selection of $S P T$ models. To analyze, whether short term round-trips correspond to Simple Prospect Theory, we simulated the trading behavior of a EUT-type and $S P T$-type investor counterpart for for each investor given his or her risk and return constellations as well as number of observations to obtain the pure effects of these utility models on trading sequences and round-trip durations (Counterpart-simulation). In addition we also simulated the trading behavior of an EUT-type and SPT-type investor for various risk and return constellations, for which we assumed a trade history of 1,260 trading days (corresponding to approximately 5 years) for the calculation of those

\footnotetext{
${ }^{37}$ To establish a connection to round-trip duration, recall that our simulated Random Trader is sensitive to changes in $\sigma_{N o i s e}$, which in turn drives the characteristics of $\epsilon^{N o i s e}$ as an increase in $\sigma_{N o i s e}$ reduces the average round-trip length.
} 
artificial trading histories and, to reduce fluctuations from the simulations, we repeated these calculations 120 times (Artificial-simulation). In both simulations, we run a behavioral trading model based on the assumption, that differences in utility $\Delta_{t}\left(U_{k} \mid \boldsymbol{\theta}_{\boldsymbol{k}}\right)$ plus an error term $\epsilon_{i}$ (for the simulation $\sigma_{i}$ was set close to zero (0.01)) as implied by equation (3.1) matter for the decision to hold/buy or sell the respective stock at the end of a particular day $t$. To fill in the necessary parameters for both simulations, we've chosen a prospect horizon of two weeks and a parameterization of the associated risk parameters as proposed in Gollier (2001) and Tversky and Kahneman (1992). Both simulated trading histories we obtained suggest that investors, who decide according to $S P T$, exhibit round-trips with considerably longer durations (approximately 73.8 days on average for the Counterpart-simulation and 87.1 days on average for the Artificial-simulation) than Random Traders with $\sigma_{N o i s e}$ set to $50 \%$ and are only comparable to Random Trading in our case if $\sigma_{i}$ is larger than $32 \%$ for the Artificial-simulation. In comparison to an EUT-type investor with an average round-trip length of 63.3 days (Counterpart-simulation), trading sequences of a $S P T$-type investor appear to be longer instead of shorter, contradicting our hypothesis, according to which $S P T$ is associated with round-trips of shorter duration. However, statistical tests of the hazard ratios (Mantel (1966)) from a proportional hazard model (Cox (1972) $)^{38}$ indicate that we cannot reject the hypothesis that the respective hazard rates of an EUT-type and SPT-type investor are equal ( $p$-value 0.221 for the Counterpart-simulation, $p$-value 0.374 for the Artificial-simulation). In the light of this evidence, we wouldn't expect substantial changes in the results from utility model selection if switching from FIFO to LIFO. ${ }^{39}$ With regard to our dataset and despite the results from our simulations, however, Table (7) reveals that our dataset contains a considerable variation and no clear pattern in average round-trip lengths as measured in days as well as hazard rates across all utility models. ${ }^{40}$ Based on the results from our simulations, we suspect that the selection of a particular utility model is driven not only by round-trip duration, but also the timing of the trades, such that we expect only moderate effects on utility model selection from a change of the underlying accounting rule.

If our results are insensitive to round-trip length and thus accounting principles are unlikely to cause the vast overhang of $S P T$ models in our dataset, then the large proportion of $S P T$ might be driven by the structure of our dataset, particularly if our dataset is biased towards exogenous variables that correlate with specific utility

\footnotetext{
${ }^{38}$ The proportional hazard model is widely used to analyze trading pattern from individual investors (e.g. Ivcovic et al. (2005), Shumway and Wu (2006) and Nolte (2012)), although the assumption of proportionality of the hazard rates implies a constant baseline hazard rate, which seems questionable as Barber and Odean (2013) suspect a considerable variability of the baseline hazard rate over time acording to their results. Thus, as our results rely on the assumption that hazard rates are proportional, for which a Logrank test is considered to be appropriate (Savage (1956) and Mantel (1966)), its reliability could be subject for debate.

${ }^{39}$ Furthermore, recall that the difference in the likelihoods of Random Traders and the investors in our dataset is significant in all cases such that the overhang of $S P T$ is unlikely to be driven by round-trip length but rather by the timing of the trades, which we interpret as an indication of (at least partly) preference-driven trading.

${ }^{40}$ If hazard rates are estimated on an aggregate level, we also found variations of hazard rates across utility model classes: For EUT-type investors, the hazard rate is 0.88 , for $R D U$ the hazard rate is 1.00 and for CPT-type investors we found a hazard rate of 0.82 and a hazard rate for $S P T$-type investors of 1.02 in our dataset. If estimated per value functional class, we found for $C R R A$ functions a hazard rate of 1.09, whereas a utility functional according to DeGiorgi and Hens (2006) yield a hazard rate of 0.96. Lower values are estimated for investors with a powerfunctional (0.92) and exponential power functionals as in Saha (1993) (0.78). Sorted by decision weight functionals, hazard rates ranged from 0.96 for Tversky and Kahneman (1992) decision weights and 0.88 for decision weights according to Quiggin (1982).
} 

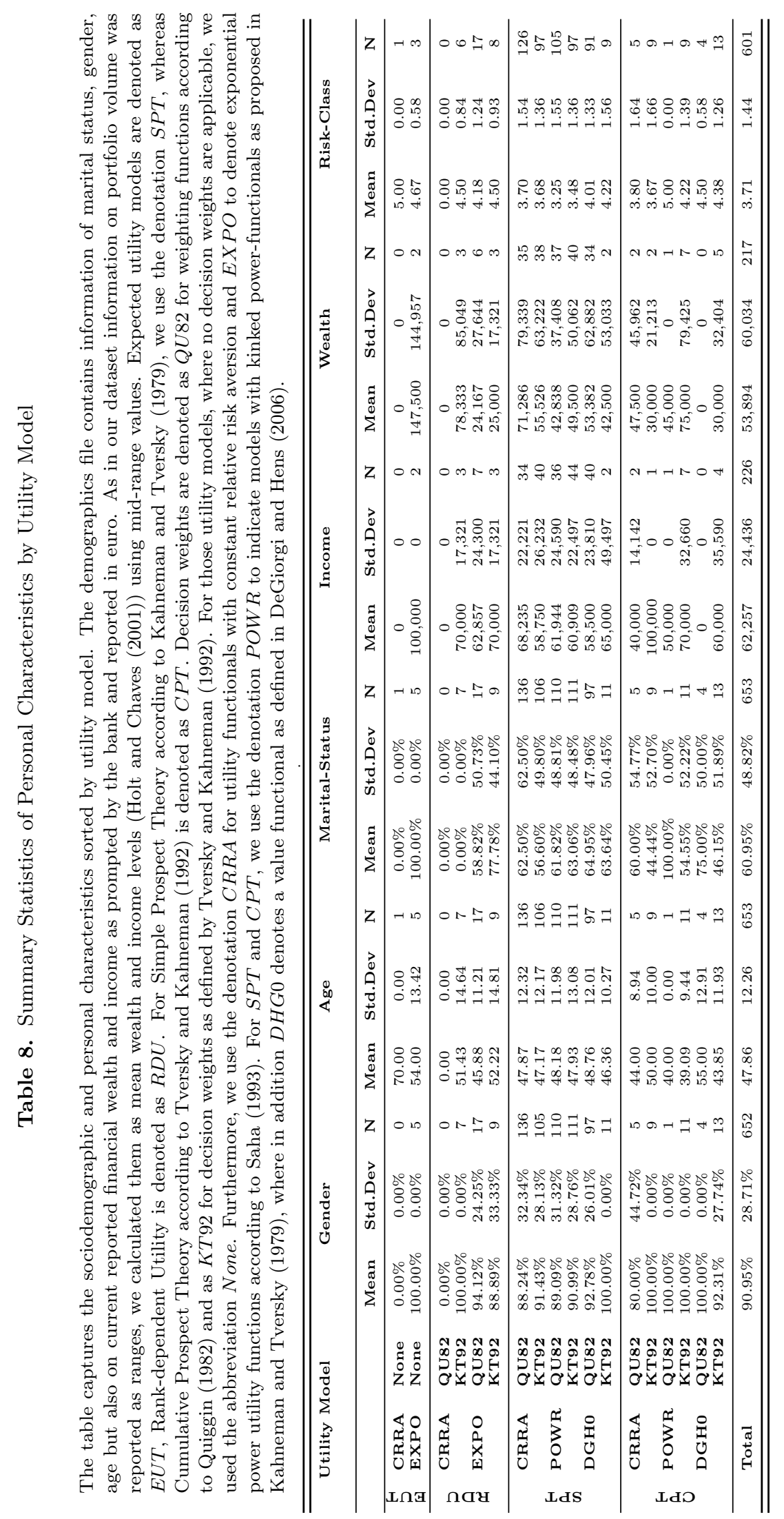
models. Literature from experimental economics suggests that some personal and socioeconomic characteristics might correspond to different types of preferences if represented by their parameterization (e.g. Fennema and van Assen (1999), Donkers and van Soest (1999), Donkers et al. (2001), Gaechter et al. (2007), Croson and Gneezy (2009), Booij and Van de Kuilen (2009), Booij et al. (2010), Charness and Gneezy (2010) and Charness and Gneezy (2012)), although we noted that empirical evidence from field data with respect to the linkage between an investors' personal characteristics and utility classification is rather scarce (exceptions are Harrison et al. (2007) and Anderson et al. (2010)). Following Hosmer et al. (2013), visual inspection of a tabulation of these characteristics by utility model as depicted in Table (8) for a selection of relevant exogenous variables such as gender (Barsky et al. (1997), Fehr-Duda et al. (2006), Bruhin et al. (2007), Gaechter et al. (2007), Booij and Van de Kuilen (2009), Croson and Gneezy (2009)), age (Harbaugh et al. (2002), Gaechter et al. (2007), Booij et al. (2010) and von Gaudecker et al. (2009)) and wealth (Guiso and Paiella (2008), Brunnermeier and Nagel (2008)) not only reveals some differences with respect to the characteristics of the dataset used in Weber et al. (2014) such as gender and age, ${ }^{41}$ but also indicates several structural problems in our dataset that may bias estimation results (Hosmer et al. (2013)).

According to Table (8), particular attention should be paid to fields where our dataset contains no entries such as for reported wealth and income levels as it is the case for $C P T$ given a $D G H 0$ value functional. Zero entries may yield point estimates for the respective odd ratio that are either zero or infinitively large (Cox and Snell (1989), Collett (2002), Hirji (2005) and Hosmer et al. (2013)) if conventional logistic regression methods are applied. For other utility models such as EUT, our dataset contains only a handful of observations, giving rise to concerns that maximum likelihood estimators from logistic regressions may be subject to small sample bias (King and Zeng (2001)). In addition, Table (8) provides some indication that quasi-complete separation with respect to some investor characteristics such as gender or marital status may drive our results (Anderson and Richardson (2002), McLachlan (1980), Schaefer (1983), Albert and Anderson (1984), Santner and Duffy (1986), Cordeiro and McCullagh (1991) and Heinze (2006)). To address these shortcomings in the structure of our dataset, we follow King and Zeng (2001) and apply a penalized maximum likelihood logistic regression as proposed by Firth $(1993)^{42}$ to reduce possible biases due to rare events such as in case of EUT. Heinze and Schemper (2002) furthermore showed in a simulation study that Firth's adjustment of logistic can also solve quasi-complete separability problems as running a conventional logistic regression yields infinite and thus inestimable estimates as, according to the authors, the affected estimates approach a boundary value.

\footnotetext{
${ }^{41}$ We detected some differences to the dataset of Weber et al. (2014), there Table (1) in age and gender characteristics. Weber reported that $84 \%$ of the investors in his dataset are male (90.6\% in our dataset) with an average age of 51 years (in our dataset 47.8 years), averages for other characteristics are smaller in terms of percentage differences.

${ }^{42}$ Firth suggested a modification of the score equations to remedy the inherent bias in generalized linear models - for further details on the asymptotic properties of Firth's correction and a generalization for multinomial logistic regressions we refer to Bull et al. (2002). Technically, Firth proposed a modification that penalizes the log-likelihood with one-half of the logarithm of the determinant of the Information Matrix (Firth (1993)). Although there exist other methods to overcome perfect separation problems such as exact logistic regression, where the outcomes are modeled as linear combinations of the covariates used (Hosmer et al. (2013)), we refrain from invoking the corresponding function exactlogistic due to its large memory requirements that make efficient estimation impossible. Firth's penalized maximum likelihood estimation can be accessed by the firthlogit command in Stata.
} 
Table 9. Personal Characteristics and Utility-Type Classification: Results from a Penalized Maximum Likelihood Logistic Regression

The table shows the results from a penalized maximum likelihood logistic regression as proposed by Firth (1993). Each cell contains the respective coefficients, where the dichotomous dependent variable is defined as an index taking the value of one if the respective utility model in the first row obtained the first rank and zero otherwise. Expected utility models are denoted as EUT, Rank-dependent Utility is denoted as $R D U$. For Simple Prospect Theory according to Kahneman and Tversky (1979), we use the denotation SPT, whereas Cumulative Prospect Theory according to Tversky and Kahneman (1992) is denoted as CPT. Decision weights are denoted as QU82 for weighting functions according to Quiggin (1982) and as KT92 for decision weights as defined by Tversky and Kahneman (1992). For those utility models, where no decision weights are applicable, we used the abbreviation None. Furthermore, we use the denotation $C R R A$ for utility functionals with constant relative risk aversion and $E X P O$ to denote exponential power utility functions according to Saha (1993). For SPT and $C P T$, we use the denotation $P O W R$ to indicate models with kinked power-functionals as proposed in Kahneman and Tversky (1979), where in addition DHG0 denotes a value functional as defined in DeGiorgi and Hens (2006). We reported the associated standard errors in parentheses and use $* * *, * *$ and $*$ to indicate significance at the $1 \%, 5 \%$ and $10 \%$ levels respectively.

\begin{tabular}{|c|c|c|c|c|c|c|c|c|c|c|}
\hline & EUT & RDU & SPT & CPT & CRRA & EXPO & POWR & DGHO & QU82 & KT92 \\
\hline Gender & $\begin{array}{l}-1.593 \\
(2.081)\end{array}$ & $\begin{array}{l}-0.250 \\
(1.008)\end{array}$ & $\begin{array}{l}0.252 \\
(0.739)\end{array}$ & $\begin{array}{l}-0.580 \\
(0.926)\end{array}$ & $\begin{array}{l}-0.500 \\
(0.544)\end{array}$ & $\begin{array}{l}-0.755 \\
(0.976)\end{array}$ & $\begin{array}{l}0.084 \\
(0.557)\end{array}$ & $\begin{array}{l}1.077 \\
(0.945)\end{array}$ & $\begin{array}{l}-0.331 \\
(0.540)\end{array}$ & $\begin{array}{l}0.298 \\
(0.540)\end{array}$ \\
\hline Status & $\begin{array}{l}0.147 \\
(1.648)\end{array}$ & $\begin{array}{l}-1.039^{*} \\
(0.641)\end{array}$ & $\begin{array}{l}0.184 \\
(0.444)\end{array}$ & $\begin{array}{l}0.534 \\
(0.612)\end{array}$ & $\begin{array}{l}-0.576^{* * *} \\
(0.323)\end{array}$ & $\begin{array}{l}0.142 \\
(0.696)\end{array}$ & $\begin{array}{l}0.417 \\
(0.327)\end{array}$ & $\begin{array}{l}0.210 \\
(0.405)\end{array}$ & $\begin{array}{l}0.150 \\
(0.310)\end{array}$ & $\begin{array}{l}-0.191 \\
(0.310)\end{array}$ \\
\hline Age & $\begin{array}{l}0.029 \\
(0.058)\end{array}$ & $\begin{array}{l}0.058^{* *} \\
(0.026)\end{array}$ & $\begin{array}{l}-0.010 \\
(0.018)\end{array}$ & $\begin{array}{l}-0.038 \\
(0.027)\end{array}$ & $\begin{array}{l}-0.009 \\
(0.013)\end{array}$ & $\begin{array}{l}0.019 \\
(0.028)\end{array}$ & $\begin{array}{l}-0.004 \\
(0.013)\end{array}$ & $\begin{array}{l}0.016 \\
(0.016)\end{array}$ & $\begin{array}{l}0.000 \\
(0.013)\end{array}$ & $\begin{array}{l}-0.001 \\
(0.013)\end{array}$ \\
\hline R.class & $\begin{array}{l}0.135 \\
(0.645)\end{array}$ & $\begin{array}{l}0.364 \\
(0.369)\end{array}$ & $\begin{array}{l}-0.189 \\
(0.190)\end{array}$ & $\begin{array}{l}0.020 \\
(0.221)\end{array}$ & $\begin{array}{l}-0.083 \\
(0.119)\end{array}$ & $\begin{array}{l}0.417 \\
(0.367)\end{array}$ & $\begin{array}{l}-0.282^{* *} \\
(0.117)\end{array}$ & $\begin{array}{l}0.707^{* * *} \\
(0.238)\end{array}$ & $\begin{array}{l}0.019 \\
(0.114)\end{array}$ & $\begin{array}{l}-0.027 \\
(0.114)\end{array}$ \\
\hline Income & $\begin{array}{l}3.153 \\
(5.220)\end{array}$ & $\begin{array}{l}0.676 \\
(0.682)\end{array}$ & $\begin{array}{l}-0.356 \\
(0.453)\end{array}$ & $\begin{array}{l}-0.302 \\
(0.528)\end{array}$ & $\begin{array}{l}0.156 \\
(0.295)\end{array}$ & $\begin{array}{l}0.711 \\
(0.838)\end{array}$ & $\begin{array}{l}-0.100 \\
(0.287)\end{array}$ & $\begin{array}{l}-0.350 \\
(0.366)\end{array}$ & $\begin{array}{l}0.073 \\
(0.275)\end{array}$ & $\begin{array}{l}-0.123 \\
(0.275)\end{array}$ \\
\hline Portf. & $\begin{array}{l}0.618 \\
(0.842)\end{array}$ & $\begin{array}{l}-0.393 \\
(0.317)\end{array}$ & $\begin{array}{l}0.030 \\
(0.200)\end{array}$ & $\begin{array}{l}0.148 \\
(0.271)\end{array}$ & $\begin{array}{l}0.168 \\
(0.145)\end{array}$ & $\begin{array}{l}-0.326 \\
(0.328)\end{array}$ & $\begin{array}{l}-0.016 \\
(0.143)\end{array}$ & $\begin{array}{l}-0.158 \\
(0.191)\end{array}$ & $\begin{array}{l}-0.065 \\
(0.138)\end{array}$ & $\begin{array}{l}0.032 \\
(0.138)\end{array}$ \\
\hline Const. & $\begin{array}{l}-46.255 \\
(53.930)\end{array}$ & $\begin{array}{l}-9.633 \\
(7.987)\end{array}$ & $\begin{array}{l}6.281 \\
(5.086)\end{array}$ & $\begin{array}{l}1.187 \\
(5.646)\end{array}$ & $\begin{array}{l}-2.432 \\
(3.301)\end{array}$ & $\begin{array}{l}-9.296 \\
(9.449)\end{array}$ & $\begin{array}{l}1.882 \\
(3.225)\end{array}$ & $\begin{array}{l}-0.963 \\
(4.022)\end{array}$ & $\begin{array}{l}0.107 \\
(3.082)\end{array}$ & $\begin{array}{l}0.862 \\
(3.086)\end{array}$ \\
\hline Obs. & 210 & 210 & 210 & 210 & 210 & 210 & 210 & 210 & 210 & 210 \\
\hline$p>\chi_{6}^{2}$ & $\begin{array}{l}0.825 \\
-5.393\end{array}$ & $\begin{array}{l}0.141 \\
-29.604\end{array}$ & $\begin{array}{l}0.914 \\
-70.256\end{array}$ & $\begin{array}{l}0.878 \\
-43.432\end{array}$ & $\begin{array}{l}0.311 \\
-120.903\end{array}$ & $\begin{array}{l}0.682 \\
-29.904\end{array}$ & $\begin{array}{l}0.224 \\
-123.519\end{array}$ & $\begin{array}{l}0.070 \\
-80.562\end{array}$ & $\begin{array}{l}0.989 \\
-131.220\end{array}$ & $\begin{array}{l}0.981 \\
-130.894\end{array}$ \\
\hline
\end{tabular}

We report the corresponding results of our penalized maximum likelihood logistic regressions in Table (9). As it can be seen from this table, except for risk class, which represents self-stated risk aversion according to the German Securities Trading Act (WpHG) and marriage status, none of the personal characteristics chosen were statistically significant on a $1 \%$-significance level. This is contradistinctive to the results from studies by Fehr-Duda et al. (2006), Gaechter et al. (2007), Booij and Van de Kuilen (2009), Booij et al. (2010) and von Gaudecker et al. (2009), who find significant relationships between personal characteristics such as age or gender and utility model parameterizations. In particular, the famous gender effect on risk taking seems to be non existent in our dataset, which stands in contrast to the findings of Fehr-Duda et al. (2006), who found that female participants in their experiments seem to predominantly follow decision pattern consistent with Prospect Theory, whereas male subjects appear to decide according to an EUTtype decision scheme. In the light of our results, we conclude that the structure of our dataset seems to have barely any effect on the outcomes of our utility model 
selection procedure. ${ }^{43}$

\section{BY WHAT EXTENT DO PREFERENCES GOVERN TRADING DECISIONS?}

In accordance with e.g. Heath et al. (1999), Blackburn and Ukhov (2006) Barberis and Huang (2008), von Gaudecker et al. (2009), Kliger and Levy (2009), Dimmock and Kouwenberg (2010) and Hwang and Satchell (2011), whose authors found indirect evidence for Prospect Theory, up to here we contributed to this stream of literature with the insight that the majority of individual investors in our dataset indeed seem to exhibit trading pattern that match with Prospect Theory (Weber et al. (2014)). As far as the proportion of utility models in stock markets matters, our findings support studies on phenomena widely seen as related to Prospect Theory such as the Disposition Effect (e.g. Shefrin and Statman (1985), Odean (1998), Weber and Camerer (1998), Berkelaar et al. (2004), Grinblatt and Han (2005b), Gomes (2005), Dhar and Zhu (2006), Frazzini (2006), Kaustia (2010)), observed preference for skewness in stocks' return distributions (Barberis and Huang (2008)), diversification behavior (Polkovnichenko (2005) and Yao and Li (2013)) or trade clustering (Lim (2006) and Egozcue and Wong (2010)). However, up to this point, it is not clear by how much preferences drives trading of individual investors as other factors may foster such trade pattern.

By the implications of our decision model, trading of individual investors is governed by utility considerations as well as other factors that are implicitly assumed to be independent from the respective preference structure. Binary choice models such as our customized likelihood model are designed to describe individual variation without the necessity to specify neglected trading factors as they can be captured by an error term (e.g. Train (1986), Cramer (1986), Train (2009)). If these other trading factors have a substantial impact, then the likelihood function $\log L\left(\Delta_{t}\left(U_{k} \mid \hat{\boldsymbol{\theta}}_{\boldsymbol{k}}\right)\right)$ should reflect the information content of the respective utility model to observed data points (Kullback and Leibler (1951), Kullback (1968), Akaike (1973), Akaike (1974), Akaike (1981), Akaike (1983), Akaike (1992)). The suspicion that other factors might influence or even determine trading decisions of individual investors as well is backed by empirical studies such as Grinblatt and Keloharju (2001c), who pointed out that utility represents only a minor aspect for investor's decision making in stock markets. The authors provide an indication that there are other factors that drive trade decisions such as taxes (exemplarily Branch (1977), Constantinides (1984), Lakonishok and Vermaelen (1986), Chan (1986), Lakonishok and Smidt (1986), Badrinath and Lewellen (1991), Poterba and Weisbrenner (2001), Grinblatt and Keloharju (2004), Barber and Odean (2004) and Ivcovich et al. (2009) among others), differences in opinion (Varian (1989) and Wang (1994)) and overconfidence (Barber and Odean (1999), Barber and Odean (2001a), Statman et al. (2006), Glaser and Weber (2007), Chen et al. (2007), Grinblatt and Keloharju (2009)) in addition to other cognitive limitations, that are not related to preferences (Barber and Odean (1999), Chang et al. (2012)).

To quantify the magnitude of the impact of preferences and other trading motives on trading behavior, we follow Burnham and Anderson (2002) and Burnham and

\footnotetext{
${ }^{43}$ Running a logit regression with reversed dependent variables as suggested in Pennings and Smidts (2002) and comparing Nagelkerkes' $R^{2}$ showns no clear pattern of causality. However, it should be kept in mind that our dataset is not representative for the overall population of investors as discount brokerage data might be succumb to some selection bias, as SPT-type investors may be attracted to trade at such online trading platforms.
} 
Table 10. Summary Statistics: Share of Preferences

The table presents the averaged relative distance of each utility model with first-rank, measured in terms of $\Pi_{\exp }\left(\epsilon_{t}^{I}\right)$ referring to the exponential proportion measure and $\Pi_{l i n}\left(\epsilon_{t}^{I}\right)$ denoting the linear proportion measure, to zero-information likelihood $\log L\left(\Delta_{t}\left(\epsilon_{t}^{\neg I}\right)\right)$. Entries are reported as percentage and can be interpreted as relative share of preferences to total trading where $0 \%$ corresponds to the case where trading behavior is completely independent from preferences. Expected utility models are denoted as EUT, Rank-dependent Utility is denoted as $R D U$. For Simple Prospect Theory according to Kahneman and Tversky (1979), we use the denotation $S P T$, whereas Cumulative Prospect Theory according to Tversky and Kahneman (1992) is denoted as $C P T$. Decision weights are denoted as $Q U 82$ for weighting functions according to Quiggin (1982) and as KT92 for decision weights as defined by Tversky and Kahneman (1992). For those utility models, where no decision weights are applicable, we used the abbreviation None. Furthermore, we use the denotation $C R R A$ for utility functionals with constant relative risk aversion and EXPO to denote exponential power utility functions according to Saha (1993). For $S P T$ and $C P T$, we use the denotation $P O W R$ to indicate models with kinked power-functionals as proposed in Kahneman and Tversky (1979), where in addition DHG0 denotes a value functional as defined in DeGiorgi and Hens (2006).

\begin{tabular}{|c|c|c|c|c|c|c|c|c|c|}
\hline & & \multicolumn{2}{|c|}{ EUT } & \multicolumn{2}{|c|}{ RDU } & \multicolumn{2}{|c|}{ SPT } & \multicolumn{2}{|c|}{ CPT } \\
\hline & & $\Pi_{\exp }\left(\epsilon_{t}^{I}\right)$ & $\Pi_{l i n}\left(\epsilon_{t}^{I}\right)$ & $\Pi_{\exp }\left(\epsilon_{t}^{I}\right)$ & $\Pi_{l i n}\left(\epsilon_{t}^{I}\right)$ & $\Pi_{\exp }\left(\epsilon_{t}^{I}\right)$ & $\Pi_{l i n}\left(\epsilon_{t}^{I}\right)$ & $\Pi_{\exp }\left(\epsilon_{t}^{I}\right)$ & $\Pi_{l i n}\left(\epsilon_{t}^{I}\right)$ \\
\hline 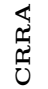 & $\begin{array}{l}\text { None } \\
\text { QU82 } \\
\text { KT92 }\end{array}$ & $\begin{array}{l}2.39 \% \\
0.00 \% \\
0.00 \%\end{array}$ & $\begin{array}{l}1.74 \% \\
0.00 \% \\
0.00 \%\end{array}$ & $\begin{array}{c}0.00 \% \\
0.00 \% \\
41.03 \%\end{array}$ & $\begin{array}{c}0.00 \% \\
0.00 \% \\
34.09 \%\end{array}$ & $\begin{array}{c}0.00 \% \\
55.81 \% \\
47.60 \%\end{array}$ & $\begin{array}{c}0.00 \% \\
48.70 \% \\
40.48 \%\end{array}$ & $\begin{array}{c}0.00 \% \\
31.99 \% \\
41.50 \%\end{array}$ & $\begin{array}{c}0.00 \% \\
26.06 \% \\
34.41 \%\end{array}$ \\
\hline 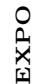 & $\begin{array}{l}\text { None } \\
\text { QU82 } \\
\text { KT92 }\end{array}$ & $\begin{array}{c}17.04 \% \\
0.00 \% \\
0.00 \%\end{array}$ & $\begin{array}{c}13.11 \% \\
0.00 \% \\
0.00 \%\end{array}$ & $\begin{array}{c}0.00 \% \\
30.36 \% \\
28.44 \%\end{array}$ & $\begin{array}{c}0.00 \% \\
24.15 \% \\
23.05 \%\end{array}$ & $\begin{array}{l}0.00 \% \\
0.00 \% \\
0.00 \%\end{array}$ & $\begin{array}{l}0.00 \% \\
0.00 \% \\
0.00 \%\end{array}$ & $\begin{array}{l}0.00 \% \\
0.00 \% \\
0.00 \%\end{array}$ & $\begin{array}{l}0.00 \% \\
0.00 \% \\
0.00 \%\end{array}$ \\
\hline $\int_{0}^{2}$ & $\begin{array}{l}\text { None } \\
\text { QU82 } \\
\text { KT92 }\end{array}$ & $\begin{array}{l}0.00 \% \\
0.00 \% \\
0.00 \%\end{array}$ & $\begin{array}{l}0.00 \% \\
0.00 \% \\
0.00 \%\end{array}$ & $\begin{array}{l}0.00 \% \\
0.00 \% \\
0.00 \%\end{array}$ & $\begin{array}{l}0.00 \% \\
0.00 \% \\
0.00 \%\end{array}$ & $\begin{array}{c}0.00 \% \\
6.22 \% \\
65.64 \%\end{array}$ & $\begin{array}{c}0.00 \% \\
57.21 \% \\
58.61 \%\end{array}$ & $\begin{array}{c}0.00 \% \\
4.55 \% \\
27.04 \%\end{array}$ & $\begin{array}{c}0.00 \% \\
38.22 \% \\
21.16 \%\end{array}$ \\
\hline 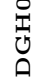 & $\begin{array}{l}\text { None } \\
\text { QU82 } \\
\text { KT92 }\end{array}$ & $\begin{array}{l}0.00 \% \\
0.00 \% \\
0.00 \%\end{array}$ & $\begin{array}{l}0.00 \% \\
0.00 \% \\
0.00 \%\end{array}$ & $\begin{array}{l}0.00 \% \\
0.00 \% \\
0.00 \%\end{array}$ & $\begin{array}{l}0.00 \% \\
0.00 \% \\
0.00 \%\end{array}$ & $\begin{array}{c}0.00 \% \\
36.04 \% \\
22.88 \%\end{array}$ & $\begin{array}{c}0.00 \% \\
29.75 \% \\
17.74 \%\end{array}$ & $\begin{array}{c}0.00 \% \\
13.79 \% \\
20.86 \%\end{array}$ & $\begin{array}{c}0.00 \% \\
10.49 \% \\
16.38 \%\end{array}$ \\
\hline
\end{tabular}

Anderson (2004) and propose two measures, based on the difference between the logarithm of the likelihood function $\log L\left(\Delta_{t}\left(U_{k} \mid \hat{\boldsymbol{\theta}}_{\boldsymbol{k}}\right)\right)$ and a zero-information likelihood, denoted as $\log L\left(\Delta_{t}\left(\epsilon_{t}^{\neg I}\right)\right)$ and defined as $\log L\left(\Delta_{t}\left(\epsilon_{t}^{\neg I}\right)\right)=n t \ln (0.5)$, where $n t$ denotes the number of observations of a particular investor. In analogy to our analysis of the trading pattern of a Random Trader, if trading of an investor is independent from preferences, the inclusion of any utility model $k$ shouldn't improve the $\log L\left(\Delta_{t}\left(U_{k} \mid \hat{\boldsymbol{\theta}}_{\boldsymbol{k}}\right)\right)$. Consequently $\log L\left(\Delta_{t}\left(U_{k} \mid \hat{\boldsymbol{\theta}}_{\boldsymbol{k}}\right)\right)$ should not be statistically distinct to $\log L\left(\Delta_{t}\left(\epsilon_{t}^{\neg I}\right)\right)$ given the usual Likelihood-ratio tests. We borrow from Akaike (1981) and construct a first measure $\Pi_{\exp }\left(\epsilon_{t}^{I}\right)$ that caters the requirements of a measure that permits an interpretation as share of preference in trading decisions. In detail, we propose a monotonic transformation of the difference between the two likelihood functions $\log L\left(\Delta_{t}\left(U_{k} \mid \hat{\boldsymbol{\theta}}_{\boldsymbol{k}}\right)\right)$ and $\log L\left(\Delta_{t}\left(\epsilon_{t}^{\neg I}\right)\right)$ using the exponential function and emphasize that it is imperative to divide $\log L\left(\Delta_{t}\left(U_{k} \mid \hat{\boldsymbol{\theta}}_{\boldsymbol{k}}\right)\right)$ and $\log L\left(\Delta_{t}\left(\epsilon_{t} I\right)\right)$ by the number of observations $n_{i}$ for each investor $i$ to ensure that $\Pi_{\text {exp }}\left(\epsilon_{t}^{I}\right)$ is insensitive to variations in the number of observations across individual investors. This allows us to rewrite $\Pi_{\text {exp }}\left(\epsilon_{t}^{I}\right)$ in the form of an cumulative exponential distribution, defined as $\Pi_{\exp }\left(\epsilon_{t}^{I}\right):=1-e^{\kappa}$ and scaled up by the factor two, where $\kappa=\log L\left(\Delta_{t}\left(U_{k} \mid \hat{\boldsymbol{\theta}}_{\boldsymbol{k}}\right)\right)-\log L\left(\Delta_{t}\left(\epsilon_{t}^{\neg I}\right)\right)$ to calculate the proportion, by which investors trading behavior is driven by preferences (for a related but mathematically distinct approach see Burnham and Anderson (2002)). 
By construction, measure $\Pi_{\text {exp }}\left(\epsilon_{t}^{I}\right)$ takes the value of zero if both log-likelihoods are equal, which is tantamount to cases where other factors completely determine an individual investors' trading behavior such that consequently the preference share for this individual is zero. On the other hand, $\Pi_{\text {exp }}\left(\epsilon_{t}^{I}\right)$ converges to one the larger the distance between the two log-likelihoods, although even in the case of a perfectfit our measure never reaches the hypothetical boundary of $100 \% .{ }^{44}$ Although in line with relevant litererature, a major drawback in using cumulative exponential distributions instead of normalizing as in Akaike (1981) to determine the proportion of preferences in trading data is the fact that for all values of $\log L\left(\Delta_{t}\left(U_{k} \mid \hat{\boldsymbol{\theta}}_{\boldsymbol{k}}\right)\right)$ between the zero-information likelihood $\log L\left(\Delta_{t}\left(\epsilon_{t}^{\neg I}\right)\right)$ and the case where $\log L\left(\Delta_{t}\left(U_{k} \mid \hat{\boldsymbol{\theta}}_{\boldsymbol{k}}\right)\right)$ hypothetically equals zero, our first measure $\Pi_{\exp }\left(\epsilon_{t}^{I}\right)$ overestimates the impact of preferences on trading decisions. ${ }^{45}$

Consequently, we calculated a second measure $\Pi_{l i n}\left(\epsilon_{t}^{I}\right)$, defined as a linear function $\Pi_{l i n}\left(\epsilon_{t}^{I}\right)=1-\log L\left(\Delta_{t}\left(U_{k} \mid \hat{\boldsymbol{\theta}}_{\boldsymbol{k}}\right)\right)\left(\log L\left(\Delta_{t}\left(\epsilon_{t}^{I I}\right)\right)\right)^{-1}$. Analogous to $\Pi_{\text {exp }}\left(\epsilon_{t}^{I}\right)$, this measure is zero if $\log L\left(\Delta_{t}\left(U_{k} \mid \hat{\boldsymbol{\theta}}_{\boldsymbol{k}}\right)\right)$ equals $\log L\left(\Delta_{t}\left(\epsilon_{t}^{\neg I}\right)\right)$ and is bounded at unity at the theoretical maximum of the logarithm of the likelihood function, but allows a more intuitive interpretation of the obtained values for $\log L\left(\Delta_{t}\left(U_{k} \mid \hat{\boldsymbol{\theta}}_{\boldsymbol{k}}\right)\right)$ of the first-ranked utility model for any investor under investigation. We provide a summary of the results for $\Pi_{\exp }\left(\epsilon_{t}^{I}\right)$ and $\Pi_{l i n}\left(\epsilon_{t}^{I}\right)$ in Table (10). Note that all reported likelihoods are significantly different from the zero-information likelihood $\log L\left(\Delta_{t}\left(\epsilon_{t}^{\neg I}\right)\right)$ on a $1 \%$ level according to accompanying Likelihood-ratio tests. For our dataset, the average share, by which preferences seem to drive trading is $50.6 \%$ (median share of $51.9 \%$ ) for $\prod_{\exp }\left(\epsilon_{t}^{I}\right)$ and $43.9 \%$ (median share of $43.3 \%$ ) for $\Pi_{l i n}\left(\epsilon_{t}^{I}\right)$. From Table (10), it can be seen that the average share of a utility model $k$ in an investors trading to the zero-information likelihood $\log L\left(\Delta_{t}\left(\epsilon_{t}^{\neg I}\right)\right)$ displays a considerable variety across utility models with larger values for SPT-type investors, which is in line with Han and Kumar (2010), and only moderate share for EUT-type investors. As literature on trading motives of individual investors such as Lakonishok and Smidt (1986) and Grinblatt and Keloharju (2001c) suggests, the proportion, by which trading behavior seems to be driven by preferences, is rather moderate, even for individual investors classified as $S P T$ investors, such that other trading motives seem to motivate the commissioning of trade orders in our dataset (see also Breuer et al. (2014) for dependence of risk aversion results from a lottery like questionaire and the propensity to invest in stocks).

Investors in our dataset differ not only in the timing, but also in the frequency, by which they commission orders to the discount brokerage firm and the duration

\footnotetext{
${ }^{44}$ Note that, in distinction to Akaike (1981), our intention is to derive an interpretation with respect to the zero-information likelihood $\log L\left(\Delta_{t}\left(\epsilon_{t}^{\neg I}\right)\right)$ as we do not strive for a relative comparison to utility model $m$ with the lowest value for $\log L\left(\Delta_{t}\left(U_{m} \mid \hat{\boldsymbol{\theta}}_{\boldsymbol{m}}\right)\right)$. As a consequence, a normalization by the sum of transformed differences to the smallest maximum likelihood value, which constitutes Akaike weights, is not expedient (Burnham and Anderson (2004)). Furthermore, we suspect that in addition Akaike weights might be sensitive to the number of models evaluated, which differs among the individual investors under consideration. An increase in evaluated utility models increases the number of transformed likelihoods added to the sum in the denominator, thus decreasing the Akaike weight for utility model $k$. Therefore, according to our interpretation, an increased number of models evaluated would falsely indicate a decreased proportion of preferences in terms of utility model $k$ in an investors trading decision.

${ }^{45}$ To illustrate this, note that for $\log L\left(\Delta_{t}\left(U_{k} \mid \hat{\boldsymbol{\theta}}_{\boldsymbol{k}}\right)\right)=\frac{1}{2} n \ln (0.5)$ a measure $\Pi_{\exp }\left(\epsilon_{t}^{I}\right)$ that follows a cumulative exponential distribution, returns the value 0.586 or $58.6 \%$ respectively, whereas one would expect that $\Pi_{\exp }\left(\epsilon_{t}^{I}\right)$ should reflect the $50 \%$ share of preferences, thus overstating the proportion, by which a particular utility model drives the trading pattern of this individual investor.
} 
Table 11. Share of Preferences on Trading Behavior by Round-Trip Duration

This table displays the average proportion of preferences $\Pi_{l i n}\left(\epsilon_{t}^{I}\right)$ and $\Pi_{\text {exp }}\left(\epsilon_{t}^{I}\right)$ as well as the average of per-observation log-likelihood values $\log . L L$ for various duration groups, where the baseline log-likelihood is -0.693 . Average duration in days is denoted as Ave.dur. and the number of observations is denoted as Obs. Respective values of the respective measure for the minimum are denoted as min and maximum max.

\begin{tabular}{|c|c|c|c|c|c|c|}
\hline Duration & $<10$ days & $<20$ days & $<60$ days & $<126$ days & $<252$ days & $<504$ days \\
\hline log. LL & -.243 & -.330 & -.463 & -.518 & -.531 & -.506 \\
\hline $\min$ & -.337 & -.490 & -.656 & -.683 & -.683 & -.683 \\
\hline $\max$ & -.100 & -.100 & -.100 & -.100 & -.100 & -.100 \\
\hline$\Pi_{\exp }\left(\epsilon_{t}^{I}\right)$ & $72.04 \%$ & $60.18 \%$ & $40.05 \%$ & $31.03 \%$ & $29.14 \%$ & $33.37 \%$ \\
\hline min & $59.87 \%$ & $36.64 \%$ & $7.17 \%$ & $2.07 \%$ & $2.07 \%$ & $2.07 \%$ \\
\hline $\min$ & $89.48 \%$ & $89.48 \%$ & $89.48 \%$ & $89.48 \%$ & $89.48 \%$ & $89.48 \%$ \\
\hline$\Pi_{l i n}\left(\epsilon_{t}^{I}\right)$ & $64.92 \%$ & $52.36 \%$ & $40.05 \%$ & $25.15 \%$ & $23.37 \%$ & $17.83 \%$ \\
\hline $\min$ & $51.32 \%$ & $29.19 \%$ & $7.17 \%$ & $1.50 \%$ & $1.50 \%$ & $1.50 \%$ \\
\hline $\max$ & $85.57 \%$ & $85.57 \%$ & $85.57 \%$ & $85.57 \%$ & $85.57 \%$ & $85.57 \%$ \\
\hline \multirow{2}{*}{$\begin{array}{l}\text { Ave. dur. } \\
\text { Obs. }\end{array}$} & 7.59 & 11.73 & 36.53 & 64.15 & 114.78 & 214.75 \\
\hline & 5 & 13 & 64 & 122 & 213 & 347 \\
\hline Duration & $\geq 10$ days & $\geq 20$ days & $\geq 60$ days & $\geq 126$ days & $\geq 252$ days & $\geq 504$ days \\
\hline $\log . \mathrm{LL}$ & -.390 & -.390 & -.381 & -.359 & -.320 & -.256 \\
\hline $\min$ & -.683 & -.683 & -.683 & -.677 & -.652 & -.597 \\
\hline $\max$ & -.083 & -.083 & -.083 & -.083 & -.083 & -.083 \\
\hline$\Pi_{\exp }\left(\epsilon_{t}^{I}\right)$ & $50.49 \%$ & $50.47 \%$ & $51.82 \%$ & $55.17 \%$ & $61.08 \%$ & $70.26 \%$ \\
\hline $\min$ & $2.07 \%$ & $2.07 \%$ & $2.07 \%$ & $3.24 \%$ & $8.06 \%$ & $18.33 \%$ \\
\hline $\min$ & $91.38 \%$ & $91.38 \%$ & $91.38 \%$ & $91.38 \%$ & $91.38 \%$ & $91.38 \%$ \\
\hline$\Pi_{l i n}\left(\epsilon_{t}^{I}\right)$ & $43.76 \%$ & $43.75 \%$ & $45.10 \%$ & $48.24 \%$ & $53.87 \%$ & $63.07 \%$ \\
\hline min & $1.50 \%$ & $1.50 \%$ & $1.50 \%$ & $2.36 \%$ & $5.94 \%$ & $13.87 \%$ \\
\hline $\max$ & $88.07 \%$ & $88.07 \%$ & $88.07 \%$ & $88.07 \%$ & $88.07 \%$ & $88.07 \%$ \\
\hline Ave. dur. & 574.58 & 581.58 & 628.24 & 686.52 & 790.73 & 973.36 \\
\hline Obs. & 648 & 640 & 589 & 531 & 440 & 306 \\
\hline
\end{tabular}

of their round-trips. Triggered by Barber and Odean (2001b), who stated that knowledge on day trading is limited but their importance might be significant, the natural focus of studies on discount brokerage data in particular turned to shortterm trades and, in its most extreme version, (intra) day trading. (Intra)day Trades are typically characterized by their trade pattern, which is quite distinct in comparison to the large bulk of trades as average round-trips of day traders are found to be rather short (e.g. Harris and Schultz (1998), Garvey and Murphy (2002) and Feng and Seasholes (2005)), resulting in a higher trading frequency (e.g. Seasholes and $\mathrm{Wu}(2004)$ ), are characterized by a remarkable sensitivity to market changes such as past price pattern (Grinblatt and Keloharju (2001b), Garvey and Murphy (2004) and Kaustia (2010)) or price peaks (Cohen et al. (2002), Dhar and Kumar (2002), Hvidkjaer (2006)) and a higher portfolio turnover (Garvey and Murphy (2002), Jordan and Diltz (2003), Jordan and Diltz (2004), Barber et al. (2004), Linnainmaa (2005)) and display a significant erosion in their performance, which is in the majority of studies found to be closely connected to round-trip duration and turnover (see Barber and Odean (2000), Garvey and Murphy (2002), Barber and Odean (2001b), Barber et al. (2004), Linnainmaa (2005) among others). Due to the pronounced short durations of their round-trips, (intra)day trading is considered to be rather associated with Noise Trading (Barber and Odean (2001b), Barber et al. $(2009 b))$ than to be connected to preferences.

If the assertion holds that investors with round-trips characterized by short duration are likely to trade on noise than preferences, then we expect to observe lower 
values for $\Pi_{l i n}\left(\epsilon_{t}^{I}\right)$ and $\Pi_{\text {exp }}\left(\epsilon_{t}^{I}\right)$ as well as the log likelihood values $\log L\left(\Delta_{t}\left(U_{k} \mid \hat{\boldsymbol{\theta}}_{\boldsymbol{k}}\right)\right)$ per observation for those investors who engage in short-term trading as their trading is driven by changes in stock prices and by a lesser extent by preference considerations. Recall that in Chapter three, we simulated Random Trader counterparts for all investors in our dataset and found that $\log$ likelihood values $\log L\left(\Delta_{t}\left(U_{k} \mid \hat{\boldsymbol{\theta}}_{\boldsymbol{k}}\right)\right)$ were close to the baseline $\log \operatorname{likelihood} \log L\left(\Delta_{t}\left(\epsilon^{\text {Noise }}\right)\right)$. In contrast to these results, we found for simulated $E U T$-type and $S P T$-type investors that the respective $\log$ likelihoods $\log L\left(\Delta_{t}\left(U_{k} \mid \hat{\boldsymbol{\theta}}_{\boldsymbol{k}}\right)\right)$ revealed a remarkable steepness according to their score vectors and broadly display values for $\log L\left(\Delta_{t}\left(U_{k} \mid \hat{\boldsymbol{\theta}}_{\boldsymbol{k}}\right)\right)$ significantly distinct to the respective baseline likelihood. If $\log L\left(\Delta_{t}\left(\epsilon^{\text {Noise }}\right)\right)$ serves as a proxy for $\log L\left(\Delta_{t}\left(\epsilon_{t}^{\neg I}\right)\right)$, implying that our construction of a Random Trader approximates the trading behavior of a Noise Trader in the sense of Kyle (1985) and Black (1986) and if shorter round-trip duration indicates trading on noise, then we would expect to observe $\Pi_{l i n}\left(\epsilon_{t}^{I}\right)$ and $\Pi_{\text {exp }}\left(\epsilon_{t}^{I}\right)$ to decrease in round-trip duration across all individual investors in our dataset.

A first indication whether our results are in line with our hypothesis can be taken from Table (11), where we find some consensus with our hypothesis, according to which investors with shorter round-trip durations display smaller values for $\log L\left(\Delta_{t}\left(U_{k} \mid \hat{\boldsymbol{\theta}}_{\boldsymbol{k}}\right)\right)$ per observation and thus for both measures $\Pi_{\text {exp }}\left(\epsilon_{t}^{I}\right)$ and $\Pi_{l i n}\left(\epsilon_{t}^{I}\right)$. However, a first visual inspection of our results is not indicative as we also noted that for round-trip length below 20 trading days (or approximately one month), this effect reverses, which we contribute to small sample effects. In addition, our definition of short-duration round-trips doesn't coincide with (intra)day trading as we calculate average durations per investors, which is in contrast to empirical studies such as Linnainmaa (2005), who define an investor as day trader if they can identify at least one (intra)day round-trip in the investors' trade record. To test our hypothesis and to control for the effects of personal and sociodemographic characteristics on trade duration, we estimated a proportional hazard model (Cox (1972), in which we investigate the relation between hazard rates and $\Pi_{\exp }\left(\epsilon_{t}^{I}\right)$ and $\Pi_{l i n}\left(\epsilon_{t}^{I}\right)$. Our results indicate, that the share of preferences increases with roundtrip duration: for $\Pi_{\text {exp }}\left(\epsilon_{t}^{I}\right)$ we find that hazard rates increase by $7.4 \%$ and by $8.1 \%$ in case of $\Pi_{\text {exp }}\left(\epsilon_{t}^{I}\right)$, both being statistically significant at $1 \%$ even after controlling for personal characteristics. These hazard rates provide some evidence that particularly for investors with short round-trips, other trading factors rather than preferences seem to dominate (Barber and Odean (2001b), Grinblatt and Keloharju (2001b), Cohen et al. (2002), Dhar and Kumar (2002), Garvey and Murphy (2004), Hvidkjaer (2006), Glaser and Weber (2007), Zhang and Swanson (2010)), which is also in line with literature on noise trading (Barber and Odean (2000), Garvey and Murphy (2002), Barber and Odean (2001b), Barber and Odean (2001b), Barber et al. (2004), Linnainmaa (2005) and Barber et al. (2009b)).

To the best of our knowledge literature on preferences in financial markets provides no direct evidence (Holt and Chaves (2001), Guiso and Paiella (2008)) or mixed results at best to the question, by how much preferences are connected to personal characteristics and govern trading decisions of individual investors (Barsky et al. (1997), Foucault et al. (2011)). However, studies from the field of experimental economics indicate that some personal traits such as age and gender might be connected to the tendency to hold stocks (Dohmen et al. (2009)). To investigate the magnitude of the impact of personal characteristics on the commissioning of sales or buying orders, we run an Ordinary-Least-Square (OLS) regression to establish the connections between observable variables and the share, by which preferences seem 
Table 12. Personal Characteristics and Share of Preferences: Results from a OLS Regression

This table reports the results from an OLS regression, where the respective share of preference $\Pi_{\text {exp }}\left(\epsilon_{t}^{I}\right)$ and $\Pi_{l i n}\left(\epsilon_{t}^{I}\right)$ is used as dependent variable, performed by each utility classification (utility-type, functional-type and decision-weight-type) of our dataset. Expected utility models are denoted as EUT, Rank-dependent Utility is denoted as $R D U$. For Simple Prospect Theory according to Kahneman and Tversky (1979), we use the denotation SPT, whereas Cumulative Prospect Theory according to Tversky and Kahneman (1992) is denoted as CPT. Decision weights are denoted as QU82 for weighting functions according to Quiggin (1982) and as KT92 for decision weights as defined by Tversky and Kahneman (1992). For those utility models, where no decision weights are applicable, we used the abbreviation None. Furthermore, we use the denotation $C R R A$ for utility functionals with constant relative risk aversion and EXPO to denote exponential power utility functions according to Saha (1993). For $S P T$ and $C P T$, we use the denotation $P O W R$ to indicate models with kinked power-functionals as proposed in Kahneman and Tversky (1979), where in addition $D H G 0$ denotes a value functional as defined in DeGiorgi and Hens (2006). Note that results for EUT were omitted due to the small number of observations for this utility model that match with certain investor characteristics (see also the results from Table (8)). We reported the associated standard errors in parentheses and use $* * *, * *$ and $*$ to indicate significance at the $1 \%, 5 \%$ and $10 \%$ levels respectively.

\begin{tabular}{|c|c|c|c|c|c|c|c|c|c|}
\hline & RDU & SPT & CPT & CRRA & EXPO & POWR & DGHO & QU82 & КТ92 \\
\hline \multicolumn{10}{|c|}{ Results for Exponential Proportion Measure $\Pi_{\exp }\left(\epsilon_{t}^{I}\right)$} \\
\hline Gender & $\begin{array}{l}-0.066 \\
(0.103)\end{array}$ & $\begin{array}{l}-0.051 \\
(0.063)\end{array}$ & $\begin{array}{l}0.204 \\
(0.150)\end{array}$ & $\begin{array}{l}0.067 \\
(0.082)\end{array}$ & $\begin{array}{l}-0.044 \\
(0.122)\end{array}$ & $\begin{array}{l}-0.111 \\
(0.092)\end{array}$ & $\begin{array}{l}-0.198 \\
(0.248)\end{array}$ & $\begin{array}{l}0.073 \\
(0.082)\end{array}$ & $\begin{array}{l}-0.208^{* *} \\
(0.088)\end{array}$ \\
\hline Status & $\begin{array}{l}-0.140^{*} \\
(0.053)\end{array}$ & $\begin{array}{l}-0.013 \\
(0.037)\end{array}$ & $\begin{array}{l}0.074 \\
(0.062)\end{array}$ & $\begin{array}{l}-0.033 \\
(0.052)\end{array}$ & $\begin{array}{l}-0.078 \\
(0.164)\end{array}$ & $\begin{array}{l}-0.024 \\
(0.054)\end{array}$ & $\begin{array}{l}0.050 \\
(0.067)\end{array}$ & $\begin{array}{l}0.015 \\
(0.051)\end{array}$ & $\begin{array}{l}-0.014 \\
(0.045)\end{array}$ \\
\hline Age & $\begin{array}{l}0.006^{* *} \\
(0.002)\end{array}$ & $\begin{array}{l}-0.001 \\
(0.002)\end{array}$ & $\begin{array}{l}-0.005 \\
(0.005)\end{array}$ & $\begin{array}{l}-0.002 \\
(0.002)\end{array}$ & $\begin{array}{l}0.001 \\
(0.009)\end{array}$ & $\begin{array}{l}0.001 \\
(0.002)\end{array}$ & $\begin{array}{l}-0.002 \\
(0.003)\end{array}$ & $\begin{array}{l}-0.001 \\
(0.002)\end{array}$ & $\begin{array}{l}-0.002 \\
(0.002)\end{array}$ \\
\hline R.class & $\begin{array}{l}0.075 \\
(0.039)\end{array}$ & $\begin{array}{l}-0.051^{* * *} \\
(0.013)\end{array}$ & $\begin{array}{l}0.003 \\
(0.120)\end{array}$ & $\begin{array}{l}-0.015 \\
(0.018)\end{array}$ & $\begin{array}{l}0.033 \\
(0.083)\end{array}$ & $\begin{array}{l}-0.050^{* * *} \\
(0.019)\end{array}$ & $\begin{array}{l}-0.006 \\
(0.041)\end{array}$ & $\begin{array}{l}-0.056^{* * *} \\
(0.017)\end{array}$ & $\begin{array}{l}-0.036^{* *} \\
(0.019)\end{array}$ \\
\hline Income & $\begin{array}{l}0.067 \\
(0.080)\end{array}$ & $\begin{array}{l}-0.007 \\
(0.031)\end{array}$ & $\begin{array}{l}-0.122 \\
(0.085)\end{array}$ & $\begin{array}{l}0.000 \\
(0.048)\end{array}$ & $\begin{array}{l}0.071 \\
(0.118)\end{array}$ & $\begin{array}{l}-0.022 \\
(0.044)\end{array}$ & $\begin{array}{l}0.001 \\
(0.082)\end{array}$ & $\begin{array}{l}0.019 \\
(0.047)\end{array}$ & $\begin{array}{l}-0.060 \\
(0.039)\end{array}$ \\
\hline Portf. & $\begin{array}{l}0.013 \\
(0.030)\end{array}$ & $\begin{array}{l}0.034^{* *} \\
(0.016)\end{array}$ & $\begin{array}{l}-0.040 \\
(0.055)\end{array}$ & $\begin{array}{l}0.038 \\
(0.024)\end{array}$ & $\begin{array}{l}-0.047 \\
(0.066)\end{array}$ & $\begin{array}{l}0.035 \\
(0.023)\end{array}$ & $\begin{array}{l}-0.021 \\
(0.034)\end{array}$ & $\begin{array}{l}0.023 \\
(0.022)\end{array}$ & $\begin{array}{l}0.040^{*} \\
(0.021)\end{array}$ \\
\hline Const. & $\begin{array}{l}-1.171 \\
(0.928)\end{array}$ & $\begin{array}{l}0.523 \\
(0.354)\end{array}$ & $\begin{array}{l}1.952^{* *} \\
(0.600)\end{array}$ & $\begin{array}{l}0.188 \\
(0.517)\end{array}$ & $\begin{array}{l}-0.221 \\
(1.394)\end{array}$ & $\begin{array}{l}0.705 \\
(0.519)\end{array}$ & $\begin{array}{l}0.847 \\
(0.815)\end{array}$ & $\begin{array}{l}0.216 \\
(0.521)\end{array}$ & $\begin{array}{l}1.143^{* *} \\
(0.451)\end{array}$ \\
\hline Obs. & 11 & 182 & 15 & 77 & 10 & 84 & 39 & 110 & 98 \\
\hline$R^{2}$ & 0.827 & 0.111 & 0.693 & 0.066 & 0.582 & 0.152 & 0.056 & 0.113 & 0.162 \\
\hline \multirow[t]{2}{*}{$\operatorname{adj} \cdot R^{2}$} & 0.567 & 0.081 & 0.464 & -0.014 & -0.253 & 0.086 & -0.121 & 0.062 & 0.107 \\
\hline & \multicolumn{9}{|c|}{ Results for Linear Proportion Measure $\Pi_{l i n}\left(\epsilon_{t}^{I}\right)$} \\
\hline Gender & $\begin{array}{l}-0.053 \\
(0.082)\end{array}$ & $\begin{array}{l}-0.049 \\
(0.061)\end{array}$ & $\begin{array}{l}0.165 \\
(0.129)\end{array}$ & $\begin{array}{l}0.059 \\
(0.078)\end{array}$ & $\begin{array}{l}-0.035 \\
(0.095)\end{array}$ & $\begin{array}{l}-0.113 \\
(0.091)\end{array}$ & $\begin{array}{l}-0.165 \\
(0.222)\end{array}$ & $\begin{array}{l}0.068 \\
(0.078)\end{array}$ & $\begin{array}{l}-0.202^{* *} \\
(0.086)\end{array}$ \\
\hline Status & $\begin{array}{l}-0.114^{*} \\
(0.043)\end{array}$ & $\begin{array}{l}-0.012 \\
(0.036)\end{array}$ & $\begin{array}{l}0.061 \\
(0.053)\end{array}$ & $\begin{array}{l}-0.031 \\
(0.050)\end{array}$ & $\begin{array}{l}-0.061 \\
(0.128)\end{array}$ & $\begin{array}{l}-0.023 \\
(0.054)\end{array}$ & $\begin{array}{l}0.044 \\
(0.060)\end{array}$ & $\begin{array}{l}0.013 \\
(0.049)\end{array}$ & $\begin{array}{l}-0.013 \\
(0.044)\end{array}$ \\
\hline Age & $\begin{array}{l}0.005^{* *} \\
(0.002)\end{array}$ & $\begin{array}{l}-0.001 \\
(0.001)\end{array}$ & $\begin{array}{l}-0.004 \\
(0.004)\end{array}$ & $\begin{array}{l}-0.002 \\
(0.002)\end{array}$ & $\begin{array}{l}0.000 \\
(0.007)\end{array}$ & $\begin{array}{l}0.001 \\
(0.002)\end{array}$ & $\begin{array}{l}-0.002 \\
(0.003)\end{array}$ & $\begin{array}{l}-0.001 \\
(0.002)\end{array}$ & $\begin{array}{l}-0.001 \\
(0.002)\end{array}$ \\
\hline R.class & $\begin{array}{l}0.062 \\
(0.031)\end{array}$ & $\begin{array}{l}-0.051^{* * *} \\
(0.013)\end{array}$ & $\begin{array}{l}0.003 \\
(0.021)\end{array}$ & $\begin{array}{l}-0.014 \\
(0.017)\end{array}$ & $\begin{array}{l}0.026 \\
(0.065)\end{array}$ & $\begin{array}{l}-0.052^{* * *} \\
(0.019)\end{array}$ & $\begin{array}{l}-0.007 \\
(0.037)\end{array}$ & $\begin{array}{l}-0.055^{* * *} \\
(0.016)\end{array}$ & $\begin{array}{l}-0.038^{* *} \\
(0.019)\end{array}$ \\
\hline Income & $\begin{array}{l}0.052 \\
(0.064)\end{array}$ & $\begin{array}{l}-0.008 \\
(0.030)\end{array}$ & $\begin{array}{l}-0.101 \\
(0.073)\end{array}$ & $\begin{array}{l}0.004 \\
(0.046)\end{array}$ & $\begin{array}{l}0.056 \\
(0.092)\end{array}$ & $\begin{array}{l}-0.025 \\
(0.044)\end{array}$ & $\begin{array}{l}-0.003 \\
(0.073)\end{array}$ & $\begin{array}{l}0.014 \\
(0.045)\end{array}$ & $\begin{array}{l}-0.054 \\
(0.038)\end{array}$ \\
\hline Portf. & $\begin{array}{l}0.014 \\
(0.024)\end{array}$ & $\begin{array}{l}0.034^{* *} \\
(0.015)\end{array}$ & $\begin{array}{l}-0.033 \\
(0.047)\end{array}$ & $\begin{array}{l}0.037 \\
(0.023)\end{array}$ & $\begin{array}{l}-0.038 \\
(0.051)\end{array}$ & $\begin{array}{l}0.036 \\
(0.023)\end{array}$ & $\begin{array}{l}-0.018 \\
(0.030)\end{array}$ & $\begin{array}{l}0.024 \\
(0.021)\end{array}$ & $\begin{array}{l}0.038^{*} \\
(0.020)\end{array}$ \\
\hline Const. & $\begin{array}{l}-0.971 \\
(0.742)\end{array}$ & $\begin{array}{l}0.470 \\
(0.343)\end{array}$ & $\begin{array}{l}1.601^{* *} \\
(0.516)\end{array}$ & $\begin{array}{l}0.073 \\
(0.495)\end{array}$ & $\begin{array}{l}-0.176 \\
(1.086)\end{array}$ & $\begin{array}{l}0.679 \\
(0.513)\end{array}$ & $\begin{array}{l}0.764 \\
(0.727)\end{array}$ & $\begin{array}{l}0.198 \\
(0.497)\end{array}$ & $\begin{array}{l}1.019^{* *} \\
(0.438)\end{array}$ \\
\hline Obs. & 11 & 182 & 15 & 77 & 10 & 84 & 39 & 110 & 98 \\
\hline$R^{2}$ & 0.839 & 0.118 & 0.672 & 0.066 & 0.590 & 0.162 & 0.058 & 0.118 & 0.165 \\
\hline $\operatorname{adj} \cdot R^{2}$ & 0.597 & 0.088 & 0.425 & -0.015 & -0.232 & 0.097 & -0.119 & 0.067 & 0.110 \\
\hline
\end{tabular}


to explain trading behavior in our dataset. Due to the fact that only two investors with EUT-type preferences provided further information on their wealth and income, we decided to drop these from our analysis. The results of this regressions are performed for groups of preferences and presented in Table (12). Our results are robust with respect to round-trip length. Similar to our results from Table (9), we only find a notable significant connection between the variable RiskClass and the proportion of preferences, which indicates that personal and sociodemographic characteristics are weak indicators for individual preferences in general (for a similar conclusion see Hoffmann et al. (2010)). We suspect that more preference-driven investors put a higher emphasis on risk and select a higher value for their risk classification according to the German Securities Act (WpHG) as risk also enters their utility function and thus seems to play a crucial role in the decision, whether to buy a stock or not. Thus, it appears to us that trading of individuals is governed by other factors than preferences, which is in line with Grinblatt and Keloharju (2009), although the share, by which preferences govern trading decisions might be different for buying and selling orders (Barber and Odean (2008)).

\section{Conclusion}

Microeconomic modeling of investors behavior in financial markets and its results crucially depends on assumptions about the mathematical shape of the underlying preference functions as well as their parameterizations. With the purpose to shed some light on the question, which preferences towards risky financial outcomes prevail in stock markets, we adopted and applied a maximum likelihood approach from the field of experimental economics on a randomly selected dataset of 656 private investors of a large German discount brokerage firm. According to our analysis we found evidence that the majority of these clients follow trading pattern in accordance with Prospect Theory (Kahneman and Tversky (1979)). We also found that observable sociodemographic and personal characteristics such as gender or age don't seem to correlate with specific preference types. With respect to the overall impact of preferences on trading behavior, we find a moderate impact of preferences on trading decisions of individual investors. A classification of investors according to various utility types reveals that the strength of the impact of preferences on an investors' trading behavior is not connected to most personal characteristics, but seems to be related with round-trip length. 


\section{ApPendix A. Notes on the ESTIMATION OF STOCKS MARKET PARAMETERS}

In this paper, we use the the first two moments of the observed return distribution to estimate values for the required upside and downside returns $\hat{R}_{U, t}$ and $\hat{R}_{D, t}$. In particular, we calculate stock-specific values for $\hat{R}_{S, t}$ using the fact that we can assign values for $\hat{R}_{D, t}$ and $\hat{R}_{U, t}$ by calculating from $\hat{\mu}_{t}$ and $\hat{\sigma}_{t}$ at time $t$ for differing formation periods with $\hat{R}_{U, t}=e^{\frac{\hat{\mu}_{t}}{l}+\sqrt{\frac{1-\hat{p}_{t}}{\hat{p} t} \frac{\hat{\sigma}_{t}^{2}}{l}}}$ and $\hat{R}_{D, t}=e^{\frac{\hat{\mu}_{t}}{l}-\sqrt{\frac{\hat{p}_{t}}{1-\hat{p}_{t}} \frac{\hat{\sigma}_{t}^{2}}{l}}}$, respectively. This is a standard procedure (Ingersoll (1987)) and is widely applied as similar expressions can be found in Johnson et al. (1997) for non-standardized skewness, Barberis and Xiong (2009), Ebert and Strack (2009) and Johnson et al. (2012). The corresponding upside probabilities $\hat{p}_{t}$ are derived from our estimates of $\hat{\Gamma}_{t}$, where we use $\hat{p}_{t}$ as the remaining degree of freedom to implement the connection to the skewness of the return distribution, such that $\hat{p}_{t}=\frac{\left(4+l \hat{\Gamma}_{t}^{2} \pm \sqrt{l \hat{\Gamma}_{t}^{4}+4 l \hat{\Gamma}_{t}^{2}}\right)}{\left(8+2 l \hat{\Gamma}_{t}^{2}\right)}$, where + if $\hat{\Gamma}_{t}<0$ and - if $\hat{\Gamma}_{t}>0$, which implies that $\hat{p}_{t}=0.5$ if $\hat{\Gamma}_{t}=0$. Ebert and Strack (2009) states for $l=1$ that this expression is strictly positive and unique such that the requirements of Kolmogoroff are satisfied. Furthermore, we use the 3-Month Euribor as retrieved from Thompson Reuters Datastream on 02.12.2012 as a proxy for the riskfree return $R_{f, t}$.

\section{Appendix B. Notes on the Set of Utility functions Used}

To restrict the set of utility functions, we focus primarily on those preferences mentioned by the studies presented above, partly due to missing empirical evidence as utility functions left out are of rather pedagogically than empirically relevant or as some forms may arise computational difficulties the econometric approach applied here simply cannot cope with. In asset pricing, theories of rational decision making play an important role, reflected by the fact that expected utility paradigm is still widely applied. Consequently, we model preferences as in Landskroner (1988), Morin and Suarez (1983), Blume and Easley (1992), Levy (1994), Ait-Sahalia and Lo (2000), Jackwerth (2000), Kliger and Levy (2002), Bliss and Panigirtzoglou (2004), Brunnermeier and Nagel (2008), Guiso and Paiella (2008) as well as Chiappori and Paiella (2011) and define the utility of an Expected Utility-type investor (EUT) according to

$$
U_{E U T}\left(W_{t} \mid \boldsymbol{\theta}_{E U T}\right)=\sum_{j=1}^{t+1} \hat{p}_{j, t} u_{E U T}\left(W_{t} \mid \boldsymbol{\theta}_{E U T}\right),
$$

where $\hat{p}_{j, t}$ denotes the respective probabilities associated with the respective state. In particular, we denote the utility functional as $u_{E U T}$ given the flexible expo-power specification as used in Saha (1993), where $\boldsymbol{\theta}_{\boldsymbol{E} \boldsymbol{U} \boldsymbol{T}}$ incorporates parameters of relative and absolute risk aversion such that (dependent on the respective constellation of its parameterization (e.g. Saha et al. (1994))), utility function $u_{E U T}\left(W_{t} \mid \boldsymbol{\theta}_{E U T}\right)$ principally reflects properties of $D A R A, C R R A$ and IARA as well as $D R R A$ or $I R R A$. Moreover, to benchmark the case where $u_{E U T}\left(W_{t} \mid \boldsymbol{\theta}_{E U T}\right)$ converges to $C R R A$ utility we additionally model $C R R A$-utility according to the form used in Gollier (2001), simultaneously covering mean-variance preferences (see Back (2012).

There is some evidence that generalized expected utility theories such as rankdependent utility (Polkovnichenko (2005) and Prigent (2010)) might be relevant in financial markets. Thus we consider an investor with Rank-dependent Utility $(R D U)$ according to Quiggin (1982), Quiggin (1993) and Wakker (1994), where the 
utility drawn from a stock is written as

$$
U_{R D U}\left(W_{t} \mid \boldsymbol{\theta}_{R D U}\right)=\sum_{j=1}^{t+1} \pi_{j, t}\left(\Delta \omega\left(\hat{p}_{j, t} \mid \boldsymbol{\theta}_{R D U}\right)\right) u_{R D U}\left(W_{t} \mid \boldsymbol{\theta}_{R D U}\right) .
$$

In comparison to expected utility (EUT) as presented above, $R D U$ may lead to first-order risk aversion due to its application of cumulative decision weights (Yaari (1965)), leaving the utility functionals unaltered. These decision weights, denoted as $\pi_{j, t}\left(\omega\left(\hat{p}_{j, t} \mid \boldsymbol{\theta}_{R D U}\right)\right)$ are defined as decumulative probability transformation functions according to Abdellaoui (2000) in the following process, although alternative formulations exist such as in the original version of $R D U$ (see Quiggin (1982) and Quiggin (1993)). ${ }^{46}$ To grasp the particular structure of the decision weighting functional $\omega\left(\hat{p}_{j, t} \mid \boldsymbol{\theta}_{R D U}\right)$, we adopted the frequently used form of Karmarkar (1979), Karmarkar (1978) and Quiggin (1982), according to which the decision weights if added up across all states of nature equals unity (Abdellaoui (2000)). Contrasting this, studies explicitly dealing with the implications of nonlinear probability treatments caused by decision weights can be found more often lately in the context of asset pricing (e.g.(Barberis and Huang (2008) and Barberis (2011)) so that, in order to cater this stream of literature, we implemented a subadditive weighting function as proposed by Kahneman and Tversky (1979), Tversky and Kahneman (1992) and used in Wu and Gonzalez (1996).

We also acknowledge the recognition of alternative utility functions such as Prospect Theory (Kahneman and Tversky (1979)) and its refinement, Cumulative Prospect Theory (Tversky and Kahneman (1992)) in studies dealing with asset pricing, portfolio choice and trading behavior (Berkelaar et al. (2004), Gomes (2005), Polkovnichenko (2005), Barberis and Xiong (2009), Barberis (2011), Jin and Zhou (2008), Bernard and Ghossoub (2010), He and Zhou (2011) and Ingersoll and Jin (2013)). Reflecting this trend, we model preferences for both versions of Prospect Theory, namely Simple Prospect Theory $(S P T)$ and Cumulative Prospect Theory $(C P T)$, and define utility functionals $u_{S P T}\left(W_{t}, W_{R P} \mid \boldsymbol{\theta}_{S P T}\right)$ where gains and losses form the support of this functional. These gains and losses are assumed to be marked against a static reference point $W_{R P}$, which is usually based on an initial wealth level or purchase price (also see Grinblatt and Keloharju (2001b), Garvey and Murphy (2004), for dynamic reference points Meng (2010)) such that in general, both versions of Prospect Theory can be expressed as

$$
U_{S P T}\left(W_{t}, W_{R P} \mid \boldsymbol{\theta}_{S P T}\right)=\sum_{j=1}^{t+1} \pi_{j, t}\left(\omega\left(\hat{p}_{j, t} \mid \boldsymbol{\theta}_{S P T}\right)\right) u_{S P T}\left(W_{t}, W_{R P} \mid \boldsymbol{\theta}_{S P T}\right) .
$$

The original formulation of Kahneman and Tversky (1979) with respect to the utility functional has been adapted in countless studies on various issues in asset pricing (Berkelaar et al. (2004), Berkelaar and Kouwenberg (2009), Kliger and Levy (2009) and others) such that we model $u_{S P T}\left(W_{t}, W_{R P} \mid \boldsymbol{\theta}_{S P T}\right)$ accordingly as a kinked power-function as elaborated in the appendix of Kahneman and Tversky (1979), although some studies model the demand of $S P T$-type investors according to a different form of the value functional and apply a mathematical construct similar to CRRA utility (e.g. Barberis et al. (2001), Gomes (2005) or Barberis and

\footnotetext{
${ }^{46} \mathrm{~A}$ preliminary dry-run of our program as a test of the econometric procedure used evinced that the original formulation of the decision weights has virtually no effect on the outcomes. Based on these simulations, we are confident enough to omit an explicit application of the original formulation of $R D U$.
} 
Huang (2008)).47 For Cumulative Prospect Theory (CPT), we calculate the utility of the financial prospects according to Tversky and Kahneman (1992) as

$$
U_{C P T}\left(W_{t}, W_{R P} \mid \boldsymbol{\theta}_{C P T}\right)=\sum_{j=1}^{t+1} \pi_{j, t}\left(\Delta \omega\left(\hat{p}_{j, t} \mid \boldsymbol{\theta}_{C P T}\right)\right) u_{C P T}\left(W_{t}, W_{R P} \mid \boldsymbol{\theta}_{C P T}\right),
$$

where as the distinguishing feature, differences in decision weights across states, ranked according to their associated prospects and denoted as $\pi_{j, t}\left(\Delta \omega\left(\hat{p}_{j, t} \mid \boldsymbol{\theta}_{C P T}\right)\right)$ represent the central constituent of $C P T$ (see Tversky and Kahneman (1992) and Fennema and Wakker (1997) for details). Note that this contrasts $S P T$, in which a specific decision weight $\pi_{j, t}\left(\omega\left(\hat{p}_{j, t} \mid \boldsymbol{\theta}_{S P T}\right)\right)$ is assigned to each state of nature as elaborated above. Furthermore, it appears noteworthy to say that for $C P T$, we use the same specifications with respect to $u_{C P T}\left(W_{t}, W_{R P} \mid \boldsymbol{\theta}_{C P T}\right)$ as for the original version of Prospect Theory.

\section{REFERENCES}

\section{REFERENCES}

Abdellaoui, M. (2000). Parameter-free elicitation of utilities and probability weighting functions. Management Science 46, 1497-1512.

Abdellaoui, M., F. Vossmann, and M. Weber (2005). Choice-based elicitation and decomposition of decision weights for gains and losses under uncertainty. Management Science 51, 1384-1399.

Adda, J. and R. Cooper (2003). Dynamic Economics Quantitative Methods and Applications. MIT Press.

Aggarwal, R. and P. R. Rao (1990). Institutional ownership and distribution of equity returns. The Financial Review 25, 211-229.

Ait-Sahalia, Y. and A. W. Lo (2000). Nonparametric risk management and implied risk aversion. Journal of Econometrics 94, 9-51.

Akaike, H. (1973). Information Theory and an extention of the maximum likelihood principle, in: B.N. Petrox and F. Caski (Eds.) Second International Symposium on Information Theory. Akademiai Kiado.

Akaike, H. (1974). A new look at the statistical model identification. IEEE Transaction on Automatic Control AC-19, 716-723.

Akaike, H. (1981). Likelihood of a model and information criteria. Journal of Econometrics 16, 3-14.

Akaike, H. (1983). Information measures and model selection. International Statistical Institute 44, 277-291.

Akaike, H. (1992). Information Theory and an extention of the maximum likelihood principle, in: S. Kotz and N. L. Johnson (Eds.) Breakthroughs in Statistics, Vol. 1. Springer VErlag.

Albert, A. and J. A. Anderson (1984). On the existence of maximum likelihood estimates in logistic regression models. Biometrica 71, 1-10.

Allais, M. (1953). Le comportement de l'homme rationnel devant le risque: Critique des postulates et axioms de l'ecole americaine. Econometrica 21, 503-546.

Amemiya, T. (1975). Qualitative response models. Annals of Economic and Social Measurement 4(3), 363-372.

\footnotetext{
${ }^{47}$ Its worthwhile to mention that in Barberis et al. (2001) and Barberis and Huang (2008), state specific changes in consumption instead of changes in wealth enter the functional $u_{S P T}\left(W_{t}, W_{R P} \mid \boldsymbol{\theta}_{S P T}\right)$ (also Barberis and Xiong (2009)) such that a direct comparison of the results drawn in those papers to implications of equation(B.3) is necessarily flawed to some extend.
} 
Amemiya, T. (1980). Selection of regressors. International Economic Review 21(2), 331-354.

Amemiya, T. (1981). Qualitative response models: A survey. Journal of Econometric Literature 19, 1483-1536.

Amemiya, T. (1985). Advanced Econometrics. Harvard University Press.

Anderson, J. A. and S. C. Richardson (2002). Logistic discrimination and bias correction in maximum likelihood estimation. Technometrics 21, 71-78.

Anderson, S., G. W. Harrison, M. I. Lau, and E. E. Rutsrom (2010). Preference heterogeneity in experiments: Comparing the field and laboratory. Journal of Economic Behavior and Organization 73(2), 209-224.

Andrade, S. C., C. S. M. Chang, and M. Seasholes (2008). Trading imbalances, predictable reversals and cross-stock price pressure. Journal of Financial Economics 88, 406-423.

Andreassen, P. B. (1987). On the social psychology of the stock market: Aggregate attributional effects and the regressiveness of prediction. Journal of Personality and Social Psychology 53, 490-496.

Andreassen, P. B. (1988). Explaining the price-volume relationship: The difference between price changes and changing prices. Organizational Behavior and Human Decision Processes 41, 371-389.

Andreassen, P. B. and S. J. Kraus (1990). Judgmental extrapolation and the salience of change. Journal of Forecasting 9(4), 347-372.

Arrow, K. J. (1971). Essays in the Theory of Risk Bearing. Noth Holland Publishing Company/Elsevir.

Aumann, R. (1976). Agreeing to disagree. Annals of Statistics 4, 1236-1239.

Back, K. E. (2012). Asset Pricing and Portfolio Choice Theory. Oxford University Press.

Badrinath, S. G. and W. G. Lewellen (1991). Evidence on tax-motivated securities trading behavior. Journal of Finance 46(1), 369-382.

Baker, M. and J. Wurgler (2004). A catering theory of dividends. Journal of Finance 59(3), 1125-1165.

Ballinger, T. P. and N. T. Wilcox (1997). Decision, error and heterogeneity. Economic Journal 10\%, 1090-1105.

Barber, B., Y.-T. Lee, Y.-J. Liu, and T. Odean (2004). Do individual day traders make money? evidence from taiwan. Working Paper, University of California, Berkeley.

Barber, B., Y.-T. Lee, Y.-J. Liu, and T. Odean (2009). Just how much do individual investors lose by trading? Review of Financial Studies 22(2), 609632 .

Barber, B. and T. Odean (2000). Trading is hazardous to your wealth: The common stock performance of individual investors. Journal of Finance 55(2), 773-806.

Barber, B. and T. Odean (2002). Online investors: Do the slow die first? Review of Financial Studies 15(2), 455-487.

Barber, B. and T. Odean (2008). All that glitters: The effect of attention and news on the buying behavior of individual and institutional investors. Review of Financial Studies 21(2), 785-818.

Barber, B., T. Odean, and N. Zhu (2009a). Do retail trades move markets? Review of Financial Studies 22(1), 151-186.

Barber, B., T. Odean, and N. Zhu (2009b). Systematic noise. Journal of Financial Markets 12, 547-569.

Barber, B. M. and T. Odean (1999). The courage of misguided convictions. Financial Analysts Journal 55, 41-55. 
Barber, B. M. and T. Odean (2001a). Boys will be boys: Gender, overconfidence, and common stock investment. Quarterly Journal of Economics 116(1), 261292.

Barber, B. M. and T. Odean (2001b). The internet and the investor. Journal of Economic Perspectives 15(1), 41-54.

Barber, B. M. and T. Odean (2004). Are individual investors tax-savy? evidence from retail and discount brokerage accounts. Journal of Public Economics 88(1), 419-442.

Barber, B. M. and T. Odean (2013). The behavior of individual investors, in:. Handbook of the Economics of Finance 2(B), 1533-1570.

Barber, B. M., T. Odean, and M. A. Strahilevitz (2011). Once burned twice shy: Naive learning, counterfactuals and the repruchase of stocks previously sold. Journal of Marketing Reseach 48(SPL), 102-120.

Barber, B. M., T. Odean, and N. Zhu (2006). Systematic noise. Journal of Financial Markets 12(4), 547-569.

Barberis, N. C. (2011). A model of casino gambling. Management Science.

Barberis, N. C. (2013). Thirty years of prospect theory in economics: A review and assessment. Working paper, Yale University.

Barberis, N. C. and M. Huang (2001). Mental accounting, loss aversion, and individual stock returns. Journal of Finance 56, 1247-1292.

Barberis, N. C. and M. Huang (2008). Stocks as lotteries: The implications of probability weighting for security prices. American Economic Review 98(5), 2066-2100.

Barberis, N. C. and M. Huang (2009). Preferences with frames: A new utility specification that allows for the framing of risks. Journal of Economic Dynamics and Control 33(8), 1555-1576.

Barberis, N. C., M. Huang, and T. Santos (2001). Prospect theory and asset prices. Quarterly Journal of Economics 141, 1-53.

Barberis, N. C., M. Huang, and R. H. Thaler (2001). How distance, language, and culture influence stockholdings and trades. Journal of Finance 56(3), 1053-1073.

Barberis, N. C. and W. Xiong (2009). What drives the disposition effect? an analysis of a long-standing preference-based explanation. Journal of Finance 64 (2), 751-785.

Barsky, R. B., F. T. Juster, M. S. Kimball, and M. D. Shapiro (2002). Preference parameters and behavioral heterogeneity: An observational approach in the health and retirement study. Quarterly Journal of Economics 112(2), 537579.

Barsky, R. B., F. T. Juster, S. M. Kimball, and M. D. Shapiro (1997). Preference parameter and behavioral heterogeneity: an experimental approach in the health and retirement study. Quarterly Journal of Economics 112, 537-579.

Baule, R. and C. Tallau (2011). The pricing of path-dependent structured financial retail products: The case of bonus certificates. Journal of Derivatives 18(4), 54-71.

Ben-Akiva, M. and S. R. Lerman (1985). Discrete Choice Analysis: Theory and Application to Travel Demand. MIT Press.

Benartzi, S. and R. H. Thaler (1995). Myopic loss aversion and the equity premium puzzle. Quarterly Journal of Economics 110, 75-92.

Berkelaar, A. B. and R. Kouwenberg (2009). From boom 'til bust: How loss aversion affects asset prices. Journal of Banking and Finance 33, 1005-1013.

Berkelaar, A. B., R. Kouwenberg, and T. Post (2004). Optimal portfolio choice under loss aversion. Review of Economics and Statistics 86, 973-987. 
Bernard, C. and M. Ghossoub (2010). Static portfolio choice under cumulative prospect theory. Mathematical and Financial Economics 2(4), 277-306.

Berndt, E. R., B. H. Hall, R. E. Hall, and J. A. Hausman (1974). Estimation and inference in non-linear structural models. Annals of Economic and Social Measurement 3, 653-665.

Bernoulli, D. (1954). Exposition of a new theory on the measurement of risk; translation of bernoulli d. specimen theoriae novae de mensura sortis; commentarii academiae scientiarum imperalis petropolitanae, vol. 5, pp. 175-192). Econometrica 22, 23-36.

Berrada, T., J. Hugonnier, and M. Rindisbacher (2007). Heterogeneous preferences and equilibrium trading volume. Journal of Financial Economics 83, $719-750$.

Bilias, Y., D. Georgarakos, and M. Haliassos (2010). Portfolio inertia and stock market fluctuations. Journal of Money, Credit and Banking 42(4), 715-742.

Birnbaum, M. H., J. N. Patton, and M. K. Lott (1999). Evidence against rankdependent utility theories test of cumulative independence. Organizational Behavior and Human Decision Making 7r(1), 44-83.

Black, F. (1986). Noise. Journal of Finance 41, 529-543.

Blackburn, D. W. and A. D. Ukhov (2006). Estimating preferences towards risk: evidence from dow jones. Working Paper, University of Indiana.

Blake, D. (1996). Efficiency, risk aversion and portfolio insurance: An analysis of financial asset portfolios held by investors in the united kingdom. The Economic Journal 62(1), 107-118.

Bleichrodt, H. and J. L. Pinto (2000). A parameter-free elicitation of the probability weighting function in medical decision analysis. Management Science 46 , 1485-1496.

Bliss, R. R. and N. Panigirtzoglou (2004). Option-implied risk aversion estimates. Journal of Finance 61(1), 407-446.

Blondel, S. (2002). Testing theories of choice under risk: Estimation of individual functionals. Journal of Risk and Uncertainty 24(3), 251-265.

Blume, E. and E. Easley (1992). Evolution and market behavior. Journal of Economic Theory 58, 9-40.

Blume, M. E. and I. Friend (1975). The asset structure of individual portfolios and some implications for utility functions. Journal of Finance 30(2).

Bonaparte, Y. and R. Cooper (2010). Rationalizing trading frequency and returns. NBER Working Paper No. w16022.

Booij, A. S. and G. Van de Kuilen (2009). A parameter-free analysis of the utility of money for the general population under prospect theory. Journal of Economic Psychology 30, 651-666.

Booij, A. S., B. M. S. van Praag, and G. van de Kuilen (2010). A parametric analysis of prospect theory's functionals for the general population. Decision Theory 68, 115-148.

Booij, A. S., B. M. S. van Praag, and G. Van de Kuilen (2010). A parametric analysis of prospect theory's functionals for the general population. Theory and Decision 68(1-2), 115-148.

Bozdogan, H. (2000). Akaike's information criterium and recent developments in information complexity. Journal of Mathematical Psychology 44, 62-91.

Branch, B. (1977). A tax loss trading rule. Journal of Business 50(2), 198-207.

Brandt, M. W., A. Brav, J. R. Graham, and A. Kumar (2010). The idiosyncratic volatility model: Time trend or speculative episodes? Review of Financial Studies 23(2), 863-899. 
Breuer, W., M. Riesener, and A. J. Salzmann (2014). Risk aversion vs. individualism: What drives risk taking in household finance? Working Paper, University of Aachen.

Brockwell, P. and R. Davis (2009). Time Series: Theory and Methods, 2nd. ed. Springer Verlag.

Brown, M. (1975). A method for combining non-independent, one-sided tests of significance. Biometrics 31(4), 987-992.

Brown, P., N. Chappel, R. R. Da Silva, and T. Walter (2006). The reach of the disposition effect: Large sample evidence across investor classes. International Review of Finance 6(1), 43-78.

Brown, S. J. and W. N. Goetzmann (1995). Performance persistence. Journal of Finance 50, 679-698.

Bruhin, A., H. Fehr-Duda, and T. Epper (2007). Risk and rationality: Uncovering heterogeneity in probability distribution. SOI Working Paper No. 0705.

Brunnermeier, M. and S. Nagel (2008). Do wealth fluctuations generate timevarying risk aversion? micro-evidence on individuals' asset allocation. American Economic Review 98(3), 713-736.

Bull, S. B., , C. Mak, and C. M. T. Greenwood (2002). A modified score function estimator for multinomial logistic regression in small samples. Computational Statistics and Data Analysis 39, 57-74.

Burnham, K. P. and D. R. Anderson (2002). Model Selection and Multimodel Inference: A Practical Information-Theoretic Approach, 2nd. ed. Springer Verlag.

Burnham, K. P. and D. R. Anderson (2004). Multimodel inference- understanding aic and bic in model selection. Sociological Methods and Research 33(2), 261304.

Calvet, L., J. Y. Campbell, and P. Sodini (2007). Down or out: Assessing the welfare costs of household investment mistakes. Journal of Political Economy 115(5), 707-747.

Calvet, L., J. Y. Campbell, and P. Sodini (2009). Fight or flight? portfolio rebalancing by individual investors. Quarterly Journal of Economics 124(1), 301-348.

Camerer, C. and H. C. Kunreuther (1989). Subjectively weighted utility: A descriptive extention of the expected utility model. Journal of Risk and Insurance 2, 265-300.

Camerer, C. F. and T. Ho (1994). Violations of the betweenness axiom and nonlinearity in probability. Journal of Risk and Uncertainty 8, 167-196.

Campbell, J. Y., S. J. Grossmann, and J. Wang (1993). Trading volume and serial correlation of stock returns. Quarterly Journal of Economics 108(4), $232-236$.

Campbell, J. Y. and A. S. Kyle (1993). Smart money, noise trading and stock price behavior. Review of Economic Studies 60(1), 1-34.

Carbone, E. (1997). Investigation of stochastic preference theory using experimental data. Economic Letters 57(3), 305-311.

Carbone, E. and J. D. Hey (1994). Discriminating between preference functionals: A preliminary monte carlo study. Journal of Risk and Uncertainty 8, 223-242.

Carbone, E. and J. D. Hey (1995). A comparison of the estimates of eu and noneu preference functionals using data from pairwise choice and complete ranking experiments. Geneva Papers on Risk and Insurance Theory 20, 111-133.

Carbone, E. and J. D. Hey (2000). Which error story is best. Journal of Risk and Uncertainty 20, 161-176. 
Carhart, M. M. (1997). On the persistence of mutual fund performance. Journal of Finance 52, 57-82.

Chan, H., N. Jegadeesh, and R. Wermers (2000). The value of active mutual fund management: An examination of stockholdings and trades of mutual fund managers. Journal of Financial and Quantitative Analysis 35, 343-368.

Chan, K. C. (1986). Can tax-loss selling explain the january seasonal in stock returns? Journal of Finance 41(5), 1115-1128.

Chang, T., D. Solomon, and M. Westerfiled (2012). Looking for someone to blame; delegation, cognitive dissonance and the disposition effect. Working Paper.

Charness, G. and U. Gneezy (2010). Portfolio choice and risk attitudes: An experiment. Economic Inquiry 48(1), 133-146.

Charness, G. and U. Gneezy (2012). Strong evidence for gender differences in risk taking. Journal of Economic Behavior and Organization 83(1), 50-58.

Chen, G., K. A. Kim, J. R. Nofsinger, and O. M. Rui (2007). Trading performance, disposition effect, overconfidence, representativeness bias, and experience of emerging market investors. Journal of Behavioral Decision Making 20(4), 425-451.

Chiappori, P.-A., B. Jullien, B. Salanie, and F. Salanie (2009). Asymmetric information in insurance: General testable implications. RAND Journal of Economics 37(4), 783-398.

Chiappori, P.-A. and M. Paiella (2011). Relative risk aversion is constant: evidence from panel data. Journal of the European Economic Association 9(6), 1021-1052.

Choi, S., R. Fisman, D. Gale, and S. Kariv (2007). Consistency and heterogeneity of individual behavior under uncertainty. American Economic Review 97(5), 1921-1938.

Chui, M. W. (2001). An experimental study of the disposition effect: Evidence from macao. Journal of Psychology and Financial Markets 2(4), 215-221.

Clarke, K. A. (2003). Nonparametric model discrimination in international relations. Journal of Conflict Resolution 47, 72-93.

Clarke, K. A. (2007). A simple distribution-free test for nonnested model selection. Political Analysis 15, 347-363.

Cohen, R. B., P. A. Gompers, and T. Vuolteenaho (2002). Who underreacts to cash-flow news? evidence from trading between individuals and institutions. Journal of Financial Economics 66(2), 409-462.

Collett, D. (2002). Modelling Binary Data. Chapman and Hall.

Constantinides, G. M. (1984). Optimal stock trading with personal taxes: Implications for prices and the abnormal january returns. Journal of Financial Economics 13(1), 65-89.

Conte, A., J. D. Hey, and P. G. Moffatt (2011). Mixture models of choice under risk. Journal of Econometrics 162(1), 79-88.

Cordeiro, G. M. and P. McCullagh (1991). Bias correction in generalized linear models. Journal of the Royal Statistical Society Series B (Methodological) 53, 629-643.

Coval, J. and T. Moskowitz (2001). The geography of investment: Informed trading and asset prices. Journal of Political Economy 109, 811-841.

Coval, J. D. and T. Shumway (2005). Do behavioral biases affect prices? Journal of Finance 60(1), 1-34.

Cox, D. R. (1972). Regression models and life-tables. Journal of the Royal Statistical Society Series B (Methodological) 34, 187-220.

Cox, D. R. and E. J. Snell (1989). Analysis of Binary Data. Chapman and Hall. 
Cox, J. C., S. A. Ross, and M. Rubinstein (1979). Option pricing: A simplified approach. Journal of Financial Economics 7, 229-264.

Cramer, J. S. (1986). Econometric Applications of Maximum Likelihood Methods. Cambridge University Press.

Croson, R. and U. Gneezy (2009). Gender differences in preferences. Journal of Economic Literature 47(2), 448-474.

Cuoco, D. and F. Zapatero (2000). On the recoverability of preferences and beliefs. Review of Financial Studies 13(2), 417-431.

Currim, I. and R. K. Sarin (1989). Prospect versus utility. Management Science 35, 22-41.

Cutler, D. M. and R. Zeckhauser (2004). Extending the theory to meet the practice of insurance. Brookings-Wharton Papers on Financial Services.

D'Agostino, R. B., A. Belanger, and R. B. D'Agostino Jr. (1990). A suggestion for using powerful and informative tests of normality. American Statistician 44(4), $316-321$.

Daniel, K., M. Grinblatt, S. Titman, and R. Wermers (1997). Measuring mutual fund performance with characteristic-based benchmarks. Journal of Finance 52, 1035-1058.

de Palma, A., M. Ben-Akiva, D. Brownstone, C. Holt, T. Magnac, D. McFadden, P. Moffatt, N. Picard, K. Train, P. Wakker, and J. Walker (2008). Risk, uncertainty and discrete chopice models. Marketing Letters 19, 269-285.

DeBondt, W. (1993). Betting on trends: Intuitive forecasts of financial return and risk. International Journal of Forecasting 9, 355-371.

DeBondt, W. (1998). A portrait of the individual investor. European economic Review 42, 831-844.

DeGiorgi, E. and T. Hens (2006). Making prospect theory fit for finance. Journal of Financial Markets and Portfolio Management 20(3), 339-360.

DeLong, B. J., A. Shleifer, L. H. Summers, and R. J. Waldmann (1990). Noise trader risk in financial markets. Journal of Political Economy 98, 703-738.

Dhar, R. and A. Kumar (2002). A non-random walk down the main street: Impact of price trends on trading decisions of individual investors. Working Paper, Yale University, New Heaven, CT.

Dhar, R. and M. Zhu (2006). Up close and personal: An individual level analysis of the disposition effect. Management Science 52(5), 726-740.

Dhrymes, P. J. (1971). Distributed Lags- Problems of estimation and Formulation. Holden Day.

Dimmock, S. G. and R. Kouwenberg (2010). Loss-aversion and household portfolio choice. Journal of Empirical finance 17, 441-459.

Dohmen, T., A. Falk, D. Huffman, U. Sunde, J. Schupp, and G. G. Wagner (2009). Individual risk attitudes: Measurement, determinants and behavioral consequences. Working Paper.

Donkers, B., B. Melenberg, and A. van Soest (2001). Estimating risk attitudes using lotteries: A large sample approach. Journal of Risk and Uncertainty 22(2), $165-195$.

Donkers, B. and A. van Soest (1999). Subjective measures of household preferences and financial decisions. Journal of Economic Psychology 20, 613-642.

Dorn, D., G. Huberman, and P. Sengmueller (2008). Correlated trading and returns. Journal of Finance 63, 885-919.

Duffie, D. (2001). Dynamic asset pricing theory, 3rd. ed. Princeton University Press.

Easley, D. and L. Yang (2011). Loss aversion, survival and asset prices. Working Paper. 
Ebert, S. and P. Strack (2009). An experimental methodology testing for prudence and third-order preferences. Working paper, Bonn University.

Ebert, S. and P. Strack (2012). Until the bitter end: On prospect theory in the dynamic context. Working paper, Bonn University.

Eckstein, Z. and K. I. Wolpin (1989). The specification and estimation of dynamic stochastic discrete choice models. Journal of Human Resources 24(4), 562-598.

Edwards, W. (1953). Probability-preferences in gambling. American Journal of Psychology 66(3), 349-364.

Edwards, W. (1954). Probability-preferences among bets with differing expected values. American Journal of Psychology 67(1), 56-67.

Edwards, W. (1962). Subjective probabilities inferred from decisions. Psychological Review 69(2), 109-135.

Egozcue, M. and W.-K. Wong (2010). Segregation and integration: A study of the behaviors of investors with extended value functions. Advances in Decision Sciences 2010, 1-8.

Entrop, O., M. McKenzie, M. Wilkens, and C. Winkler (2013). The performance of individual investors in structured financial products. Working Paper, University of Augsburg.

Fehr-Duda, H., M. Gennaro, and R. Schubert (2006). Gender, financial risk and probability weights. Theory and Decision 60, 283-313.

Feng, L. and M. S. Seasholes (2005). Do investor sophistication and trading experience eliminate behavioral biases in financial markets? Review of Finance 9, 305-351.

Fennema, H. and M. van Assen (1999). Measuring the utility of losses my means of the trade-off method. Journal of Risk and Uncertainty 17(3), 277-295.

Fennema, H. and P. P. Wakker (1997). Original and cumulative prospect theory: A discussion of empirical differences. Journal of Behavioral Decision Making 10, 53-64.

Ferris, S. P., R. A. Haugen, and A. L. Makhija (1988). Predicting contemporary volue at differential price levels: Evidence supporting the disposition effect. Journal of Finance 43, 677-697.

Firth, D. (1993). Bias reduction of maximum likelihood estimates. Biometrica 80, $27-38$.

Fisher, R. A. (1922). On the mathematical foundations of theoretical statistics. Philosophical Transactions of the Royal Society of London A222.

Fisher, R. A. (1925). Statistical Methods for Research Workers. Oliver and Boyd.

Fisher, R. A. (1948). Combining independent tests of significance. American Statistican 10,30.

Fisher, R. A. (1956). Statistical Methods and Scientific Inference. Oliver and Boyd.

Fletcher, R. (1980). Practical Methods of Optimization. Wiley.

Foucault, T., D. Sraer, and D. J. Thesmar (2011). Individual investors and volatility. Journal of Finance 66(4), 1369-1406.

Fox, C. and A. Tversky (1998). A belief-based account of decision under uncertainty. Management Science 44(7), 879-895.

Frazzini, A. (2006). The disposition effect and underreaction to news. Journal of Finance 61, 2017-2046.

French, K. R. (1980). Stock returns and the weekend effect. Journal of Financial Economics 8(3), 55-69.

French, K. R. and R. Roll (1986). Stock return variances: The arrival of iniformation and the reaction of traders. Journal of Financial Economics 17(9), $5-26$. 
Friedman, M. and L. J. Savage (1948). The utility analysis of choices involving risk. Journal of Political Economy 56(4), 279-304.

Friend, I. and M. E. Blume (1975). The demand for risky assets. American Economic Review 65(5).

Frino, A., D. Johnstone, and H. Zheng (2004). The propensity of local traders in future markets to ride losses: Evidence of irrational or rational behavior? Journal of Banking and Finance 28, 353-372.

Gaechter, S., E. J. Johnson, and A. Herrmann (2007). Indivual-level loss aversion in riskless and risky choices. Working Paper No. 2961, University of Bonn.

Gallant, A. R., P. E. Rossi, and G. Tauchen (1992). Stock prices and volume. Review of Financial Studies 5, 199-242.

Garvey, R. and A. Murphy (2002). How profitable day traders trade: An examination of trading profits. Working Paper, UNiversity of Utah.

Garvey, R. and A. Murphy (2004). Are professional traders too slow to realize their losses? Financial Analysts Journal 60, 35-43.

Genesove, D. and C. Mayer (2001). Loss aversion and seller behavior: Evidence from the housing market. Quarterly Journal of Economics 116, 1233-1260.

Glaser, M. and M. Weber (2007). Overconfidence and trading volume. Geneva Risk and Insurance Review 32(1), 1-36.

Gneezy, U. and J. Potters (1997). An experiment on risk taking and evaluation periods. Quarterly Journal of Economics 112(2), 631-645.

Goetzman, W. N. and R. G. Ibbotson (2005). The Equity Risk Premium: Essays and Explorations. Oxford University Press.

Goetzmann, W. N. and M. Massa (2008). Disposition matters: Volume, volatility, and price impact of a behavioral bias. Journal of Portfolio Management 34(2), $103-125$.

Gollier, C. (2001). The Economics of Risk and Time. MIT Press.

Gomes, F. J. (2005). Portfolio choice and trading volume with loss-averse investors. Journal of Business 78, 675-706.

Gordon, M. J., G. Paradis, and C. H. Rorke (1972). Experimental evidence on alternative portfolio decision rules. American Economic Review 62(1), 107118.

Gould, W., J. Pitblado, and W. Sribney (2006). Maximum Likelihood Estimation with stata. Stata Press.

Graham, J. and A. Kumar (2004). Do dividend clienteles exist? evidence on dividend preferences of retail investors. Journal of Finance 61, 1305-1336.

Green, T. C. and B. Hwang (2011). Ipo's as lotteries: Skewness preference and first-day returns. Working Paper Emory University.

Greene, W. H. (2008). Econometric Analysis. Pearson Upper Sattle River.

Greenwood, R.a nd Shleifer, A. (2014). Expectations of returns and expected returns. Review of Financial Studies 27, 714-746.

Griffiths, W. E., R. C. Hill, and P. J. Pope (1987). Small sample properties of probit model estimators. Journal of the American Statistical Association 82(399), 929-937.

Grinblatt, M. and B. Han (2005a). Prospect theory, mental accounting, and momentum. Journal of Financial Economics 78, 311-339.

Grinblatt, M. and B. Han (2005b). Prospect theory, mental accounting, and the disposition effect. Journal of Financial Economics 56, 589-616.

Grinblatt, M. and M. Keloharju (2000). The investment behavior and performance of various investor types: A study of finlands unique data set. Journal of Financial Economics 55, 43-67. 
Grinblatt, M. and M. Keloharju (2001a). How distance, language, and culture influence stockholdings and trades. Journal of Finance 56(3), 1053-1073.

Grinblatt, M. and M. Keloharju (2001b). What makes investors trade? Journal of Finance 56(2), 589-616.

Grinblatt, M. and M. Keloharju (2001c). What makes investors trade? Journal of Finance 56, 589-616.

Grinblatt, M. and M. Keloharju (2004). Tax-loss trading and wash-sales. Journal of Financial Economics 71(1), 51-76.

Grinblatt, M. and M. Keloharju (2009). Sensation seeking, overconfidence, and trading activity. Journal of Finance 64(2), 549-578.

Grinblatt, M. and S. Titmann (1989). Mutual fund performance: An analysis of quarterly portfolio holdings. Journal of Business 62, 393-416.

Grinblatt, M. and S. Titmann (1993). Performance measurement without benchmarks: an examination of mutual fund returns. Journal of Business 66, 47-68.

Guiso, L. and M. Paiella (2008). Risk aversion, wealth and background risk. Journal of the European Economic Association 6(6), 1109-1150.

Hakansson, N. H. (1970). Friedman-Savage utility functions consistent with risk aversion. Quarterly Journal of Economics 84(3), 472-487.

Hakansson, N. H. (1971). Capital growth and the mean-variance approach to portfolio selection. Journal of Financial and Quantitative Analysis 6(1), 517557 .

Han, B. and A. Kumar (2010). Speculative retail trading and asset prices. Working Paper, University of Texas.

Harbaugh, W., K. Krause, and L. Vesterlund (2002). Risk attitudes of children and adults: Choices over small and large probability gains and losses. Experimental Economics 5(1), 53-84.

Harless, D. W. and C. Camerer (1994). The predictive utility of generalized expected utility theories. econometrica 62(2), 1251-1289.

Harris, J. H. and P. H. Schultz (1998). The trading profits of SOES bandits. Journal of Financial Economics 50, 39-62.

Harrison, G. W. (2008). Maximum likelihood estimation of utility functions using stata. Working paper, University of central Florida.

Harrison, G. W., M. I. Lau, and M. B. Williams (2007). Estimating risk attitudes in denmark: a field experiment. Scandinavian Journal of Economics 109(2), 341-368.

Harrison, G. W. and E. E. Rutstrom (2008). Risk aversion in the laboratory, in:. Research in Experimental Economics 12, 41-196.

Harrison, G. W. and E. E. Rutstrom (2009). Expected utility theory and prospect theory: one wedding and a decent funeral. Experimental Economics 12, 133158.

Harvey, C. and A. Siddique (2000). Conditional skewness in asset pricing tests. Journal of Finance 55, 1263-1295.

He, X. D. and X. Zhou (2011). Portfolio choice under cumulative prospect theory: An analytical treatment. Management Science 57(2), 315-331.

Heath, C., S. Huddart, and M. Lang (1999). Psychological factors and stock option exercise. Quarterly Journal of Economics 114(2), 601-627.

Heinze, G. (2006). A comparative investigation of methods for logistic regression with separated or nearly separated data. Statistics in Medicine 25, 4216-4226.

Heinze, G. and M. Schemper (2002). A solution to the problem of separation in logistic regression. Statistics in Medicine 21, 2409-2419.

Heisler, J. (1994). Loss aversion in a futures market: An empirical test. Review of Futures Markets 13, 793-822. 
Hensher, D. A. and L. W. Johnson (1981). Applied Discrete Choice Modelling. Wiley and Sons.

Hershey, J. C. and P. J. H. Schoemaker (1980). Risk taking and problem context in the domain of losses: An expected utility analysis. Journal of Risk and Insurance 47(1), 111-132.

Hey, J. D. (1995). Experimental investigations of errors in decision making under risk. European Economic Review 39(3-4), 633-640.

Hey, J. D. and E. Carbone (1995). Stochastic choice with deterministic preferences: An experimental investigation. Economic Letters 47(2), 161-167.

Hey, J. D. and C. Orme (1994). Investigating generalizations of expected utility theory using experimental data. Econometrica 62, 1296-1326.

Hirji, F. K. (2005). Exact Analysis of Discrete Data. Chapman and Hall.

Hirshleifer, D. (2001). Investor psychology and asset pricing. Journal of Finance 56(4), 1533-1597.

Hoffmann, A. O. I., H. Shefrin, and J. M. E. Pennings (2010). Behavioral portfolio analysis of individual investors. Working Paper, University of Maastricht.

Holt, M. A. and J. P. Chaves (2001). The Econometrics of Risk. New York: Kluwer Academic Press.

Hong, D. and A. Kumar (2002). What induces noise trading around public announcement events? Working Paper, Cornell University.

Horowitz, J. L., J. M. Sparmann, and C. F. Daganzo (1982). An investigation of the accuracy of the clark approximation of the multinomial probit model. Transportation Science 16(3), 382-401.

Hosmer, D. W., S. Lemenshow, and R. X. Sturdivant (2013). Applied Logistic Regression. Wiley Series in Probability and Statistics.

Hull, J. and A. White (1988). The pricing of options on assets with stochastic volatilities. Journal of Financial and Quantitative Analysis 23, 237-251.

Hung, M. and H. Yu (2006). A heterogenous model of disposition effect. Applied Economics 38(18), 2147-2157.

Hurvich, C. M. and C. L. Tsai (1989). Regression and time series model selection in small samples. Biometrica 76, 297-307.

Hvidkjaer, S. (2006). A trade-based analysis of momentum. Review of Financial Studies 19(2), 457-491.

Hvidkjaer, S. (2008). Small trades and the cross section of stock returns. Review of Financial Studies 21, 1123-1151.

Hwang, S. and S. E. Satchell (2011). How loss averse are investors in financial markets? Journal of Banking and Finance 34, 2425-2438.

Ingersoll, J. E. (1987). Theory of Financial Decision Making. Rowman and Littlefield.

Ingersoll, J. E. and L. J. Jin (2013). Realization utility with reference-dependent preferences. Review of Financial Studies 26(3), 723-767.

Ivcovic, Z., J. Poterba, and S. J. Weisbrenner (2005). Tax-motivated trading by individual investors. American Economic Review 95, 1605-1630.

Ivcovich, Z., J. M. Poterba, and S. J. Weisbrenner (2009). Individual investor mutual fund flows. Journal of Financial Economics 92(2), 223-237.

Ivcovich, Z. and S. Weisbrenner (2009). Individual investor mutual fund flows. Journal of Financial Economics 92(2), 223-237.

Jackwerth, J. (2000). Recovering risk aversion from option prices and realized returns. Review of Financial Studies 13(2), 433-451.

Jin, H. and X. Y. Zhou (2008). Behavioral portfolio selection in continuous-time. Mathematical Finance 18, 385-426. 
Johnson, R. S., J. E. Pawlukiewicz, and J. M. Metha (1997). Binomial option pricing with skewed asset returns. Review of Quantitative Finance and Accounting 9, 89-101.

Johnson, R. S., A. Sen, and B. Balyeat (2012). A skewness-adjusted bionomial model for pricing futures options- the importance of the mean and carryingcost parameters. Journal of Mathematical Finance 2, 105-120.

Jordan, D. and J. D. Diltz (2003). The profitability of day traders. Financial Analyst Journal 59(6), 85-94.

Jordan, D. and J. D. Diltz (2004). Day traders and the disposition effect. Journal of Behavioral Finance 5(4), 192-200.

Judge, G. G., W. E. Griffiths, R. C. Hill, H. Luetkepohl, and T. C. Lee (1985). The Theory and Practice of Econometrics. North Holland.

Kahneman, D. and A. Tversky (1979). Prospect theory: An analysis of decision under risk. Econometrica 47, 263-291.

Kahneman, D. and A. Tversky (1991). Loss aversion in riskless choice: A reference-dependent model. Quarterly Journal of Economics 106(4), 10391061.

Kaniel, R., G. Saar, and S. Titman (2008). Individual investors trading and stock returns. Journal of Finance 63, 273-310.

Karmarkar, U. S. (1978). Subjectively weighted utility: A descriptive extention of the expected utility model. Organizational Behavior and Human Performance 21(1), 61-72.

Karmarkar, U. S. (1979). Subjectively weighted utility and the allais paradox. Organizational Behavior and Human Performance 24(1), 67-72.

Karpoff, J. M. (1987a). The relation between price changes and trading volume: A survey. Journal of Financial and Quantitative Analysis 22, 109-126.

Karpoff, J. M. (1987b). A theory of trading volume. Journal of Finance 41(5), 1069-1087.

Kaustia, M. (2004a). Market-wide impact of the disposition effect: Evidence form the ipo trading volume. Journal of Financial Markets 7, 207-235.

Kaustia, M. (2004b). What causes the disposition effect? an empirical evaluation. Working Paper, Helsinki School of Economics.

Kaustia, M. (2010). Prospect theory and the disposition effect. Journal of Financial and Quantitative Analysis 47, 263-291.

Keele, L. J. and D. K. Park (2006). Ambivalent about ambivalence: A reexaminatinon of heteroskedastic probit models. Working Paper, Ohio State University

Keloharju, M., S. Knuepfer, and J. Linnainmaa (2012). Do investors buy what they know? product market choices and investment decisions. Review of Financial Studies 25(10), 2921-2958.

Kent, J. T. (1982). Robust properties of likelihood ratio tests. Biometrika 69, $19-27$.

King, G. and L. Zeng (2001). Logistic regression in rare events data. Political Analysis 9, 137-163.

Kliger, D. and O. Levy (2002). Risk preferences heterogeneity: Evidence from asset markets. European Finance Review 6, 277-290.

Kliger, D. and O. Levy (2009). Theories of choice under risk: Insights from financial markets. Journal of Economic Behavior and Organization 71, 330346.

Kocherlakota, N. R. (1996). The equity premium: Its still a puzzle. Journal of Economic Literature 34(1), 42-71. 
Kon, S. J. (1984). Models of stock returns- a comparison. Journal of Finance 39, $147-165$.

Kosowski, R., A. Timmermann, R. Wermers, and H. White (2006). Can mutual fund stars really pick stocks? new evidence from a bootstrap analysis. Journal of Finance 61, 2551-2595.

Kraus, A. and R. H. Litzenberger (1976). Skewness preference and the valuation of risky assets. Journal of Finance 31, 1085-1100.

Kroll, Y., H. Levy, and A. Rapoport (1988). Experimental tests of the separation theorem and the capital asset pricing model. American Economic Review 78(3), 500-519.

Kullback, S. (1968). Information Theory and Statistics. Dover Publications.

Kullback, S. and R. A. Leibler (1951). On information and sufficiency. Annals of Mathematical Statistics 22, 79-86.

Kumar, A. (2007). Do the diversification choices of individual investors influence stock returns? Journal of Financial Markets 10, 362-390.

Kumar, A. (2009a). Dynamic style preferences of individual investors and stock returns. Journal of Financial and Quantitative Analysis 44(3), 1375-1401.

Kumar, A. (2009b). Who gambles in the stock market? Journal of Finance 64, 1889-1933.

Kumar, A. and W. N. Goetzmann (2008). Equity portfolio diversification. Review of Finance 12, 433-463.

Kumar, A. and C. M. C. Lee (2006). Retail investor sentiment and return comovements. Journal of Finance 61, 2451-2486.

Kyle, A. (1985). Continuous auctions and insider trading. Econometrica 47, $1315-1336$.

Lacey, K. (1945). Some implications of the first in-first out method of stock valuation. Economica 12(45), 26-30.

Lakonishok, J. and S. Smidt (1986). Volume for winners and losers: Taxation and other motives for stock trading. Journal of Finance 41(4), 951-974.

Lakonishok, J. and T. Vermaelen (1986). Tax-induced trading around ex-dividend days. Journal of Financial Economics 16(3), 287-319.

Landskroner, Y. (1988). risk aversion in securities markets. Journal of Banking and Finance 6(1), 1247-1292.

Latane, H. A. (1959). Criteria for choices among risky ventures. Journal of Political Economy 67(2), 144-155.

Lattimore, P. M., J. R. Baker, and A. D. Witte (1992). The influence of probability on risky choice. Journal of Economic Behavior and Organization 17, 377-400.

Laury, S. and C. A. Holt (2005). Risk aversion and incentive effects. American Economic Review 92, 1644-1655.

Lee, H., J. Park, L. J., and R. Wyer (2008). Disposition effects and underlying mechanism in e-trading of stocks. Journal of Marketing Research 45, 362-378.

Lehenkari, M. and J. Perttunen (2004). Holding on to losers: Finnish evidence. Journal of Behavioral Finance 5(2), 116-126.

Levy, H. (1994). Absolute and relative risk aversion: an experimental study. Journal of Risk and Uncertainty 8, 289-307.

Levy, M. and H. Levy (2002). Arrow-pratt risk aversion, risk premium and decision weights. Journal of Risk and Uncertainty 25(3), 265-290.

Lim, S. S. (2006). Do investors integrate losses and segregate gains? mental accounting and investor trading decisions. Journal of Business 79, 2539-2573.

Lin, Y.-H. and L.-K. Hu (2010). Prospect theory and herding behavior in the stock market. Working Paper, University of Taipei. 
Linnainmaa, J. (2005). The individual day trader. Working Paper, University of Chicago.

Liu, Y. and H. Mahmassani (2000). Global maximum likelihood estimation procedures for multinomial probit (mnd) model parameters. Transportation Research B 34, 419-444.

Llorente, G., R. Michaeli, G. Saar, and J. Wang (2002). Dynamic volume-return relation of individual stocks. Review of Financial Studies 15, 1005-1047.

Locke, P. R. and S. C. Mann (2005). Professional trader discipline and trade disposition. Journal of Financial Economics 76, 401-444.

Loomes, G., P. G. Moffatt, and R. Sugden (2002). A microeconomic test of alternative stochastic theories of risky choices. Journal of Risk and Uncertainty 24, $103-130$.

Loomes, G. and R. Sugden (1995). Incorporating a stochastic element into decision theories. European Economic Review 39, 103-130.

Lucas, R. E. (1978). Asset prices in an exchange economy. Econometrica 46(6).

Magnac, T. and D. Thesmar (2002). Identifying dynamic discrete decision processes. Econometrica 70(2), 801-816.

Mankiw, N. G. and S. Zeldes (1991). The consumption of stockholders and nonstockholders. Journal of Financial Economics 29.

Mantel, N. (1966). Evaluation of survival data and two new rank order statistics arising in this consideration. Cancer Chemotherapy Reports 50(3), 163-170.

Markowitz, H. M. (1952). The utility of wealth. Journal of Political Economy 60, $151-156$.

Markowitz, H. M. (1976). Investment for the long run: New evidence for an old rule. Journal of Finance 31(5), 1273-1286.

Marquardt, D. W. (1963). An algorithm for least squares estimation of nonlinear parameters. Journal of the Society of Industrial Applied Mathematics 11, 431441.

Marschak, J. (1960). Binary Choice constraints on random utility indications, in K. Arrow, ed. Stanford Symposium on Mathematical Methods in the social Sciences. Stanford University Press.

McCullough, B. D. and H. D. Vinod (2003). Verifying the solution from a nonlinear dolver: A case study. American Economic Review 93(3), 873-892.

McFadden, D. (1980). Econometric models for probabilistic choice among products. Journal of Business 55(3), S13-S29.

McLachlan, G. J. (1980). A note on bias correction in maximum likelihood estimation with logistic discrimination. Technometrics 22, 621-627.

McQuarrie, A. D. R. and C. L. Tsai (1998). Regression and Time Series Model Selection. World Scientific Publishing.

Mehra, R. (2008). The Handbook of the Equity Risk Premium. Elsevier.

Mehra, R. and E. Prescott (1985). The equity premium: A puzzle. Journal of Monetary Economics 15.

Meng, J. (2010). The disposition effect and expectations as reference point. Working Paper, Guanghua Peking University.

Milgrom, P. and N. Stokey (1982). Information, trade and common knowledge. Journal of Economic Theory 26, 17-27.

Mitton, T. and K. Vorkink (2007). Equilibrium underdiversification and the preferences for skewness. Review of Financial Studies 20(4), 1255-1288.

Morin, R. A. and A. F. Suarez (1983). Risk aversion revisited. Journal of Finance 106(438), 1175-1192.

Munk, C. (2013). Financial asset pricing theory. Oxford University Press. 
Murstein, B. I. (2003). Regression to the mean: One of the most neglected but important concepts in the stock market. Journal of Finance 4(4), 234-237.

Nielssen, T. D. and J. Jaffray (2004). Dynamic decision making without expected utility: An operational approach. Working paper, Universite Paris 6 .

Nolte, I. (2012). A detailed investigation of the disposition effect and individual trading behavior: a panel survival analysis. European Journal of Finance 18, 885-919.

Normandin, M. and P. St-Amour (2008). An empirical analysis of aggregate household portfolios. Journal of Banking and finance 32, 1583-1597.

Odean, T. (1998). Are investors reluctant to realize their losses? Journal of Finance 53, 1775-1798.

Odean, T. (1999). Do investors trade too much? American Economic Review 89(5), 1279-1298.

Oehler, A., K. Heilmann, V. Laeger, and M. Oberlaender (2003). Coexistence of disposition investors and momentum traders in stock markets: Experimental evidence. Journal of International Financial Markets, Institutions Money 13, 503-524.

Orme, C. (1995). On the use of artificial regressions in certain microeconometric models. Econometric Theory 11(2), 290-305.

Pasquariello, P. (2008). Prospect theory and market liquidity. Working Paper, Michigan University.

Patel, J., R. J. Zeckhauser, and D. Hendricks (1991). The rationality struggle: Illustrations from financial markets. American Economic Review 81(2), 232236.

Pawitan, Y. (2001). In all Likelihood-Statistical Modelling and Interference using likelihood. Clarendon Press.

Pennings, J. M. E. and A. Smidts (2002). The shape of utility functions and organizational behavior. Management Science 49(9), 1251-1263.

Polkovnichenko, V. (2005). Household portfolio diversification: A case for rankdependent preferences. Review of Financial Studies 18(4), 1467-1502.

Poterba, J. M. and S. J. Weisbrenner (2001). Capital gains tax rules, tax-loss trading, and turn-of-the-year returns. Journal of Finance 56(1), 353-368.

Preston, M. G. and P. Baratta (1948). An experimental study of the auction-value of an uncertain outcome. American Journal of Psychology 61(2), 183-193.

Prigent, J.-L. (2010). Portfolio optimization and rank dependent expected utility. Working Paper, University of Cergy-Pontoise.

Quiggin, J. (1982). A theory of anticipated utility. Journal of Economic Behavior and Organization 3, 323-343.

Quiggin, J. (1993). Generalized Expected Utility Theory: The Rank Dependent Model. Kluwer Academic Publishers.

Rabe-Hersketh, S. and B. Everitt (2004). A Handbook of Statistical Analysis using Stata. Chapman and Hall Press.

Rabin, M. (2000). Loss aversion and expected utility theory: A calibration theorem. Econometrica 68, 1281-1292.

Rabin, M. and R. H. Thaler (2001). Anomalies: Loss aversion. Journal of Economic Perspectives 15, 219-232.

Rao, C. R. (1973). Linear statistical inference and its applications, 2nd edition. Wiley.

Rendleman, R. J. and B. J. Bartter (1979). Two-state option pricing. Journal of Finance 34, 1093-1110.

Rice, W. R. (1990). A consensus combined P-value test and the family-wide significance of component tests. Biometrics 46, 303-308. 
Roll, R. (1986). Orange juice and the weather. American Economic Review 74(5), 421-436.

Rust, J. (1992). Do people behave according to bellman's principle of optimality? Working paper, Stanford University.

Rust, J. (1994). Structural Estimation of Markov Decision Processes in R.F. Engle and D.L. McFadden (eds.)Handbook of Econometrics Volume IV. Elsevir.

Ruud, P. (2000). An Introduction to Classical Econometric Theory. Oxford University Press.

Saha, A. (1993). Expo-power utility: A 'flexible' form of absolute and relative risk aversion. American Journal of Agricultural Economics 75(4), 905-913.

Saha, A., R. C. Shumway, and H. Talpaz (1994). Joint estimation of risk preference structure and technology using expo-power utility. American Journal of Agricultural Economics 76(5), 173-184.

Santner, T. J. and D. E. Duffy (1986). A note on a. albert's and j. a. anderson's conditions for the existence of maximum likelihood estimates in logistic regression models. Biometrica 73, 755-758.

Savage, I. R. (1956). Contributions to the theory of rank-order statistics - the two-sample case. Annals of Mathematical Statistics 27, 590-615.

Schaefer, R. L. (1983). Bias correction in maximum likelihood logistic regression. Statistics in Medicine 2, 71-78.

Schlarbaum, G., W. Lewellen, and R. Lease (1978a). Realized returns on common stock investments: The experience of individual investors. Journal of Business 51(2), 299-325.

Schlarbaum, G., W. Lewellen, R. Lease, and R. A. Cohn (1975). Individual investor risk aversion and investment portfolio composition. Journal of $\mathrm{Fi}$ nance 30(2), 605-620.

Schlarbaum, G., W. Lewellen, and R. C. Lease (1978b). The common-stockportfolio performance record of individual investors:1964-70. Journal of Finance 33, 429-441.

Schoemaker, P. J. H. and H. C. Kunreuther (1979). An experimental study of insurance decisions. Journal of Risk and Insurance 46(4), 603-618.

Schwarz, G. (1978). Estimating the dimension of a model. Annals of Statistics 6, 461-465.

Schwert, G. W. (2002). Stock volatility in the new millenium: How wacky is NASDAQ? Journal of Monetary Economics 49, 3-26.

Seasholes, M. S. and G. Wu (2004). Profiting from predictability: Smart trades, daily price limits, and investor attention. Working Paper, University of California, Berkeley.

Shapira, Z. and I. Venezia (2001). Patterns of behavior of professionally managed and independent investors. Journal of Banking and Finance 25, 1573-1587.

Shefrin, H. (2008). A Behavioral Approach to Asset Pricing. Elsevier Academic Press.

Shefrin, H. and M. Statman (1984). Explaining investors preference for cash dividends. Journal of Financial Economics 13(2), 253-282.

Shefrin, H. and M. Statman (1985). The disposition to sell winners too early and ride losers too long: Theory and evidence. Journal of Finance 40, 777-790.

Shiller, R. (1981). Do stock prices move too much to be justified by subsequent changes in dividends. American Economic Review 71(3), 421-436.

Shumway, T. and G. Wu (2006). Does disposition drive momentum? Working Paper.

Silber, R. J. (1984). Marketmaker behavior in an auction market: an analysis of scalpers in futures markets. Journal of Finance 39, 937-953. 
Singleton, J. C. and J. Wingender (1986). Skewness persistence in common stock returns. Journal of Financial and Quantitative Analysis 21, 335-341.

Sinn, H.-W. (2003). Webers law and the biological evolution of risk preferences: The selective dominance of the logarithmic utility function. The Geneva Papers on Risk and Insurance Theory 28, 87-100.

Smith, D. R. (2007). Conditional coskewness and asset pricing. Journal of Empirical Finance 14, 91-119.

Starmer, C. (2000). Developments in non-expected utility theory: The hunt for a descriptive theory of choice under risk. Journal of Economic Literature 38, 332-382.

Statman, M., S. Thorley, and K. Vorkink (2006). Investor overconfidence and trading volume. Review of Financial Studies 19(4), 1531-1565.

Stott, H. P. (2006). Cumulative prospect theorys functional menagerie. Journal of Risk and Uncertainty 32, 101-130.

Sugiura, N. (1978). Further analysis of the data by akaikes information criterion and the finite correction. Communications in Statistics - Theory and Methods 7(1), 13-26.

Thaler, R. H. (1985). Mental accounting and consumer choice. Marketing Science 4(3), 199-214.

Thaler, R. H., A. Tversky, D. Kahneman, and A. Schwartz (1997). The effect of myopia and loss aversion on risk taking: An experimental test. Quarterly Journal of Economics 112(2), 647-661.

Tirole, J. (1982). On the possibility of speculation under rational expectations. Econometrica 50(5), 1163-1182.

Train, K. E. (1986). Qualitative Choice Analysis. The MIT Press.

Train, K. E. (2009). Discrete Choice Models with Simulation, 2nd. ed. Cambridge University Press.

Turner, A. L. and E. J. Weigel (1992). Daily stock return volatility. Management Science 38, 1586-1609.

Tversky, A. and D. Kahneman (1991). Loss aversion in riskless choice-a referencerependent model. Quarterly Journal of Economics 106, 1039-1061.

Tversky, A. and D. Kahneman (1992). Advances in prospect theory: Cumulative representation of uncertainty. Journal of Risk and Uncertainty 5, 297-323.

Van Zweet, W. R. and J. Oosterhoff (1967). On the combination of independent test statistics. Annals of Mathematical Statistics 38(3), 659-680.

Varian, H. R. (1989). Differences of opinion in financial markets, in: Stone, c. financial risk theory, evidence and implications: Proceedings of the 11th annual economic policy conference of the federal reserve bank of st. louis.

Vlcek, M. and T. Hens (2011). Does prospect theory explain the disposition effect? Journal of Behavioral Finance 12(3), 141-157.

von Gaudecker, H.-M., A. van Soest, and E. Wengstroem (2009). Heterogeneity in risky choice behavior in a broad population. Working Paper No. 4022, University of Bonn.

von Neumann, J. and O. Morgenstern (1947). Theory of Games and Economic Behavior. Princeton University Press.

Vuong, Q. H. (1989). Likelihood ratio tests for model selection and non-nested hypotheses. Econometrica 57(2), 307-333.

Wahal, S. and M. D. Yavuz (2013a). Style investing, comovement and return predictability. Journal of Financial Economics 107(1), 136-154.

Wahal, S. and M. D. Yavuz (2013b). Style investing, comovement and return predictability. Journal of Financial Economics 10\%(1), 136-154. 
Wakker, P. P. (1994). Separating marginal utility and probabilistic risk aversion. Theory and Decision 36, 1-44.

Wakker, P. P. (2003). The data of levy and levy (2002) "prospect theory: Much ado about nothing?" actually support prospect theory. Management Science 49(7), 979-981.

Wakker, P. P. (2008). Explaining the characteristics of the power (crra) utility function. Health Economics 17, 1329-1344.

Wakker, P. P. (2010). Prospect Theory: For Risk and Ambiguity. Cambridge University Press.

Wakker, P. P. and D. Deneffe (1996). Eliciting von neumann-morgenstern utilities when probabilities are distorted or unknown. Management Science 42(8), 1131-1150.

Wang, J. (1994). A competitive model of stock trading. Journal of Political Economy 102(1), 127-168.

Weber, J., S. Meyer, B. Loos, and A. Hackethal (2014). Which investment behaviors really matter for individual investors? Working Paper, Goethe University Frankfurt am Main.

Weber, M. and C. F. Camerer (1998). The disposition effect in securities trading: An experimental analysis. Journal of Economic Behavior ES Organization 33, $167-184$.

Wermers, R. (2000). Mutual fund performance: An empirical decomposition inito stock-picking talent, style, transaction costs and expenses. Journal of Finance 55, 1655-1703.

Westberg, M. (1985). Combining independent statistical tests. The Statistician 34, 287-296.

Wilcox, N. T. (2008). Stochastic models for binary discrete choice under risk, in:. Research in Experimental Economics 12, 197-292.

Wu, G. and R. Gonzalez (1996). Curvature of the probability weighting function. Management Science 42, 1676-1690.

Wu, G. and R. Gonzalez (1999). Nonlinear decision weights in choice under uncertainty. Management Science 45, 74-85.

Wu, G., J. Zhang, and M. Abdellaoui (2005). Testing prospect theory using probability tradeoff consistency. Journal of Risk and Uncertainty 30, 107-131.

Yaari, M. E. (1965). Convexity in the theory of choices under risk. Quarterly Journal of Economics 79, 278-290.

Yaari, M. E. (1987). The dual theory of choice under risk. Econometrica 55(1), 95-115.

Yao, J. and D. Li (2013). Prospect theory and trading patterns. Journal of Banking and Finance 37(8), check-1231.

Zhang, Y. and P. E. Swanson (2010). Are day traders bias free? evidence from internet stock message boards. Journal of Economics and Finance 34, 96-112.

Zhu, M. (2002). The local bias of individual investors. Working Paper, Yale University. 


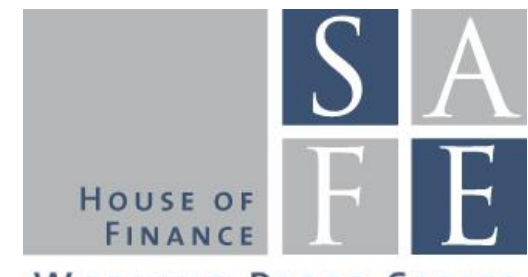

Working PAPER SERIES

\section{Recent Issues}

No. 146 Sven-Thorsten Jakusch, Steffen Meyer, Andreas Hackethal

No. 145 Christian Geppert, Alexander Ludwig, Raphael Abiry

No. 144 Mario Bellia, Loriana Pelizzon, Marti G. Subrahmanyam, Jun Uno, Darya Yuferova

No. 143 Peter Gomber, Satchit Sagade, Erik Theissen, Moritz Christian Weber, Christian Westheide

No. 142 Nathanael Vellekoop

No.141 Brigitte Haar

No. 140 Reint Gropp, Rasa Karapandza, Julian Opferkuch

No. 139 Holger Kraft, Claus Munk, Farina Weiss

No.138 Mohammed Aldegwy, Matthias Thiemann

No. 137 Elia Berdin, Cosimo Pancaro, Christoffer Kok

No.136 Matthias Thiemann, Mohammed Aldegwy, Edin Ibrocevic

No. 135 Douglas Cumming, Jochen Werth, Yelin Zhang

No.134 Markus Kröll, Devesh Rustagi
Taming Models of Prospect Theory in the Wild? Estimation of Vlcek and Hens (2011)

Secular Stagnation? Growth, Asset Returns and Welfare in the Next Decades: First Results

Low-Latency Trading and Price Discovery: Evidence from the Tokyo Stock Exchange in the Pre-Opening and Opening Periods

Spoilt for Choice: Order Routing Decisions in Fragmented Equity Markets

The Impact of Long-Run Macroeconomic Experiences on Personality

Freedom of Contract and Financial Stability through the lens of the Legal Theory of Finance

The Forward-Looking Disclosures of Corporate Managers: Theory and Evidence

Predictors and Portfolios Over the Life Cycle

How Economics Got it Wrong: Formalism, Equilibrium Modelling and PseudoOptimization in Banking Regulatory Studies

A Stochastic Forward-Looking Model to Assess the Profitability and Solvency of European Insurers

Understanding the Shift from Micro to MacroPrudential Thinking: A Discursive Network Analysis

Governance in Entrepreneurial Ecosystems: Venture Capitalists vs. Technology Parks

Got Milk? Motivation for Honesty and Cheating in Informal Markets: Evidence from India 